University of Louisville

ThinkIR: The University of Louisville's Institutional Repository

Electronic Theses and Dissertations

$5-2017$

\title{
Spatial patterning and human behavior in level " $F$ " at Lapa do Picareiro.
}

Brandon K Zinsious

University of Louisville

Follow this and additional works at: https://ir.library.louisville.edu/etd

Part of the Archaeological Anthropology Commons

\section{Recommended Citation}

Zinsious, Brandon K, "Spatial patterning and human behavior in level "F" at Lapa do Picareiro." (2017). Electronic Theses and Dissertations. Paper 2643.

https://doi.org/10.18297/etd/2643

This Master's Thesis is brought to you for free and open access by ThinkIR: The University of Louisville's Institutional Repository. It has been accepted for inclusion in Electronic Theses and Dissertations by an authorized administrator of ThinkIR: The University of Louisville's Institutional Repository. This title appears here courtesy of the author, who has retained all other copyrights. For more information, please contact thinkir@louisville.edu. 


\title{
SPATIAL PATTERNING AND HUMAN BEHAVIOR IN LEVEL “F” AT LAPA DO PICAREIRO
}

\section{By}

Brandon Zinsious

B.A., University of Louisville, 2013

\author{
A Thesis \\ Submitted to the Faculty of the \\ College of Arts and Sciences of the University of Louisville \\ In Partial Fulfillment of the Requirements \\ For the Degree of
}

Master of Arts in Anthropology

Department of Anthropology

University of Louisville

Louisville, Kentucky

May 2017 



\title{
SPATIAL PATTERNING AND HUMAN BEHAVIOR IN LEVEL "F” AT LAPA DO PICAREIRO
}

\author{
By \\ Brandon Zinsious \\ B.A., University of Louisville, 2013 \\ A Thesis Approved on \\ April 4, 2017 \\ By the following Thesis Committee:
}

Jonathan Haws

Amanuel Beyin

Joao Cascalheira 
This Thesis is dedicated to

My Parents, Paul and Angela,

For teaching me I can do anything

And to

My Advisor, Jonathan Haws,

For so many opportunities. 


\title{
ABSTRACT \\ SPATIAL PATTERNING AND HUMAN BEHAVIOR IN LEVEL "F" AT LAPA DO PICAREIRO
}

\author{
Brandon Zinsious
}

May 13, 2017

Spatial analysis at the site level offers unique perspectives and has become increasingly more accessible as advances in technology allow rapid 3-dimensional mapping and rigorous statistical analysis. This project focused on the geological stratigraphic level "F", at Lapa do Picareiro; a shallow cave in the Estremadura region of Portugal. This level, dated to 14,000 years ago calibrated BP, experienced multiple human occupations between the Last Glacial Maximum and the Younger Dryas. This work examines the recovered material from a period of Upper Magdalenian occupations and sheds light on how enclosed space was used in Estremadura Portugal. Distinct distributions of lithic and faunal remains between different zones of cave ceiling height show evidence of the impacts of head room and trampling on the assemblage. Excavator bias is also considered, as its effects are apparent in the point clouds generated from the digital recording of artifact locations in three dimensional space. 


\section{TABLE OF CONTENTS}

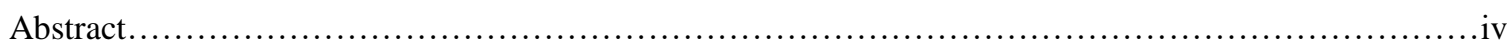

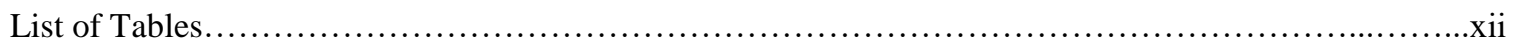

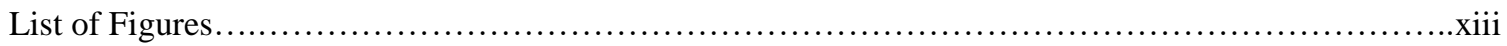

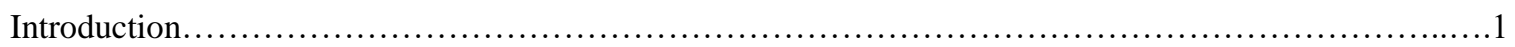

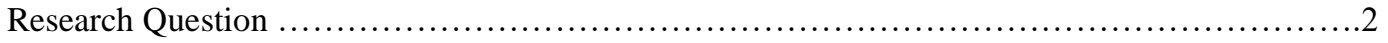

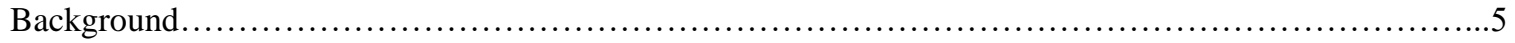

The Magdalenian or Tardiglacial in Portugal: a review of the Magdalenian in

western most Iberia.................................................................

Geographic Subdivisions of the Magdalenian in Portugal............................

Portugal between the Last Glacial Maximum and the Younger Dryas: a review of the

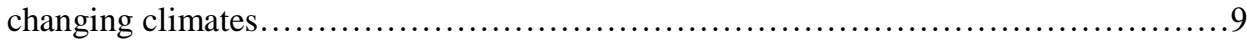

Building chronologies and recreating environmental conditions of the Allerød: Paleo

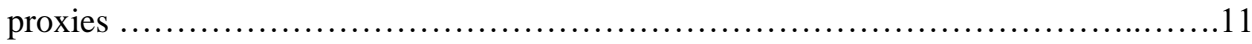

Paleo environmental Conditions and Flora of the Magdalenian ....................... 12

Fauna during the Magdalenian ................................................ 13

Micro and Meso-Fauna....................................................... 15

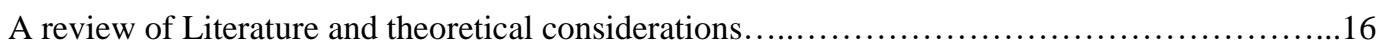

The Magdalenian in Iberia................................................. 16

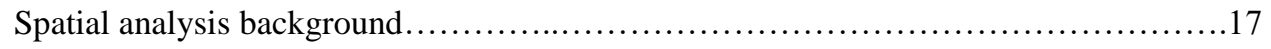

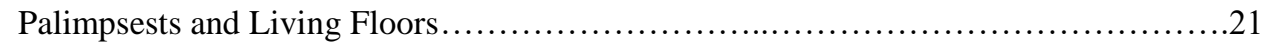

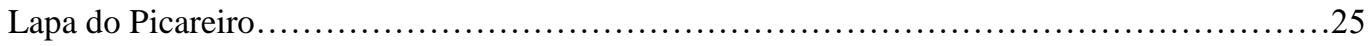

History............................................................. 26

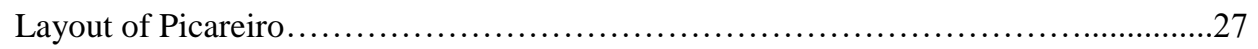

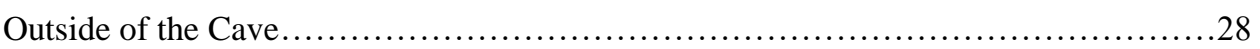

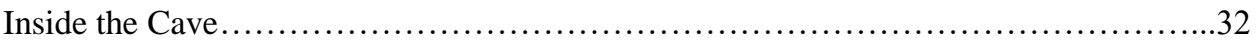




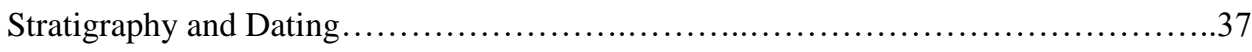

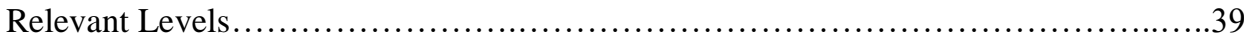

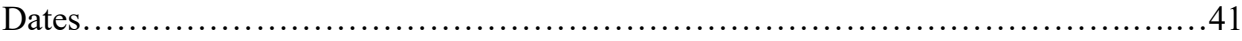

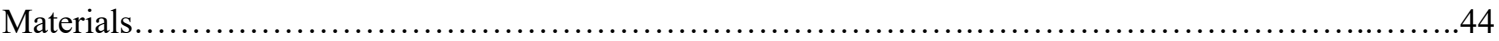

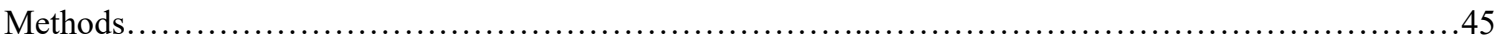

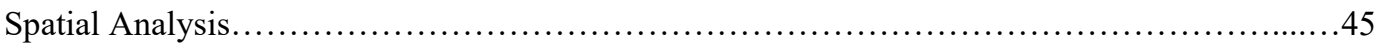

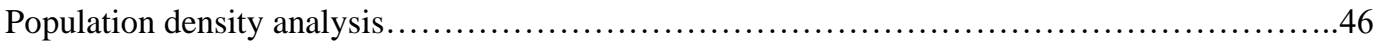

Translation of Data from Various Formats................................................47

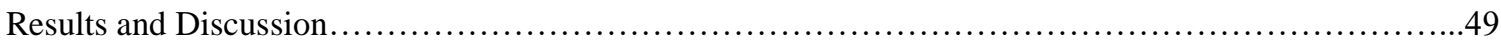

Potential Sources of Error and Bias in the Spatial Analysis of Level F............................49

The Impacts of Exposed or Collapsed Profiles on Spatial Analysis .....................49

The Impact of Physical Grids and Inexperienced Excavators on Spatial Analysis.........51

Site formation: The formation of Level $\mathrm{F}$ at Lapa do Picareiro and its Cave Context..............53

Formation of Geologic Deposits......................................................

Non-anthropogenic Sources of Post depositional movement..........................56

Anthropogenic post depositional movement........................................57

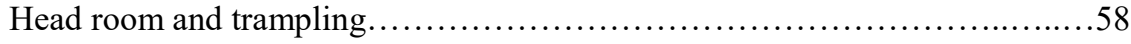

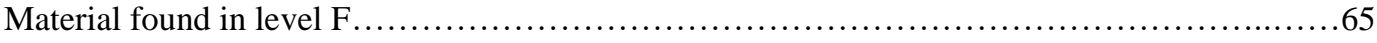

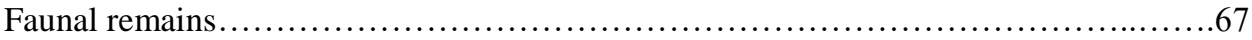

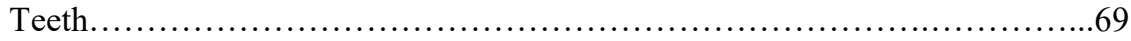

Faunal Distribution...................................................... 70

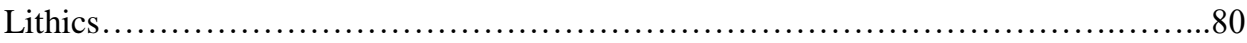

Lithic Distribution...................................................... 83

Lithic distribution by raw material................................ 86

Lithic distribution by tool type................................. 87

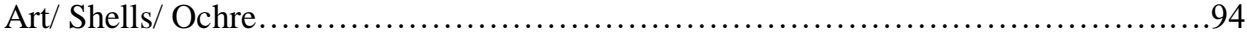

Vertical Distribution: Palimpsests and Living Floors of Level F.......................97

The Hearth and Headroom............................................................100

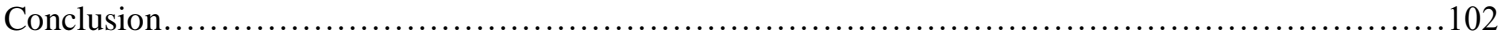

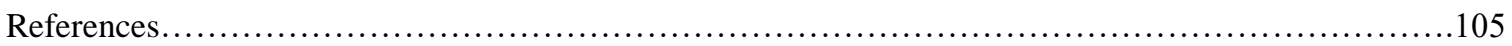

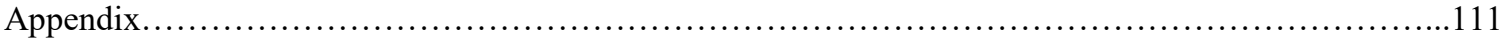

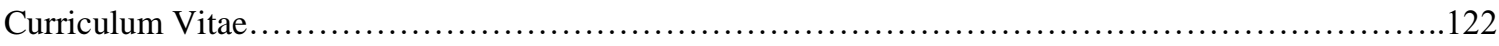




\section{LIST OF TABLES}

Table 1. The upper most stratigraphic levels (Benedetti et al n.d.)...................................

Table 2. Geological stratigraphy containing Magdalenian (Bicho 2006)(Benedetti et al n.d.)...............39

Table 3. Relevant dates for Level F in Picareiro (Bicho et al. 2006) (Haws n.d.)........................42

Table 4 Total mammal counts for relevant levels at Picareiro (Haws N.D.)...........................68

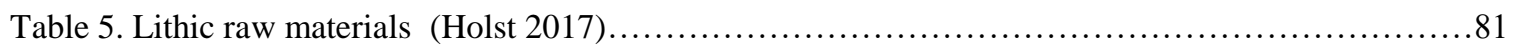

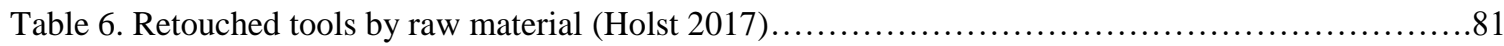




\section{LIST OF FIGURES}

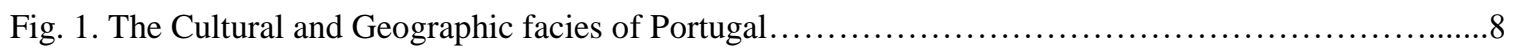

Fig. 2. NGRIP and Magnetic Susceptibility (Benedetti et al. n.d.)...................................11

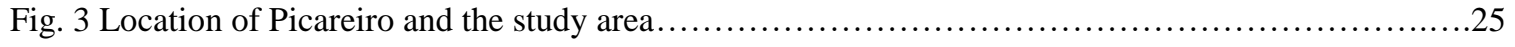

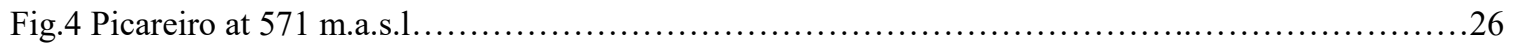

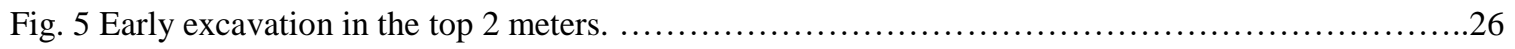

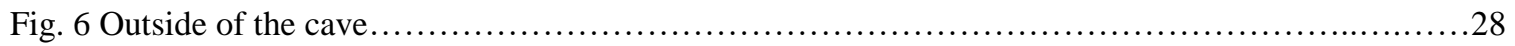

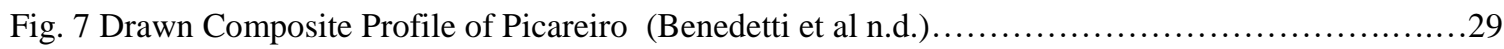

Fig. 8 A.) The path taken by the GPR specialist in 2012, outside. B.) the GPR results. (Conyers 2016)....30

Fig. 9 The low bench of units used for GPR inside the cave (Conyers 2016) .......................... 31

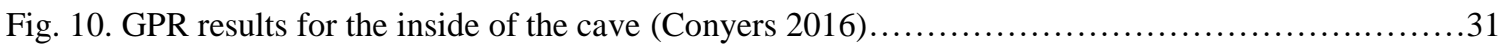

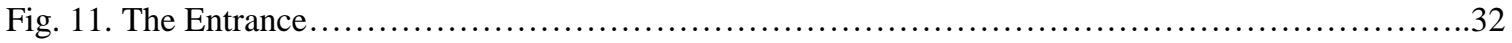

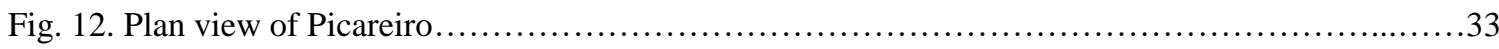

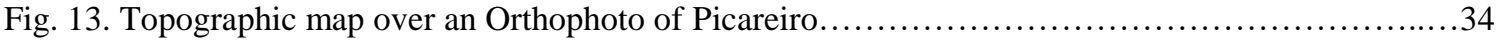

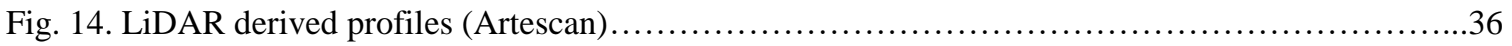

Fig. 15. Geological stratigraphy containing Magdalenian (Bicho 2006)(Benedetti et al n.d.)..............39

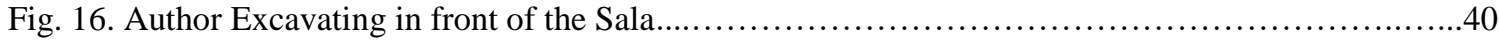

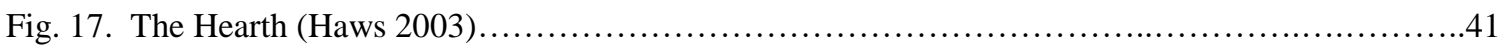

Fig. 18. Level F dates and NGRIP data (Lapa Do Picareiro NSF Proposal 2014 1998) .....................48

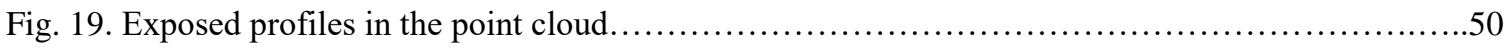

Fig. 20. The effects of physical grids seen in the point cloud. ......................................52

Fig. 21. Clast size, Magnetic Susceptibility, and NGRIP data (Benedetti et al n.d.).....................55

Fig. 22. Roof ceiling heights over faunal remains showing the two height zones.........................60

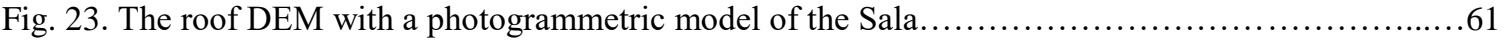

Fig. 24. The DEM representing the roof of the cave intersecting with the photogrammetric model of the

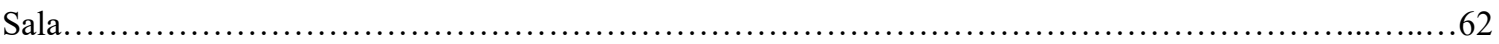

Fig. 25. Views from the mouth of the cave when level $\mathrm{F}$ was a floor.................................63 


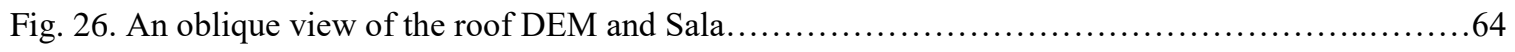

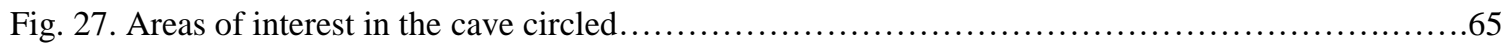

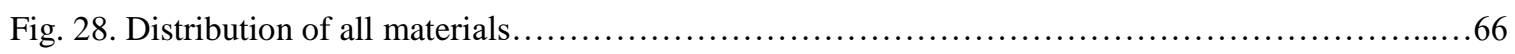

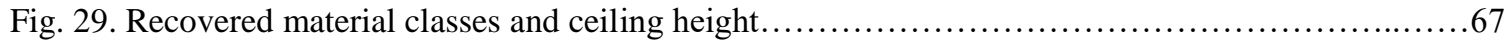

Fig. 30. Examples of faunal material recovered (Bicho et al. 2006) .................................69

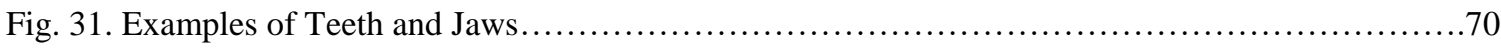

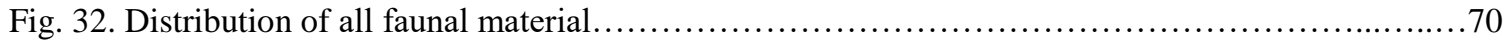

Fig. 33. Amount of bones from each anatomical region for medium and large mammals.................71

Fig. 34. Axial and long bone distributions of medium and large mammals.............................72

Fig. 35. Distributions of hind and fore limbs for medium and large mammals......................... 73

Fig. 36. Species and age distributions for medium and large mammals................................ 75

Fig. 37. Distributions of different Axial elements for medium and large mammals .....................76

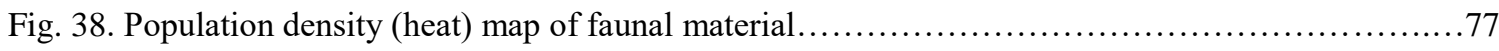

Fig. 39. Medium and large mammal bones and ceiling height zones.................................. 79

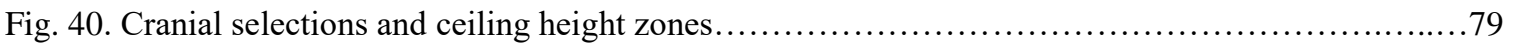

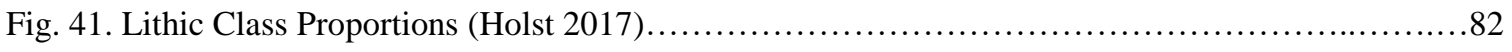

Fig. 42. A selection of Microlithic tools form level F (Bicho, Haws, and Hockett 2006)...................82

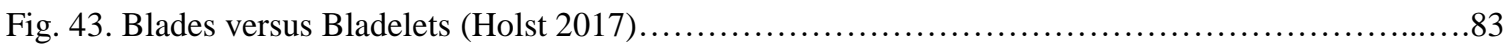

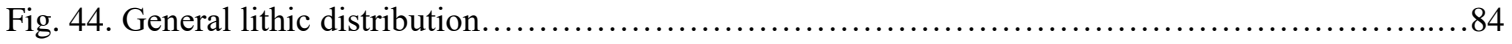

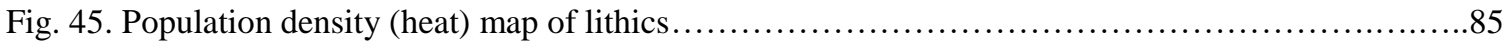

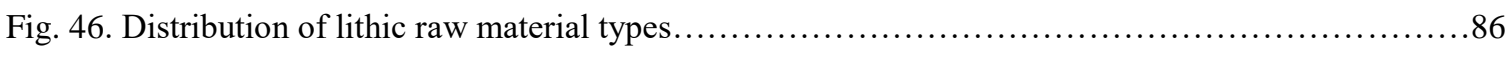

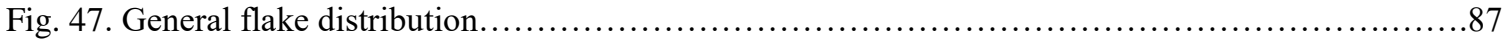

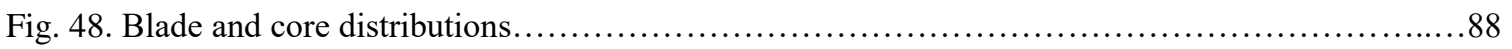

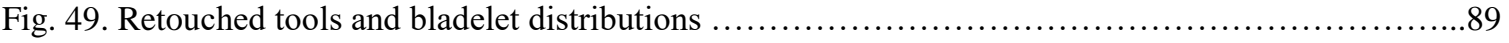

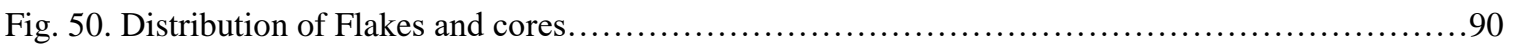

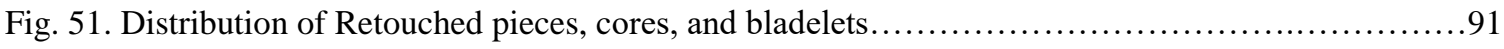

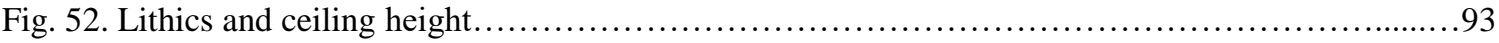

Fig. 53. A view from ZZ6 looking towards the mouth of the cave; bladelet vertical distribution and the

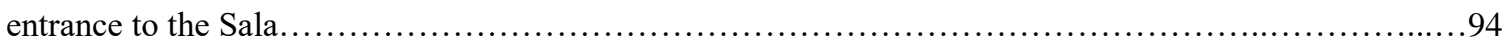

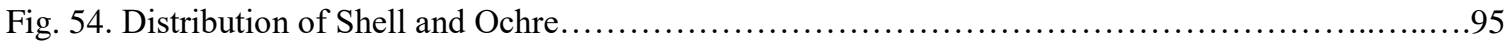

Fig. 55. Vertical distribution of shell facing the right side of the cave. ..................................96 
Fig. 56. A.) Areas of thinner vertical distribution under the roof DEM; B.) facing the left side of the cave, cave west; C.) facing the right side of the cave, or cave east. .................................... 98

Fig. 57. A.) faunal material pushed against the wall, associated with the Hearth; B.) charcoal displays this same trend. 


\section{INTRODUCTION}

Occurring later in Portugal than the rest of Europe, the Magdalenian period offers a unique vantage point for assessing human adaption at the conclusion of the Paleolithic in Europe (Straus et al. 1996). It is still being explored in western Iberia as more sites offer extensive assemblages. With the advent of better recording methods and high resolution remote sensing employed in archaeology for micro spatial analysis, assemblages dating to the Magdalenian offer more information than ever before. Geologic Level F at Lapa do Picareiro dates the Bölling/Allerød interstadial and contains a thick deposit of Late Magdalenian material. The spatial analysis of the excavated material obtained through almost two decades of excavation is the focus of this thesis

Centrally located near the town of Fatima, the cave sits atop a mountain at $560 \mathrm{~m}$ above sea level. As excavations continue and more space is being freed of clasts and sediment, the size of the cave (based on bed rock walls and ceiling) continues to expand. At the time of this writing the cave measures $20 \mathrm{~m}$ from the mouth to the back of the cave, although the sloping walls indicate a rapid expansion of space as excavation proceeds. The east to west dimensions (using cave north) varies but lies somewhere between $15 \mathrm{~m}$ and $20 \mathrm{~m}$ (at the mouth, the widest area of the cave).

The cave, which is still slightly hydrologically active, has changed drastically over the past 50,000 years as the roof slowly collapsed from seasonal spalling, due to freezing and thawing. Larger clasts have fallen, making up distinct geological layers, 
caused by cold snaps, long term climate changes, and geological events. These clasts make up the majority of the sediment matrix, with the remaining space filled by finer sediments coming from water flow through the ceiling and Aeolian deposits from the mouth of the cave.

The excavation follows the natural layers presented by geological stratigraphy, marked by changes in clast size, sediment color and texture, and sediment grain size. Arbitrary spits of 5 and $10 \mathrm{~cm}$ have been dug within these layers, or levels, for excavation control, but the geological stratigraphy takes priority. As of this writing, the deepest level is NN5, $10.6 \mathrm{~m}$ below datum (original surface height). Level " $\mathrm{F}$ ", the focus of this project is $2 \mathrm{~m}$ below datum and has been radiocarbon dated to $12,500 \mathrm{BP}$ or 14,000 calendar years ago. This level has yielded a thick hearth complex in the back of the cave. Level $\mathrm{F}$ contains hundreds of lithic artifacts and thousands of animal bones derived from several species but dominated by rabbit and red deer.

\section{RESEARCH QUESTIONS}

The main focus of this project is to examine the spatial context of material recovered in the geological level "F" at Lapa de Picareiro and to use it to discuss past human behavior during the Upper Magdalenian. Inside this layer, a hearth and multiple lithic and faunal remains were found in situ, in close association, with preserved spatial context. The project will involve reviewing existing relevant literature and draw on comparative geospatial and archaeological data that will then be used to make inferences about past human activity patterning (or lack there-of) at the site. Comparisons to other 
Paleolithic cave sites in the Portuguese Estremadura will also be made in order to understand Lapa do Picareiro in its regional context. The main research focus, in an anthropological context, is further divided into three specific questions which will structure the analysis:

1.) Are there any recognizable patterns in the distribution of faunal and lithic remains within layer "F"?

2) What are these patterns and how were they recognized/what methods were used?

3.) How did the collection method and the method of analysis effect the results of both the recognition of patterns and their analysis? Both the lithic (Bicho, et al 2006) (Holst 2017) and faunal analysis (Haws nd) have been done by other researchers prior to this analysis.

This thesis will introduce the Magdalenian, Portugal, Lapa do Picareiro, level F, and relevant theoretical and technical considerations to the spatial analysis of Picareiro. All of the materials recovered in level $\mathrm{F}$ are presented and their distributions discussed. During the Magdalenian, the size and shape of the cave would have impacted the final locations of recovered artifacts. With such a restricted area, it would be expected that headroom would have dictated which areas of the cave were used more extensively and which areas were used for access. Foot traffic, in such a limited space would also have had an impact on the final locations of material, in regards to trampling and kicking. You would expect to see these two factors having a noticeable impact on artifact location. 
This thesis pays special interest to the impacts of headroom and trampling on the spatial distribution of material from level F. 


\section{BACKGROUND}

\section{THE MAGDALENIAN OR TARDIGLACIAL IN PORTUGAL: A REVIEW OF THE MAGDALENIAN IN WESTERN MOST IBERIA}

The Magdalenian is the designation of a suite of cultural material and chronological attributes that existed in the final stages of the Upper Paleolithic in Europe. The start of the Upper Paleolithic is often placed around 45-35 Kya in western Europe (Zilhão 2006). It consisted of multiple cultural phases and ended around 10 Kya years ago with the transition to the current Epoch, the Holocene. Each cultural period in the Upper Paleolithic, including the Magdalenian, can be defined as a cultural period or as a period within a chronological framework. The Magdalenian timeline is further subdivided into phases, namely the Early, Middle, and Late stages. These designations, however, change across the central and western European landscape.

Culturally, the Magdalenian can be defined by the presence of portable art, bone artifacts, harpoons, and micro-blades, with harpoons appearing in the Upper Magdalenian, especially in France and Cantabrian Spain (Straus et al. 1996). A large increase in blanks, backed bladelets, thin side scrapers, and burins can be seen, following a general trend of smaller lithics and the absence of bifacial tools (Straus et al. 1996). 
Harpoons can be divided in to different types, separated into the geographical zones of the Atlantic or Mediterranean basin, with most sites being located relatively close to coastal areas. In Portugal, there is a marked absence of harpoons. Bone tools are also rarely seen in Portugal. Besides Escoural/ Coa Valley, cave art has not been found in other sites dated to the Magdalenian in Portugal (Bicho and Haws 2012). Examples of mobile art have been found and dated to the Magdalenian at Val Boi (Bicho and Haws 2012).

In Portugal, the Magdalenian is not represented in the same way as it is at sites in Germany, France and Spain. This was argued by Nuno Bicho almost twenty years ago (Bicho and Haws, 2012) and Joao Zilhao (Straus et al. 1996). Because the traditional Magdalenian type fossil, harpoons, are not found in Portugal, Bicho and others (1992, 1998a, others) claim the reality represented by the record in Portugal could be better served with a descriptive term such as the Tardiglacial, referring to the period of climatic warming after the Last Glacial Maximum (Bicho and Haws 2012). This view is supported by many, including Straus (1996). As Bicho (2012) points out, the use of the term Magdalenian carries with it its own set of historical connotations. The Magdalenian carries with it a heavily assertive chronological claim, as well as its use as a cultural descriptive term.

In Portugal, the Magdalenian is divided into Lower, Middle, and Late stages (Straus et al. 1996). The Late Magdalenian is dated later in Portugal than the rest of Europe, with some characteristic lithics and fossil types being dated to what would normally be called the Holocene. This is further support for the use of the term 
Magdalenian as a set of culturally similar characteristics, which is the preferred use by many working in the area (Bicho and Haws 2012).

Using sets of cultural characteristics to define deposits as Magdalenian allows for the idea that culture moves across and adapts to landscapes at different rates, which would allow culturally Magdalenian technology to be found in deposits which may radiometrically date to the Holocene (Bicho and Haws 2012). Cultures are not constant throughout geographical space, changing in response to external stimuli such as changes in natural environmental stressors. This can include but is not limited to changes in availability of food, raw material for tools, and changes in climate. All of these factors had, in some way, an effect on the continuity of the Magdalenian culture, and how and when it appeared across the western European landscape (Schmidt et al. 2012). For epistemological reasons, and reasons of continuity and to facilitate inter-site and interregional comparisons, this thesis will use the term Magdalenian to describe the suite of material culture and characteristics that occurred between the end of the Solutrean and into the start of the Holocene, similar to Bicho et al 2012.

\section{GEOGRAPHIC SUBDIVISIONS OF THE MAGDALENIAN IN PORTUGAL}

There are generally two recognized facies during the Magdalenian in Portugal; the Estremadura and the Algarve (Straus et al. 1996). The two areas are separated geographically (Figure 1). The Algarve, is the southern, coastal region of Portugal. This area is dominated by coastal cliffs, beaches, low hills and Pleistocene sand dunes. The Algarve provided warmer and more accessible environments during the Magdalenian. 


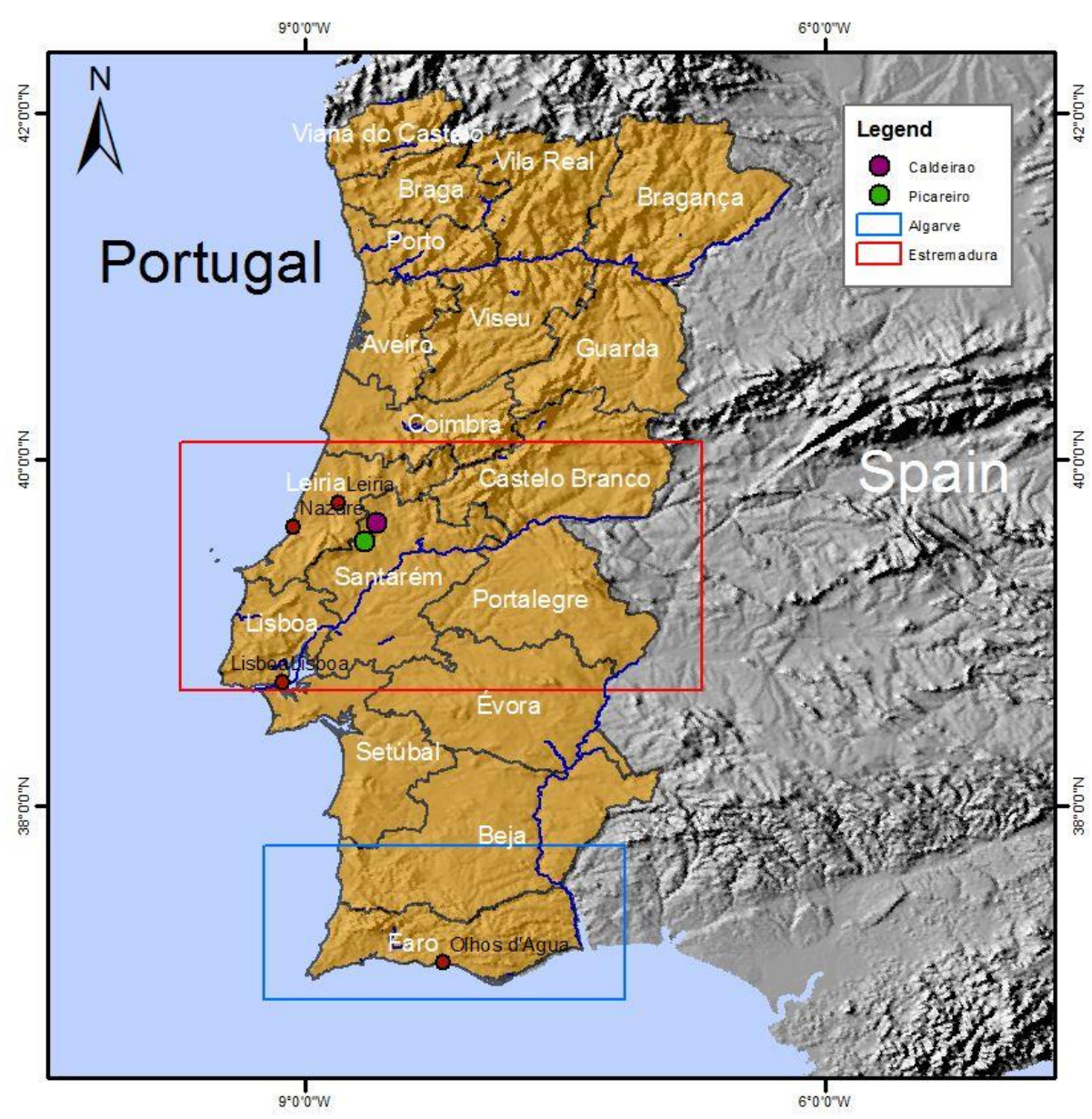

Fig. 1. The Cultural and Geographic facies of Portugal used in this analysis.

The focus of this paper is the Estremadura region in central Portugal. This region is characterized by coastal cliffs on the Atlantic side, large estuaries, and inland limestone massifs. These massifs make up part of the Serra d'Aire mountain range and are broken up by rivers and seasonally flooding basins, which form temporary lakes. These limestone massifs provided shelter in the form of caves and rock shelters for humans between the LGM and the Younger Dryas. Caves and rock shelters have been a rich source of archaeological material for the Upper Paleolithic in the Portuguese Estremadura, although their prevalence are most likely the results of survey and 
preservation bias (Haws 2003). Carbon dates for the Upper Paleolithic in Portugal are numerous, provided by sites such as Lapa do Suao, Gruta do Caldeirao. Rio Maior (open air), Lapa do Picareiro, Gruta da Oliveira, and Gruta do Almonda (Schmidt et al. 2012).

It is also important to remember that during the LGM and the Younger Dryas, a large portion of the Earth's water was held in reserves in the form of large Ice Sheets. The water level in Europe was drastically lower reaching $140 \mathrm{~m}$ below the current sea level, causing the shore line to be several kilometers further out than the present coastline (Bicho and Haws 2012). True shore-side sites containing material from this time period are currently underwater, coloring how we interpret coastal and inland activity, migration, and resource exploitation.

\section{PORTUGAL BETWEEN THE LAST GLACIAL MAXIMUM AND THE YOUNGER DRYAS: A REVIEW OF THE CHANGING CLIMATES}

The Late Upper Paleolithic saw a widespread change in cultures and a growth in population and human dispersal through Europe. Changes in lithic technologies, as well as subsistence patterns, and the wide spread occurrence of portable art characterize this time period. This time period, between $19 \mathrm{Kya}$ and $10 \mathrm{Kya}$ also saw large and rapid amelioration in climatic conditions, punctuated by Heinrich 1 and the Younger Dryas.

The Magdalenian began at the end of the Last Glacial Maximum (LGM), around 18 Kya. The rapid and widespread melting of the Northern most ice sheets, including the Scandinavian and British ice sheets over Europe, brought about drastic changes in climate that undoubtedly impacted human populations living in Europe during that time 
(Ruddiman 2008). Changes in the environment would be reflected in lithic technologies and preferred game, as well as other cultural components that can be preserved through time. Indeed, these changes are seen in the archaeological record (Straus et al. 1996). After the end of the LGM, Europe saw a rise in sea levels on its coast and a rise in temperature. This was accompanied by a period of higher humidity and precipitation, changing the geographic distributions of flora and fauna (Clark et al. 2012). Humans, like other fauna, took advantage of the vast areas outside of Portugal no longer covered by ice sheets or dominated by permafrost. With the spread of vegetation and game, humans saw a rise in population and an amount of habitable land, as these populations left areas that had remained relatively hospitable during the ice age, known as refugia (Straus et al. 1996).

Around 12 kya Europe experienced a period of rapid cooling and climate reversal known as the Younger Dryas, characterized by lower temperatures and dryer climates. The cause of this short reversal is still debated but a combination of amplifying feedback loops involving run off from melting ice sheets and ocean currents are agreed to have been involved (Ruddiman 2008). After the hiatus caused by the Younger Dryas and the subsequent temperature increase, the ice sheets continued to rapidly melt and the Pleistocene transitioned into the Holocene. Level F in Picareiro was occupied during the warm and relatively humid interstadial, the Allerød, occurring just prior to the Younger Dryas (Bicho and Haws 2012). This last interstadial of the Pleistocene, dated between 14 and 12 kya, was marked by fast expansion, especially in Mediterranean type vegetation, fueling colonization of new territories. 


\section{BUILDING CHRONOLOGIES AND RECREATING ENVIRONMENTAL}

\section{CONDITIONS OF THE ALLEROD: PALEO PROXIES}

There are a wide range of options for use as paleo proxies, normally employed in combination with one another to corroborate and refine results. Ice sheets provide a source of multiple paleo proxies, which include stable isotopes, trapped particulates and aerosols, and trace gases. Greenland has several coring programs that provide this data. This paper uses information from the North Greenland Ice Core Project, or NGRIP, which at its base dates to well over 100 Kya. NGRIP is the deepest core in Greenland and provides a robust stratigraphic record for the end of the Pleistocene using both visual stratigraphy and a suite of chemical indicators (Walker et al. 2009)

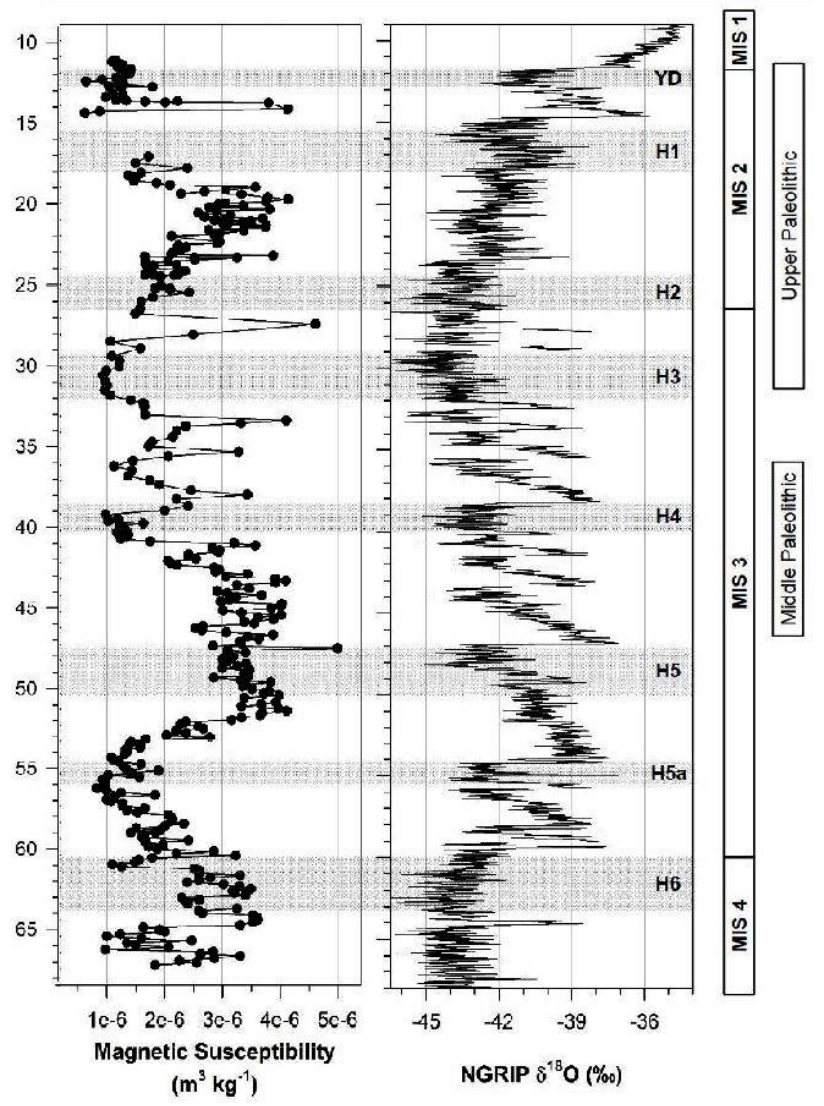

Fig. 2. NGRIP and Magnetic Susceptibility (Benedetti et al. n.d.) 
The top right of figure 2 shows the NGRIP Oxygen Isotope record through Deuterium excess ratios of the LGM through the Younger Dryas. Peaks to the right show warmer periods. The troughs to the left, which coincide with $\mathrm{H} 1$ and the Younger Dryas, show colder periods. This data is compared to the magnetic susceptibility record for this same time period. You can see the stadials and interstadials roughly align after H1. NGRIP results can be compared to marine and terrestrial sediment cores, as well as the faunal record, to recreate regional paleo environments (Walker et al. 2009).

\section{PALEOENVIRONMENTAL CONDITIONS AND FLORA OF THE MAGDALENIAN}

Paleo-environmental data in Portugal from the LGM to the Holocene is less abundant than for the rest of Europe (Haws 2003). However, there are sediment cores, charcoal, pollen, and faunal remains available to help piece together the environments of the westernmost area of Iberia (Bicho et al.2011). There are three terrestrial pollen cores collected in Portugal, and several deep sea sediment cores collected of its coast, which can be used to look at climatic changes and pollen between the LGM and the Younger Dryas (Bicho et al. 2011). These sediment cores have been used for the reconstruction of the paleo-environment of Portugal and generally agree with the NGRIP record, showing Portugal enjoyed a period of relatively warm Sea Surface Temperatures (SST) during the Allerød.

Pollen records show the presence of evergreen species such as Pinus pinaster and Pinus Pinea, as well as ericaceous shrubbery dominating the vegetation records for the Allerod. Deciduous oak, Quercus (faginea?), wild fruit trees, olive (Olea europaea and 
Olea sylvestris), birch (Betula pubescens), and ash (Frax-inus angustifolia) are represented as well. The presence of deciduous species combined with SST data provide more evidence of a relatively warm and humid period characterizing the Allerød (Bicho et al. 2001; Joao Zilhao et al. 1995)

Combining pollen records with Oxygen Isotope data, average temperature changes for western Europe can be seen in the record. Temperatures increased across western Europe between 3-5 degrees Celsius at the start of the Bölling. Climatic conditions remained relatively stable until the beginning of the Younger Dryas when temperatures dropped between 5 and 10 degrees Celsius and environments reversed back to near glacial conditions (Clark et al. 2012). SST derived from benthic foraminifera corroborate these findings (Dansgaard and Tauber 1969). The effects of the temperature and climatic changes were manifested in the flora and fauna of Iberia.

\section{FAUNA DURING THE MAGDALENIAN}

The fauna present during the Magdalenian in western Iberia, specifically Portugal, reflect the relatively drastic changes in climate that occurred between the end of the LGM and the onset of the Younger Dryas. With the end of the LGM and the onset of a warmer and more humid climate, the fauna of central Portugal changed in response to the change in vegetation cover. When combined with pollen and oxygen isotope record, faunal assemblages can act as a paleo proxy for the Magdalenian. Examples of past fauna in the Upper Paleolithic in the Portuguese Estremadura come most notably from Caldeirao Cave and Lapa do Picareiro (Hockett and Haws 2002), . 
Caldeirao Cave, a Paleolithic site in the Portuguese Estremadura, provides information for the region during the period between the LGM and the Younger Dryas, making it a useful assemblage for inter-site comparisons. Caldeirao cave contains similar geologic stratigraphy and covers roughly the same time span present at Picareiro (Haws 2003). Extensive zooarchaeological analysis has been done on the faunal remains recovered from the site and was written up in a concise report (Davis et al. 2007). The report contained faunal numbers for stratigraphic levels dating from the Mousterian to the Neolithic. The Magdalenian assemblage is comparable to Picareiro's and sheds some light on the time period between the LGM and the Younger Dryas. Unfortunately, the assemblages from Caldeirao are poorly dated and found in disturbed contexts. The assemblage is still useful in terms of a systemic inventory and the faunal record at Caldeirao cave supports the pollen and vegetation record, recording changes in species relatively sensitive to slight environmental changes.

Red deer (Cervus elaphus), Ibex (Capra pyrenaica), and chamois (Rupicapra rupicapra), were key species during the early Magdalenian, a holdover from the Solutrean. However, as the environment in the Portuguese Estremadura warmed, Ibex and Chamois may have migrated to the mountains in the north of Portugal, following the retreat of the ice sheets (Straus et al. 1996) With the expansion of truly forested areas and more vegetative ground cover, roe deer and other forest species appear in the record (Davis et al. 2007). Wild boar (Sus scrofa) and equids are seen during this time period as well.

Badgers, leopards, lynx, wildcats, and fox (Vulpes vulpes) make up the carnivores in the Magdalenian assemblages in the Portuguese Estremadura (Davis, Simon J. M., et 
al. 2007). Avian specimens include examples of owl, eagle and vulture species. Many non-anthropogenic faunal assemblages, especially micro-faunal components, come from these sources. Humans during this time would have competed with these predators for food, as well as for shelter in rock shelters and caves.

\section{MICRO AND MESO - FAUNA}

The micro fauna during this time period also changed in response to the changing climate and local environmental conditions. Rabbit (Oryctolagus cuniculus) is well represented in Magdalenian assemblages and were clearly exploited for subsistence in the Magdalenian, as represented by the assemblage at Caldeirao and the previously studied sections of Picareiro (Hockett and Haws 2002). Multiple species of vole are also present including the Mediterranean Pine Vole (Terricola duodecimcostatus) and the snow vole (Chionomys nivalis). Many different mouse species are seen, such as the field mouse (Apodemus sylvaticus) and garden dormouse (Eliomys quercinus). Because of microfaunal sensitivity to environmental changes, the ratios between one species of rodent to another in assemblages can give insight into changes paleoclimates (Straus 1990) (Bicho and Haws 2012). Birds, Bats, Fish (from the family Ciprineidea), marine and terrestrial gastropods, and marine bivalves, also make up part of the faunal record of the Magdalenian in the Portuguese Estremadura (Bicho, Haws, and Hockett 2006). 


\section{A REVIEW OF RELEVANT LITERATURE AND THEORETICAL CONSIDERATIONS}

\section{THE MAGDALENIAN IN IBERIA}

Lawrence Straus's contribution to cave archaeology and his text Humans at the End of the Ice Age (1996) were a major part of the literature available to define the Magdalenian in Iberia. His excavation at El Miron, a Paleolithic Cave Site in Cantabrian Spain, among others, provides an abundance of material with which to compare Picareiro. Although useful, there are major difference in the assemblages between the two sites. For example, besides the lack of an Azilian cultural period in central Portugal, the Pyrenees influence seen at El Miron in Spain is absent in the Portuguese Estremadura. El Miron also experienced much greater environmental fluctuation during the Upper Paleolithic (Straus and González Morales 2012). Because of this, although El Miron is an excellent source of information on the Magdalenian, a region specific approach must be used for a discussion on central Portugal. Joao Zilhao, Nuno Bicho, and Jonathan Haws have published prolifically on the Portuguese Paleolithic, including their respective dissertations, providing a large amount of the available information on Picareiro and the Paleolithic in central Iberia. Because the pool of sites with relevant material for comparison to level F at Picareiro is small, sites may be mentioned multiple times. 


\section{SPATIAL ANALYSIS BACKGROUND}

Spatial analysis is the core component of this thesis. Analyzing the distribution of material in Level $\mathrm{F}$ requires an understanding of the process and history of the science. Discerning meaning from the relationships of objects in space to each other and their surroundings has been an important and regular part of archaeology since the early twentieth century, most notably developed during the Cultural-History era of anthropology (Wheatley and Gillings 2002). Detailed maps from the $18^{\text {th }}$ century and precise artifact locations for archaeological material found in documents dating to the late $19^{\text {th }}$ century show the importance of recording spatial information for archaeological endeavors has been recognized for some time, even before the science was formalized (Wheatley and Gillings 2002). Archaeology, as a science, is a materialist undertaking, as the major component of what provides the information for study comes from the physical material we take out of the ground. The rest of the information is the context provided by where that material is located. Combining these two areas of information and using statistical methods to organize and analyze this data is spatial analysis.

Spatial analysis employs many different tools and methods to answer the research questions that guide its use. Remote sensing, the science of recording information about an object without touching it, has heavily impacted spatial analysis and archaeology as a field (Parcak 2009). Although the technical definition of remote sensing is broad, more commonly it refers to information collected about a subject by using energy along the electromagnetic spectrum (Jensen 2009). For example, the most recognizable form of remote sensing involves the passive recording of sunlight in the form of photography. Aerial and satellite imagery fall into this category. Less known, but no less utilized, are 
active forms of remote sensing. These involve the recording of energy emitted by the recording device. LiDAR (Light Detection and Ranging), GPR (Ground Penetrating Radar), and total stations are all examples of this. Total stations are perhaps the most used form of remote sensing in archaeology today, besides perhaps photography. Almost all the analysis in this paper uses total station data for discussions on Level F at Picareiro. These raw data cannot be used without going through one more stage, the post collection organization and analysis. For this, a GIS is used.

There are many available definitions for Geographic Information Systems, or GIS. Multiple definitions are provided by Wheatley and Gillings in their thorough text Spatial Technology in Archaeology (Wheatley and Gillings 2002). From these various definitions, I have synthesized my own which will be used for this paper and for defining the work done to render analysis on spatial information on Level $\mathrm{F}$ at Picareiro. A GIS is any system that allows you to organize, store, recall, search, manipulate, render, and analyze information about the physical world and where its components reside in space. Although a basic GIS may only allow users to store and manage spatial data, current digital GIS packages almost always include the above capabilities. The GIS used to complete analysis for Level $\mathrm{F}$ is the ArcGIS suite of programs. The tools available in these programs shaped the research questions for this paper, and directly influenced the data collection methods when using total stations at Picareiro.

Applying spatial analysis at Picareiro follows a tradition of using spatial information to discuss past hominin behavior from the Middle Paleolithic through the Magdalenian in western Europe. Pech de L'Aze IV is a middle Paleolithic site in south western France and was excavated in the 1970s by Francis Bordes. In the 1990s Harold 
Dibble and Shannon McPherron continued excavation of the site and analyzed Borde's previous excavation and data recording methodology. One of the results of this was a paper on excavator bias (Dibble, Raczek, and Mcpherron 2005). The bias and spatial discussions introduced in this paper mirror the excavation at Picareiro and helped shape the discussion on the data collected and archived for Level F. Dibble and McPherron went on to write another paper on excavation methodology and the use of elevation data for recording spatial data. This paper, titled $Z$, is a seminal text for the analysis of artifacts and stratigraphy independent of geology (McPherron, Dibble, and Goldberg 2005). Dibble and McPherron played a large, albeit indirect, role in the collection and organization of data from Level F at Picareiro. The pair designed a series of programs to be used with total stations that introduced a standard format to data collection used at multiple different sites around the world. This standardization is crucial for inter-site comparisons and increasing our understanding of past human behavior over large spatial scales. These programs also facilitate intra-site comparisons, making the process more efficient.

La Pena de Estebanvela is an Upper Paleolithic site in Spain at which comparable spatial analysis has been applied. A discussion on the use of space at this site by Carmen Cacho et al., and the methods used to do so, closely resemble the work done for this paper on Level F at Picareiro (Cacho et al. 2016). Spatial analysis at El Miron has also produced data for which Picareiro can use for comparisons. Although there are many similarities between the analysis done on the Magdalenian faunal assemblages for El Miron and Picareiro, there are also differences, one of the most notable being the use of individual units as discrete spatial categories for intra-site comparisons. Square- by- 
square searches in GIS were made for El Miron (Arroyo 2009). This type of information is limited to the arbitrary placement of the unit grid and the resolution of 1 meter squares. At Picareiro, with the introduction of an absolute grid in 2013, the grid boundaries were eliminated and image pixels were used as discrete spatial units for analysis, thus providing a much higher resolution and more fluid GIS queries. In Portugal, the Paleolithic cave site of Cova do Caldeirao, in the Estremadura region, provided comparable data with which to guide and compare the analysis of Level F. Although problems with the dating and context are present, it represents a close site type for comparisons in the Portuguese Estremadura and provides a gauge with which to measure the dating at Picareiro (Haws 2003).

A recurring theme in the literature discussing spatial analysis of Late Upper Paleolithic sites is the use of elevation information when recording artifact locations. A central component to excavations, the idea that the relative elevation of an artifact within a site and associated stratigraphy can represent a chronology is the basis for relative dating following the laws of superposition (Bahn and Renfrew 2011). The elevation data, which in absolute grids are assigned to the $\mathrm{z}$ axis, provide information on occupations of the site and dates of activity. One of the many goals of spatial analysis, including that of Level $\mathrm{F}$ at Picareiro, is the distinction of discrete occupations within cultural and geologic strata. This endeavor is often complicated by the presence of palimpsests. 


\section{PALIMPSESTS AND LIVING FLOORS}

The presence of thick bands of artifact and bone deposition, in times of slow geological deposition and accumulations, as well as the lack of distinct sterile lenses between occupations within a single stratigraphic level, suggest the presence of palimpsests (Straus 1990). Slow rates of deposition of natural material at Picareiro, like most caves above the water table, supports the idea that cultural material was not buried fast enough to preserve "living floors" or to keep it from being effected by a myriad of post depositional processes. Increasingly, researchers have been using elevation data to redefine living floors, discrete activity areas, and paleo-surfaces (Guan et al. 2011). A living floor can be defined as a discrete and undisturbed ground surface which displays the original or primary deposition of material remains of an occupation in its original spatial distribution and containing its original material composition. Living floors are ideal because a single occupation preserved just as the material fell would give the greatest insight into past human behavior (Dibble et al. 1997). However, problems arise when trying to prove that this is the case. This would be particularly hard at Picareiro, with thick cultural material deposition in vertical bands. With the introduction of microspatial recording methods, however, it may not be impossible.

The idea that the material recovered at an archaeological site represents distinct occupations and areas of human behavior can be taken for granted. Any discussion on the spatial distribution, and even the composition of the faunal and lithic remains of a site

would be incomplete, and most likely very flawed, if the processes which took place between the deposition of an artifact and its recovery by archaeologists were not addressed. 
The processes that effect the deposition, distribution, and preservation of the material remains at a site, along with its geological formation process, all fit into the puzzle of site formation. Strictly speaking, for zooarchaeologists, everything that effects animal remains from the moment it dies to the time it is analyzed in a laboratory falls under the study of taphonomy (Lyman 1994). This definition, although perhaps not the term itself, can be applied to any material remains at a site, following that object's "life" history directly before and after its deposition at the site. The time in an objects life history after deposition within the site is the focus of the spatial analysis of level F.

Although this thesis endeavors to assign use areas in the cave based on artifact density, a purely reconstructivist agenda is not the goal of this analysis. This discussion on the material found at Picareiro, and their location in space, acknowledges the processes that took place between original deposition and recovery. As discussed by Binford, Schiffer, and Dibble, it cannot be generally assumed that artifacts are found exactly where they were deposited or fell, a phenomenon loosely defined within the idea of a Pompeii Premise. This premise recognizes that artifact distribution rarely reflects distinct actions in the record like a snap shot in time. The disaster at Pompeii is a famous example of an exception to this rule. To make this claim, however, types of material deposition must be organized into categories. Artifacts found as deposited material in sites no longer in use can be placed into one of three categories; Primary refuse, Secondary or Abandonment refuse, and De facto refuse, a full description of which can be found in Michael Schiffer's defense of behavioral archaeology concerning the Pompeii premise (Schiffer 1985). These designations are apt if we believe prehistoric societies are similar to modern aboriginal groups, an assumption that carries a large set of 
inherent biases (Schiffer 1985). The main advantage of this thought experiment, however, is to structure how we organize and think about objects found at archaeological sites; i.e. we have to start somewhere.

The Pompeii Premise, hotly debated in the age of New Archaeology by Lewis Binford and Michael Schiffer, is an important feature of discussion for the analysis of archaeological material from Level F. Binford, leaning heavily towards being a reconstructivist, believed the spatial distribution of deposits can represent specific actions (Binford 1981). Schiffer believed total counts of depositions can only be taken as an inventory and used for a systemic index, or a list of articles which were used in a specific culture, giving information on behavior (Schiffer 1985). Although differing in their approach, the main difference in how they viewed deposits was their views on the role of post depositional movement in how an assemblage was characterized and used. Schiffer saw anthropogenic post depositional movement as subtracting from the descriptive value on discussions of assemblage distribution. Binford believed anthropogenic post depositional movement is part of the behavior being discussed. For the analysis of level F, both sides will be explored. The material at Picareiro does add to the systemic inventory used to characterize the Magdalenian in Estremadura Portugal, but does not fully represent it, an important distinction. The question of whether a distribution of artifacts represents something or not, and what that something is, is the purpose of spatial analysis. This work addresses this question in regards to Level F at Lapa do Picareiro.

A major problem in spatial analysis is the existence of palimpsests. Methods exist to tease apart palimpsests, both during and after excavation. During excavation, geological levels can be dug in arbitrary vertical sections in the decapage method, 
involving large areas being dug at the same time (Aldeias et al. 2012). This is limited, among other things, by assumptions of where palimpsests may occur, a decision often made too late to employ this method for the entire area of interest. Post excavation methods involve splitting the point could into thins sections along the vertical axis and tracking how clusters of points move along the $\mathrm{x}$ and $\mathrm{y}$ axis. This method has its merits and can produce convincing results in displaying finer resolutions of "time" in terms of discrete occupations of space. However, applying arbitrary vertical subdivisions to material that has experienced any form of post depositional movement, or over burden of more cultural material, carries with it a large suite of assumptions and biases, the full extent of which is beyond the scope of this paper. Those experienced with such processes are skeptical, in fact, doubt is commonly expressed by many that living floors can be distinguished in palimpsests at all (Aldeias et al. 2012). A project of this type would have to start in the field with the specific purpose of teasing apart palimpsests, as the fine spatial recording necessary is time and cost prohibitive (Dibble, Raczek, and Mcpherron 2005). The methods would also have to be consistent across time. A detailed dissection of the vertical distribution of level F could result in its own publication. Because of these reasons, breaking apart the vertical components of the palimpsests of level F will not be addressed in this paper. With the use of micro-spatial recording methods at Picareiro, this process may be applied to lower levels in the excavation, aided by the use of digital total stations. 


\section{LAPA DO PICAREIRO}

Lapa do Picareiro is a cave in central Portugal; located in the Serra d 'Aire mountain range, part of the limestone massifs in the Estremadura region. The site is located near the pilgrimage town of Fatima and Covao do Coelho, which translates to the great cave of rabbits in English (Bicho et al. 2006). The area is northeast of Lisboa, roughly $31 \mathrm{~km}$ from the current coast line at the western edge of Iberia. The site lies at the western extent of the Mediterranean biogeographical zone in Portugal.

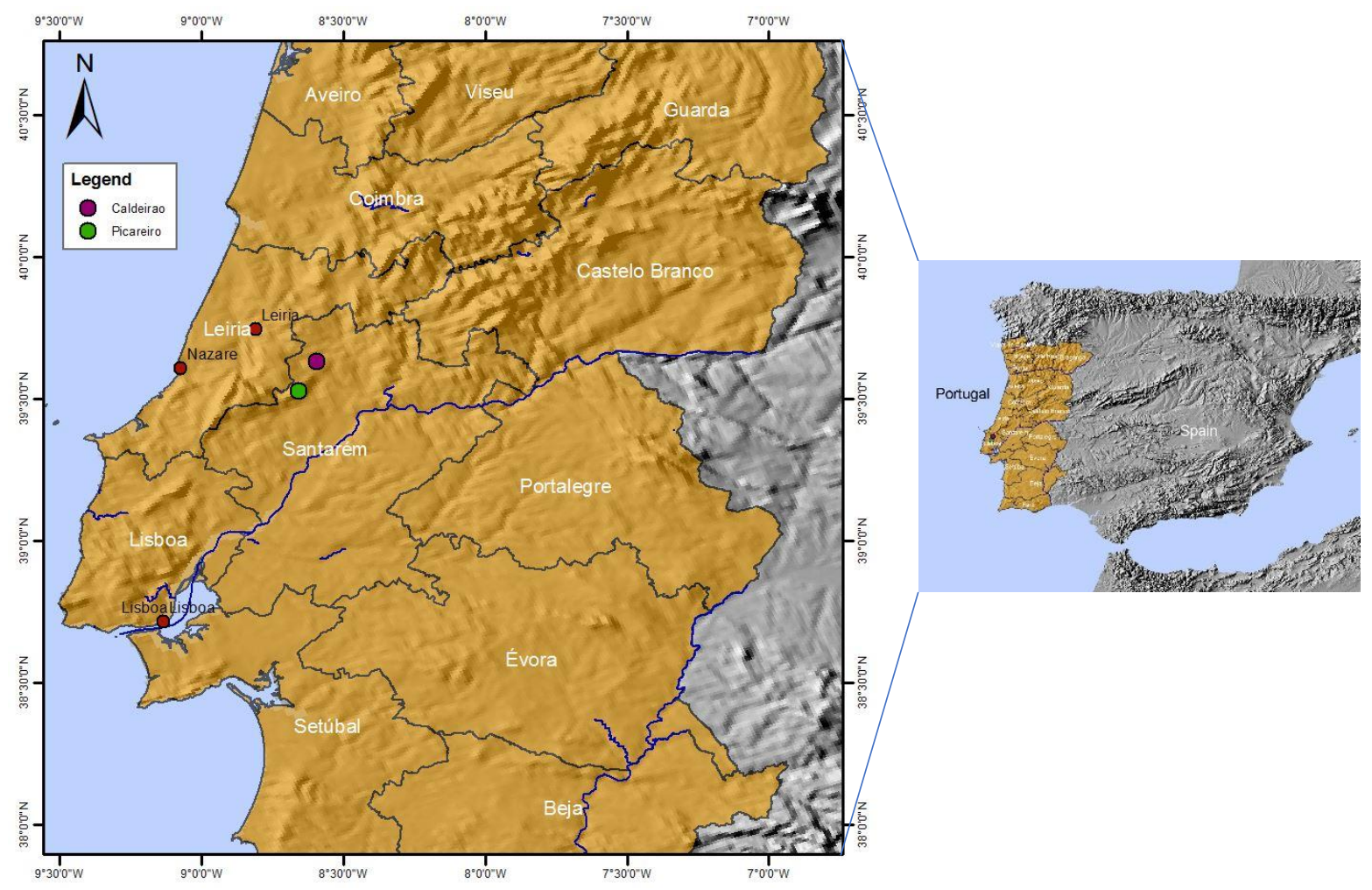

Fig. 3. Location of Picareiro and the study area 


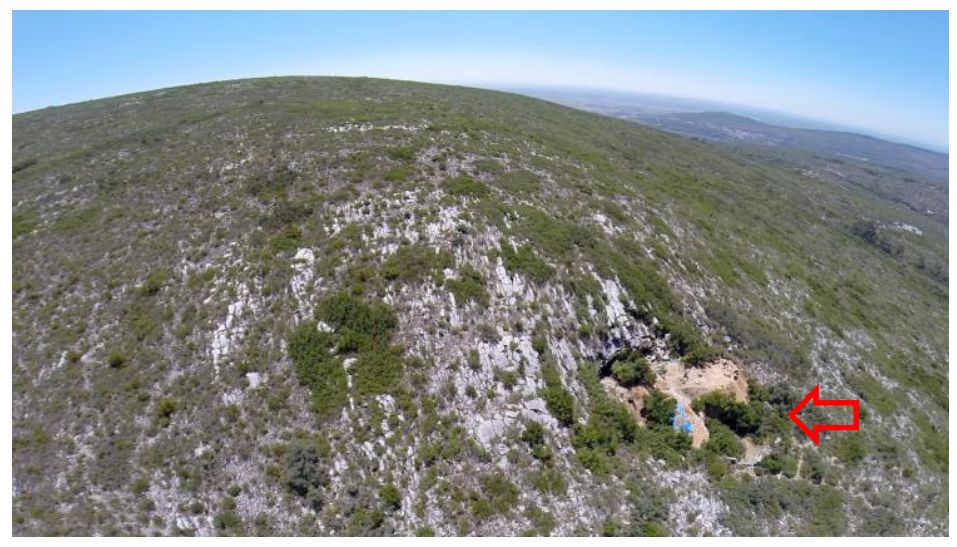

Fig.4. Picareiro at 571 m.a.s.1.

\section{HISTORY}

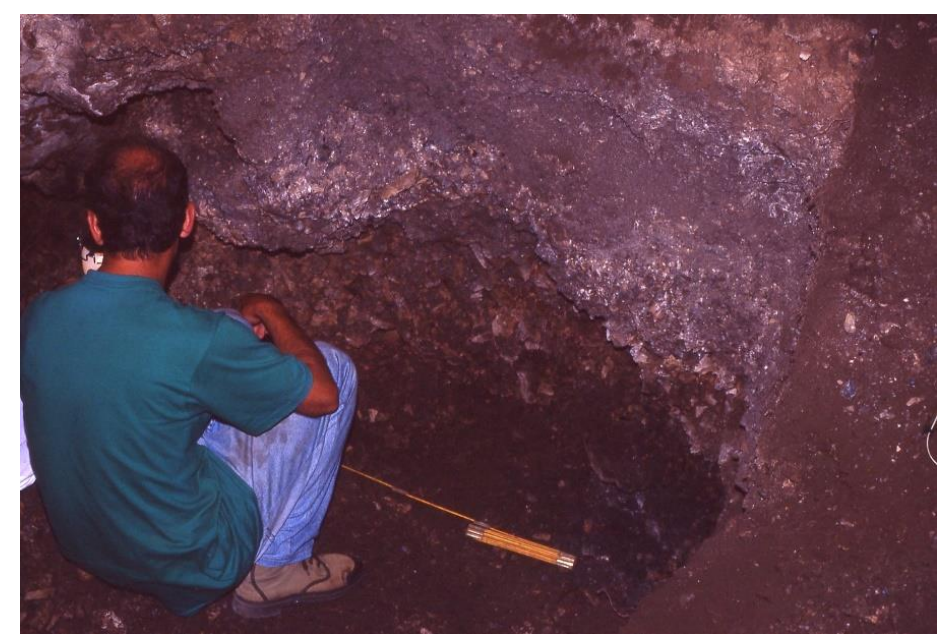

Fig. 5. Early excavation in the top 2 meters.

Picareiro was first investigated in the mid-1950s by Gustavo Marques (Zilhao 1991) and then Gil Andrade in the 1960s (Zilhao 1997)(Haws 2003). After being revisited in 1988 by Joao Zilhao, the cut left by Marques was opened into an excavation in 1994 by Nuno Bicho and Jonathan Haws (Bicho et al. 2006). This excavation lasted until 2001. Excavation resumed in 2005 with new ground being opened under the 
directorship of Jonathan Haws and Michael Benedetti, who joined the project in 2010. Teams from the University of Louisville and the University of North Carolina at Wilmington from the United States, the University of West Bohemia from the Czech Republic, and the Universidade de Algarve from Portugal now participate annually. The purpose of this excavation has been to establish a complete cultural and chronological sequence and to study the Middle to Upper Paleolithic transition in Iberia.

\section{LAYOUT OF PICAREIRO}

Lapa do Picareiro is a multi-occupational site spanning the Middle and Upper Paleolithic phases in central Portugal. The entrance to the cave is roughly $560 \mathrm{~m}$ above sea level. There are two main areas of the site, the interior and the exterior areas of the cave. The exterior consists of unexcavated surface now covered by back dirt from the interior of the site, screening areas, and areas covered by large boulders. The interior consists of the main area of excavation and is the most documented and dated area. 


\section{OUTSIDE OF THE CAVE}

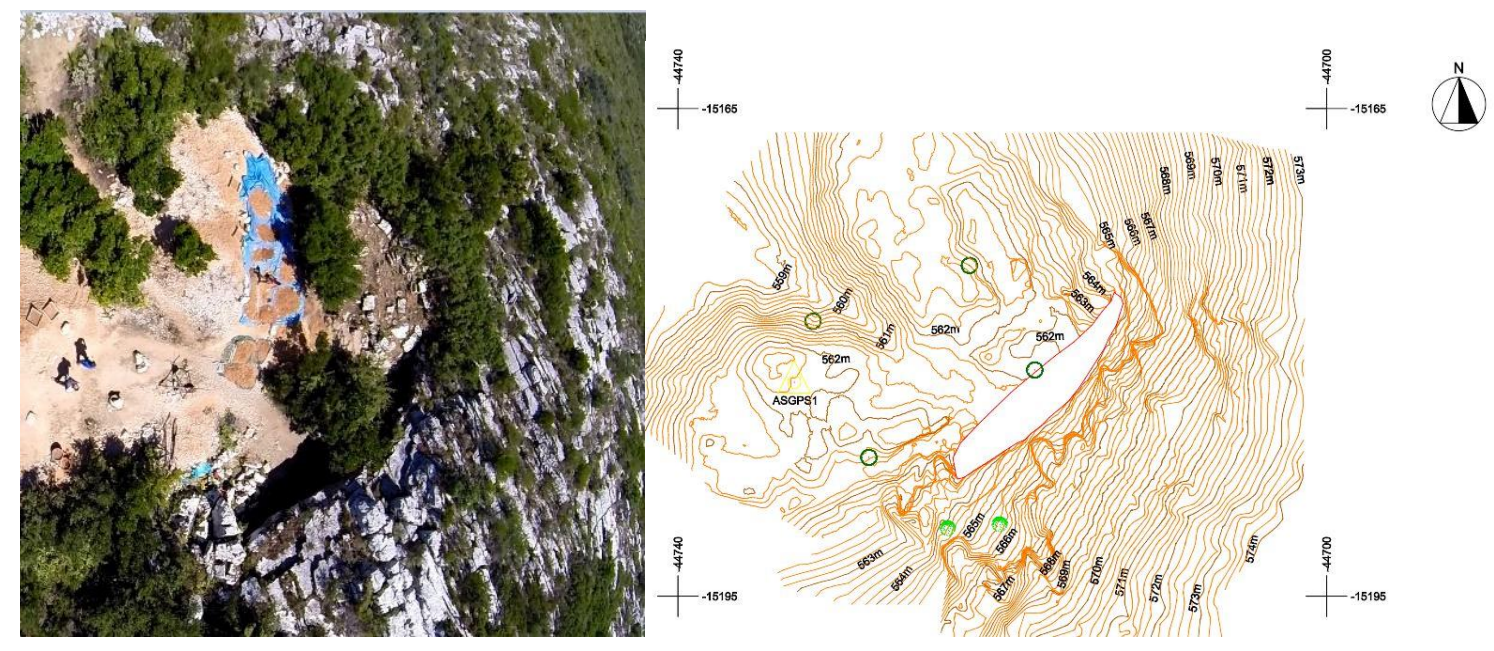

Fig. 6. Outside of the cave

Fig. 6 shows the exterior of the cave site facing north, with the elevation rising as one moves further west/ south west. On the left is imagery taken using an Unmanned Aerial Vehicle in 2013. On the right is a topographic map of the outside of the cave created from the 2016 LiDAR data. The entrance from the path opens onto a bowl like depression in the limestone bedrock of the mountainside lined by a low wall. Walls such as this, probably used for goat herding, can be seen all along the mountain sides of the area, presenting a terraced appearance and often incorporating natural limestone outcrops into their construction.

The back-dirt piles can be seen in the images in Fig 6. The top left of the figure shows the path between the two lobes of back dirt. As the interior of the cave was excavated it became clear that the cave entrance had once extended further out and a collapse had occurred, creating the present mouth of the cave. Large boulders indicate 
this collapse and show that the entrance to the cave was most likely once under where the back-dirt piles lay now, closer to the low herding wall (see fig 7).

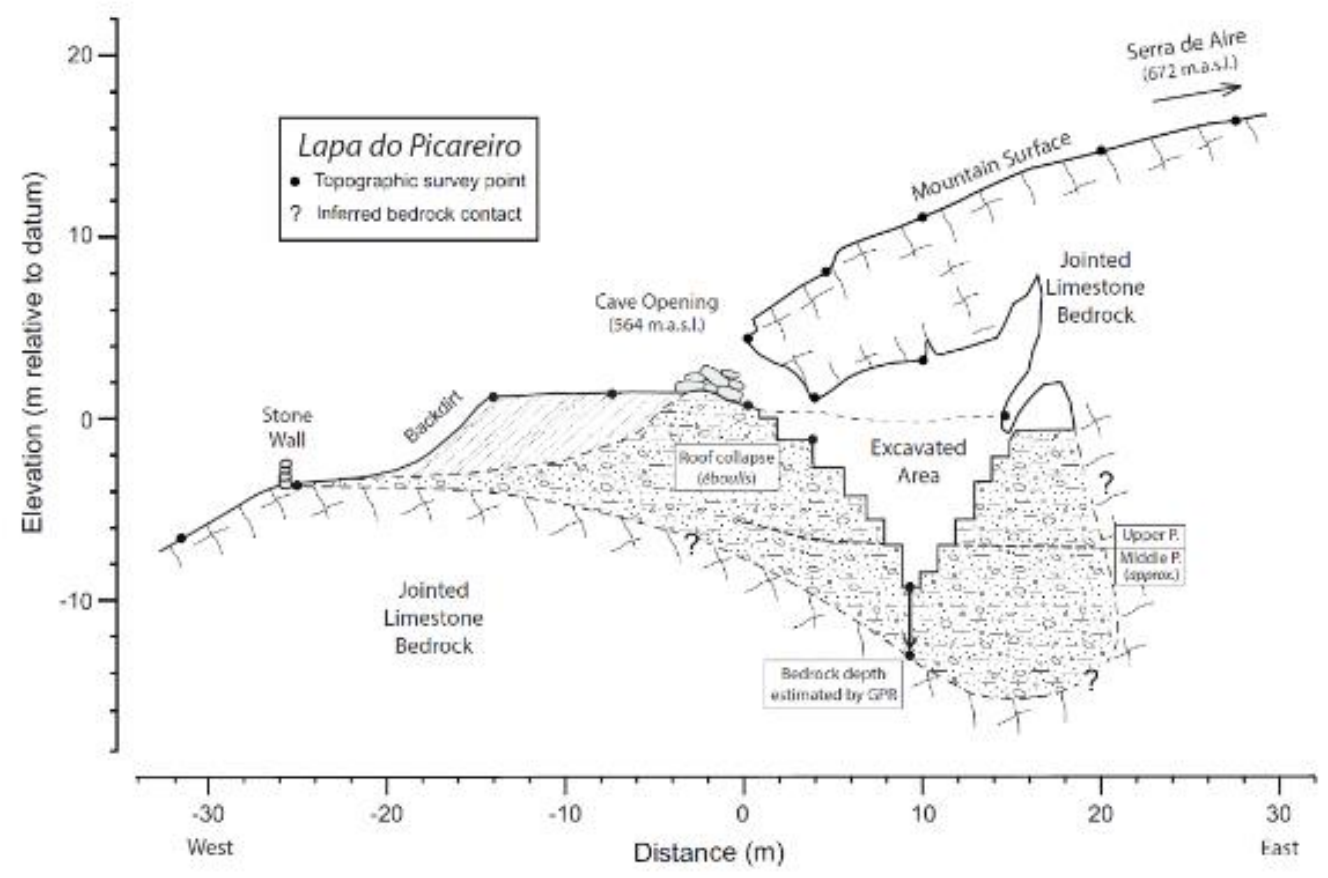

Fig. 7. Drawn Composite Profile of Picareiro (Benedetti et al n.d.)

In 2012, Ground Penetrating Radar was employed by Lawrence Conyers to map the pre-excavation surface of the outside section of the site. The hope was to determine the amount of natural deposition before the ground was covered by back dirt (Conyers 2016). 

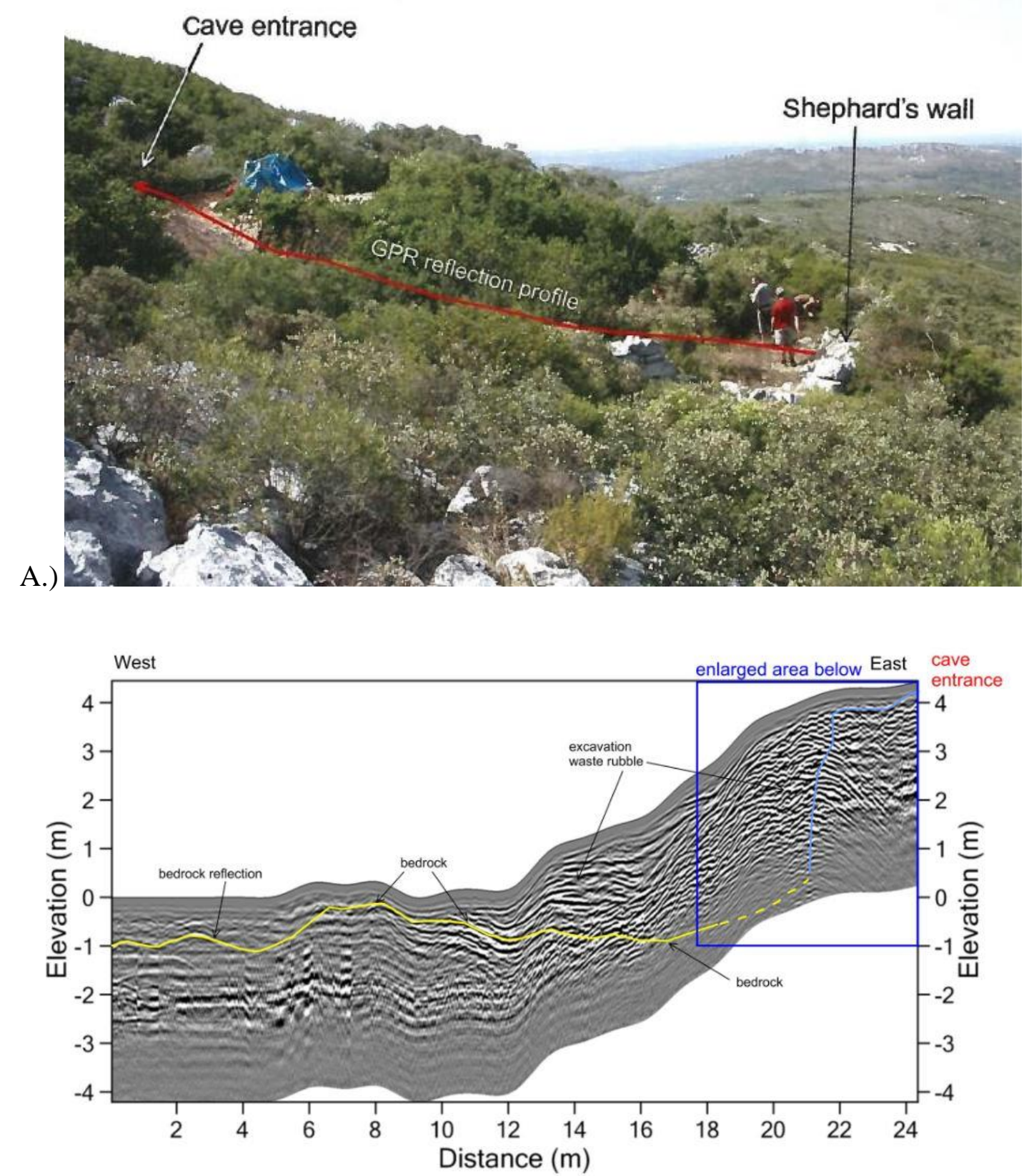

B.)

Fig. 8. A.) The path taken by the GPR specialist in 2012, outside of the cave from the shepherd's wall over one lobe of the back dirt pile. B.) the GPR results. (Conyers 2016). 
Ground Penetrating Radar was also employed within the cave to test the depth of the deposits left before bedrock. Conyers also hoped to test the energy penetration of the deposited material, which is mostly éboulis and inter-clast soils. Using a level row of units as a bench track, seen in Figure 9, the GPR showed returns up to around $8 \mathrm{~m}$ below datum at that section in the cave (Conyers 2016). No bedrock was visible, however, large clast layers were seen in the generally horizontally deposited layers (See Fig. 10). Further excavation confirmed the existence of multiple large clast layers with no sign of bedrock.

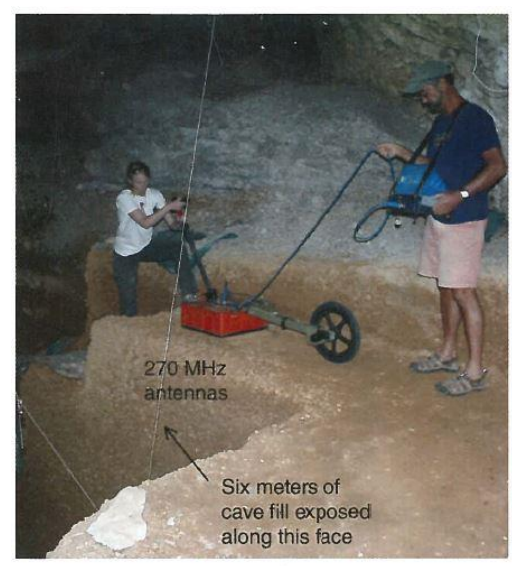

Fig. 9. The low bench of units used for GPR inside the cave (Conyers 2016).

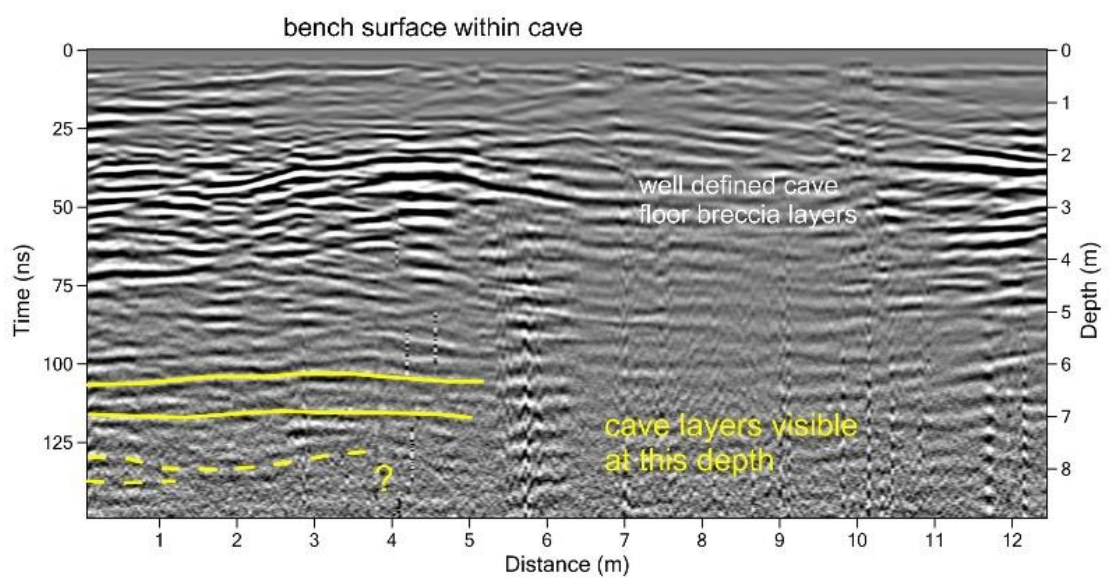

Fig. 10. GPR results for the inside of the cave (Conyers 2016). 


\section{INSIDE THE CAVE}

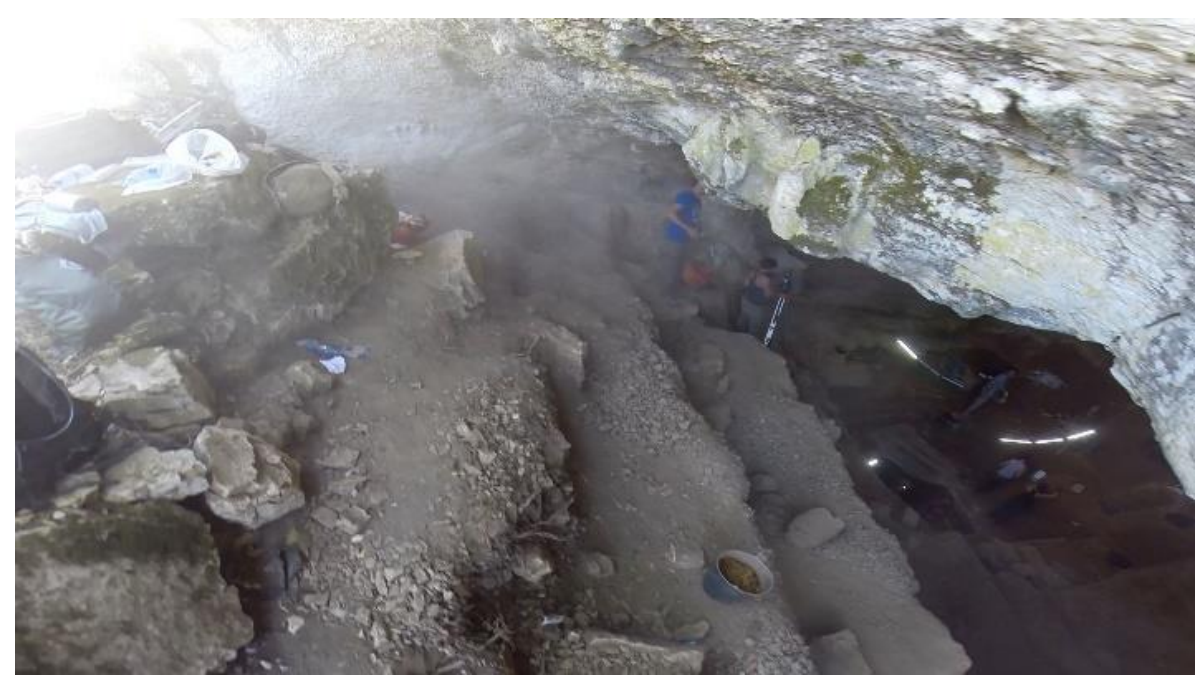

Fig. 11. The Entrance

Passing the outermost lip of the mouth of the cave places you in the interior of the site. This distinction, as obvious as it seems, is important for two reasons. First, this is the beginning of visible units being excavated. The second is, at this point, the cardinal directions used for the site change orientation. True north, used outside of the cave and given by the earth's magnetic field, is different than the arbitrarily designated "Cave North". When an arbitrary grid system was introduced to organize the cave in 1995 the Y axis lines were not lined up with magnetic north. This was not a problem at the start of the excavation, when a unit relative system was used for piece provenience. With the introduction of digital total stations and an absolute coordinate system in 2013, cardinal directions within the cave were changed to match the $\mathrm{x}$ and $\mathrm{y}$ axis of the unit grid. This was done to aid in excavation, spatial recording, and communication during excavation.

Beginning in 1995, an arbitrary, one by one-meter grid based on an alpha-numeric nomenclature system was laid out to organize the site and excavation. Columns are 
labeled by number, increasing from cave east to cave west, or left to right. Rows are lettered starting in the back of the cave with A and progressing along the alphabet towards the front of the cave. Within the last few years of excavation, the site boundaries have pushed back past row A, so double letters were used to extend the grid (Fig. \#).
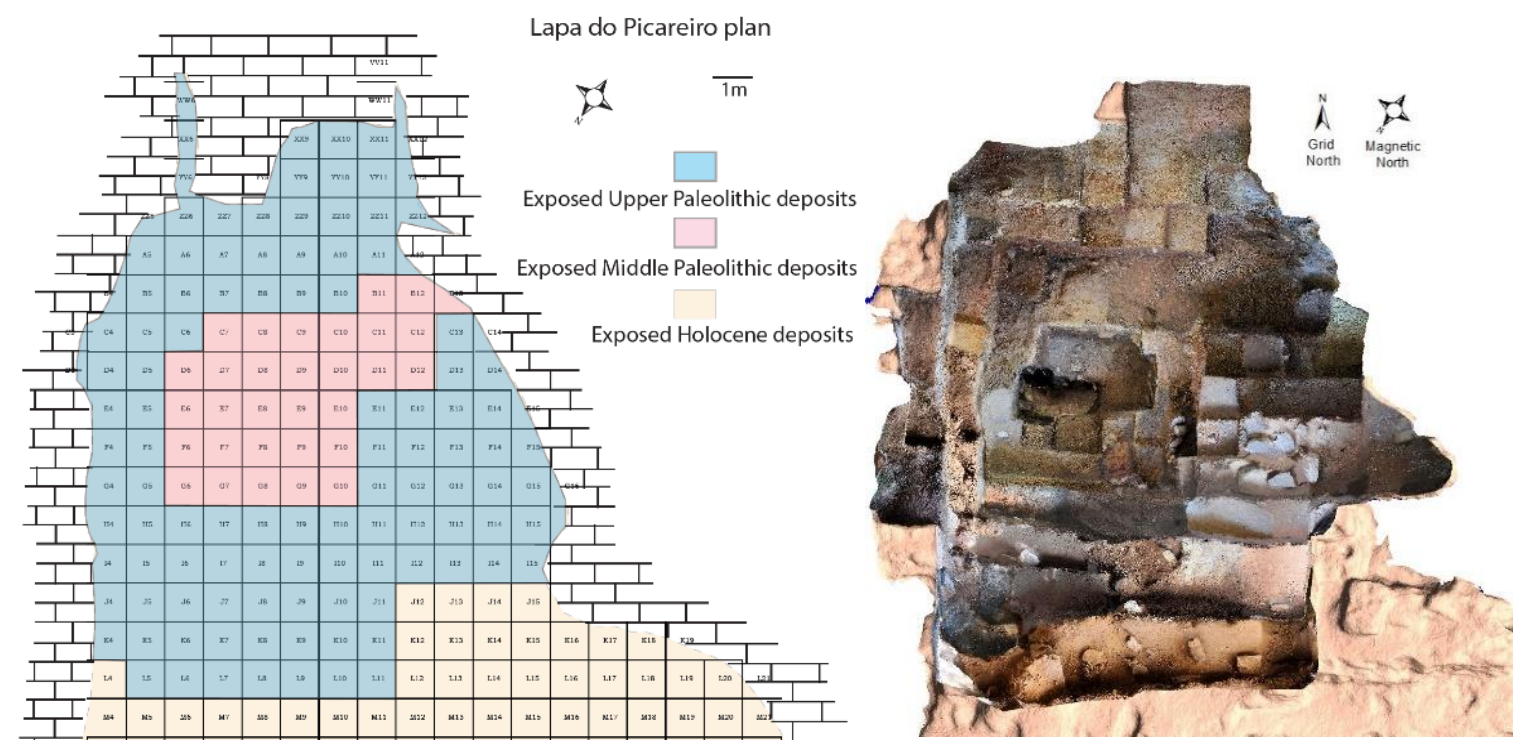

Fig. 12. Plan view of Picareiro

Collection and organization of data for Level F started in the field while excavating. The in situ location for artifacts and faunal remains equal to or greater than 1 centimeter was recorded. From the first years of the excavation in 1995 until total stations were introduced to the excavation in 2013, piece plots were taken with hand levels and stadia rods, based off of a single datum on the roof of the cave. The introduce of total stations in 2013 allowed the team to digital piece provenience, or piece plot, artifacts. In 2014 a new total station, a Sokkia CX-103, was introduced into the excavation to replace the one used in 2013, and became the standard total station for Picareiro. With the introduction of the new total station, EDM software from Harrold Dibble and Shannon 
McPherron was used to standardize the format of recorded spatial data. In 2015 a second total station was added to the excavation. The excavation was then split into two halves along the $\mathrm{X}$ axis of the grid. The split was arbitrarily placed between the $8^{\text {th }}$ and $9^{\text {th }}$ columns to divide the site between the two total stations, allowing for a smoother data collection process.

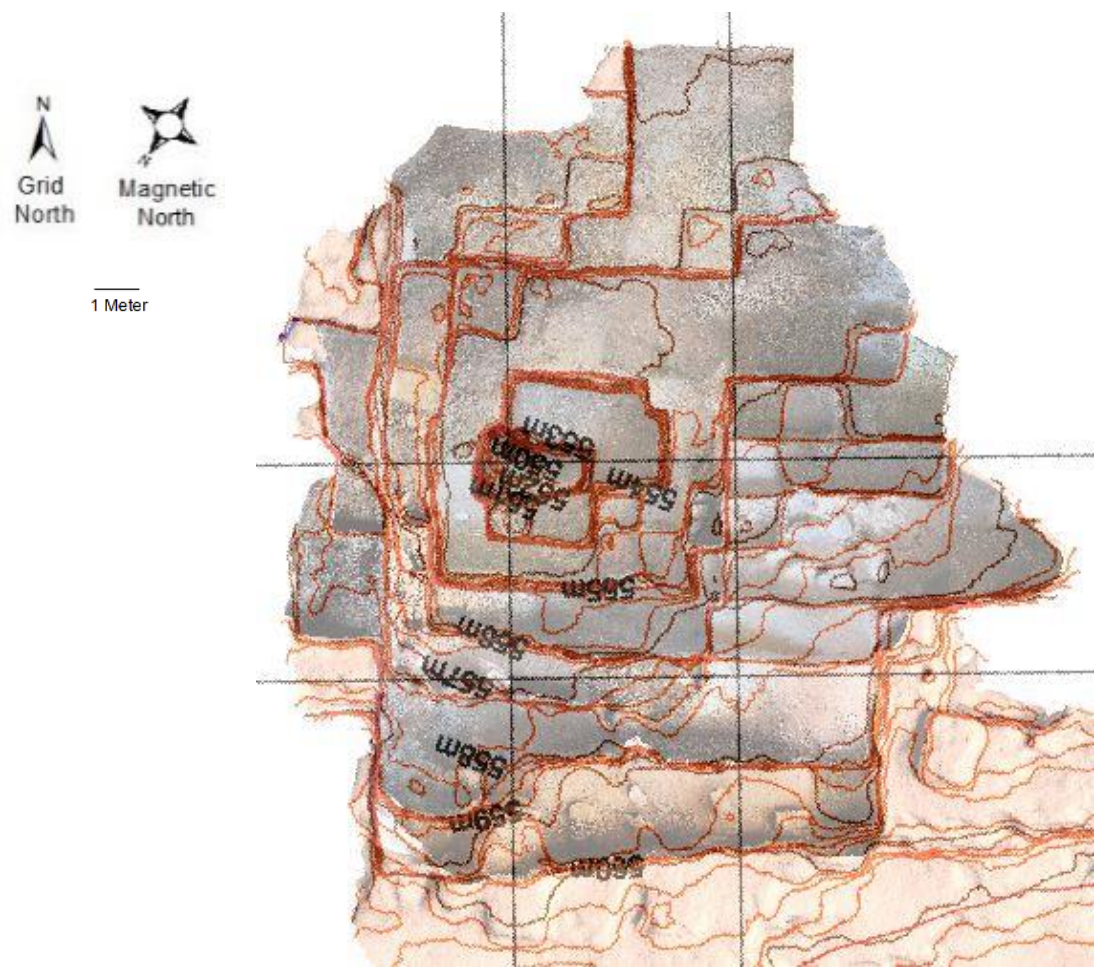

Fig. 13. Topographic map over an Orthophoto of Picareiro

The inside of the cave has been excavated to various depths. As of the 2016 field season, the site was roughly 12 meters wide and 18 meters long along the $\mathrm{x}$ and $\mathrm{y}$ axis, respectively. Figure 12 compares the grid on the left to an orthophoto of the current extent of the cave on the top right. Figure 13 is a LiDAR-derived topographic map layered over the orthophoto of the cave interior produced by Artescan at the end of 2016. 
Roughly 150 units have been excavated to some degree, at different times, with over 325 exposed possible units. The site inside the cave is bound by the roof walls, which expand outward as the site moves down in elevation. As the cave reaches lower depths the cave walls slope down and outwards revealing more units. When the entire interior of the cave is excavated to the travertine layer GG there may be up to 400 exposed and excavatable units. Many of these units will remain unexcavated for the foreseeable future to allow for an entrance to the site and to preserve profiles.

At the end of the 2016 field season, the excavation reached a depth of 10.7 meters below the site datum, exposing Level NN spit 5, although only in the deepest test pit located in unit F7. This datum, originally set in 1995, is still the primary datum for the site and sits at 571.483 meters above sea-level. 


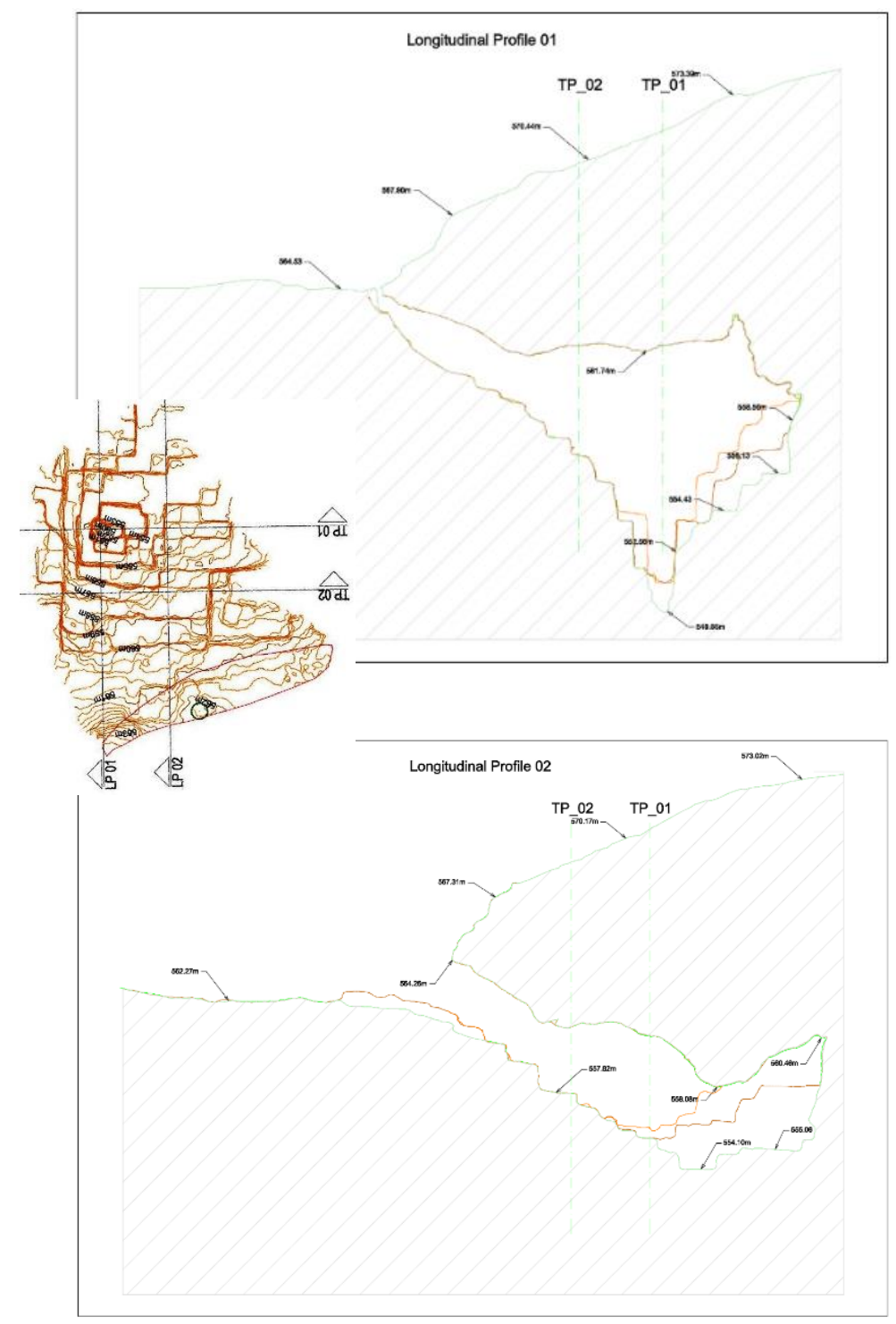

Fig. 14. LiDAR derived profiles (Artescan)

Figure 14 shows two profile views of the cave derived from the 2016 LiDAR data. These cross sections are taken from different sides of the cave. The image on the left, longitudinal Profile 01 (LP01, see inset map for figure location) shows the middle of the cave and most extensive excavation. The deepest section of the cave is shown here as the test pit in F7. This image also shows the entrance of one of the chimneys in the center of the cave roof, a potential source of water and sediment deposition. 
The image on the right sows Longitudinal Profile 02 (LP02) and shows the units on the right side of the cave, which were shaped to create a sort of "stairs" to allow access to the lower portions of the site. This image also shows the recently excavated "Sala" in the back of the cave, uncovered at the end of the 2014 field season, previously sealed off by roof spall. This area, which lay at the furthest back and most northern section of the cave, was named the "Sala", a Portuguese word for room. The Sala has yielded important lithic and faunal material for lower levels and has provided invaluable data on the formation and use of the cave during the Upper Paleolithic. Level F sealed the room and so only the top of the Sala will be discussed in this writing. The last of level F in the back of the cave was excavated in 2015. Level F still exists in some areas at the mouth of the cave and may extend out under the back dirt.

\section{STRATIGRAPHY AND DATING}

The 10 meters of deposits in the interior of the site are organized into naturally occurring, horizontal, geological stratigraphy. This stratigraphy is divided into levels by physical properties such as average clast size, sediment matrix content, sediment color, and grain size. Level designations follow the alphabet starting with A, after the organic top level $\mathrm{O}$, and proceeding further as you move down in elevation. Although almost 40 geological stratigraphic level have been identified, this thesis will only discuss the top two and half meters in detail. This is to place level F, the focus of this paper, in context. 
The upper most strata contained large amounts of organic rich sediment and was characterized by a dark color. This dark sediment gives way to lighter material as elevation decreases, suggesting the leaching of minerals. These upper levels are dated to the Epipaleolithic and Neolithic using charcoal samples and radiocarbon dating. The top meter and a half of deposit in the cave are heavily disturbed by bioturbation. Animal burrowing, roots, and foot traffic have displaced material within the first few geologic levels. Because of this, and other factors which affect charcoal dating including old wood, dating of these levels are tenuous.

\begin{tabular}{|c|c|}
\hline Level 0 & Medium-large $(2-10 \mathrm{~cm})$ limestone clasts with dark brown silt \\
\hline Level A & $\begin{array}{l}\text { Medium }(2-5 \mathrm{~cm}) \text { limestone clasts with dark yellow brown } \\
\text { compact silt }\end{array}$ \\
\hline Level B & Medium-sized limestone clasts with light yellow brown silt \\
\hline Level C & $\begin{array}{l}\text { Medium-sized limestone clasts with yellow brown silt. High } \\
\text { ash and charcoal content gives a gray appearance }\end{array}$ \\
\hline
\end{tabular}

Table 1. The upper most stratigraphic levels (Benedetti et al n.d.) 


\section{RELAVENT LEVELS}

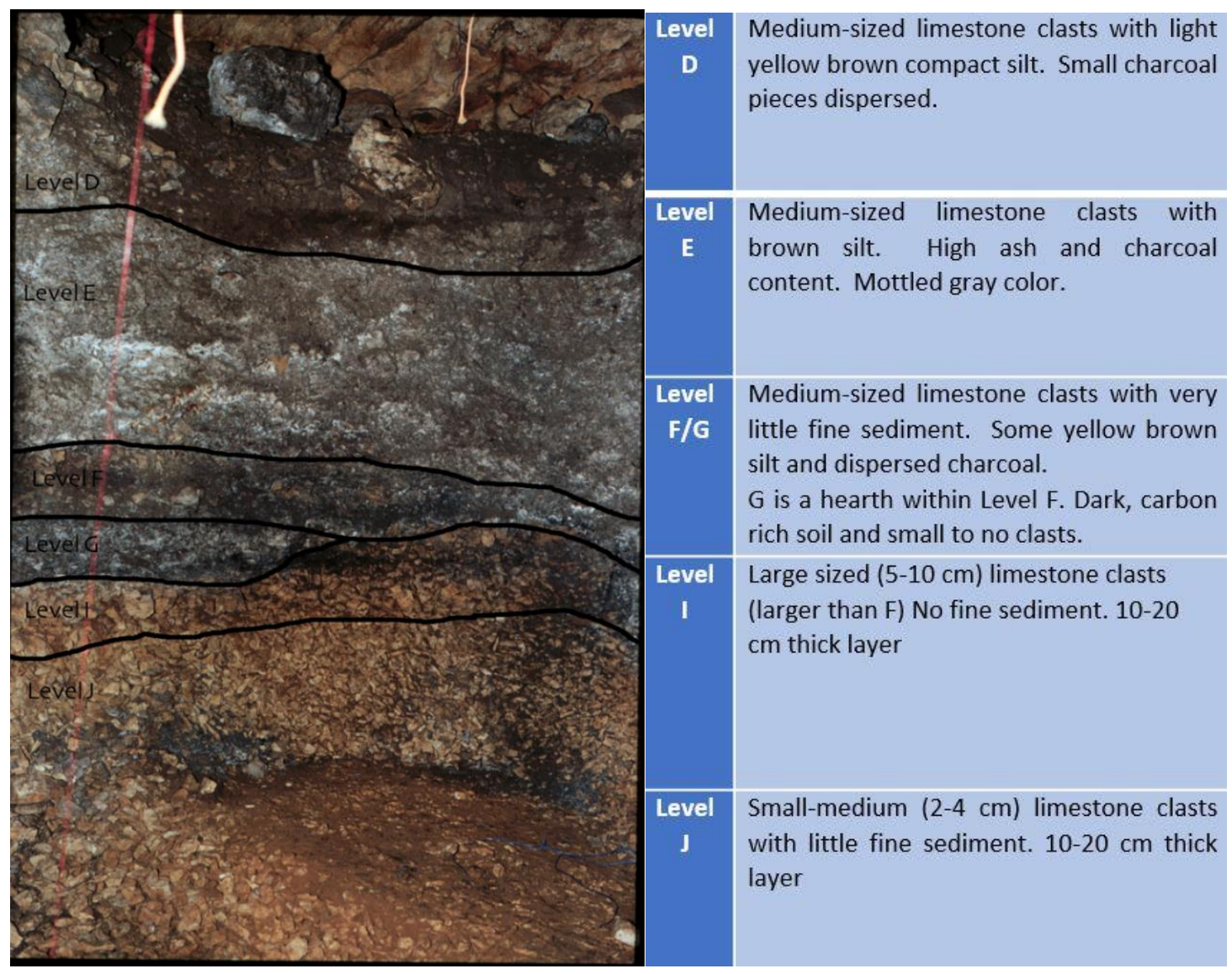

Fig. 15. And Table 2. Geological stratigraphy containing Magdalenian (Bicho 2006)(Benedetti et al n.d.)

Level E shows a transition from the Magdalenian to the Epipaleolithic with dates between roughly $10 \mathrm{Kya}$ and $12 \mathrm{Kya}$. 


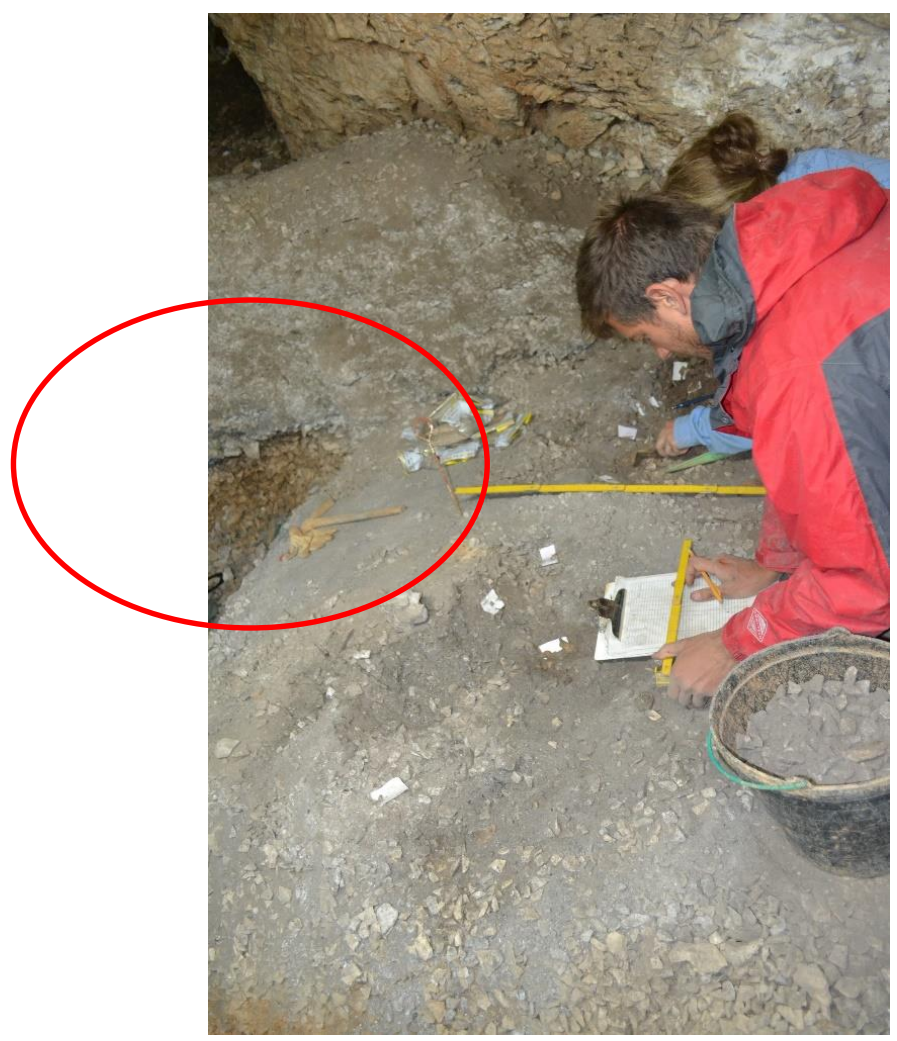

Fig. 16. Author Excavating in front of the Sala

Figure 16 shows the author plotting material in level $\mathrm{F}$ in 2012 . The profile circled in red lies directly in front of what will later be discovered as the entrance to the Sala. Level F is seen here sealing off the entrance, which at this point had not yet been discovered. This profile shows the distinct boundary between the darker, more charcoal rich sediments of level $\mathrm{F}$ and I and the deposits visibly lacking organic sediment in level $\mathrm{J}$.

Level $\mathrm{F}$ has provided two secure dates, placed between 13,772 - 13,442 kya Calibrated BP and 14,607 - 13,778 kya cal BP, in D6 and F5 respectively (Bicho Et al. 2006). Also, found in spit 3 and spit 10 respectively. Both of these dates came from charcoal associated with the large hearth excavated between 1996 and 2001, designated 
as level G. Figure 17 shows the level G hearth, construction, and dark sediment fill (Bicho et al. 2006). Level G, the cultural layer associated with the large hearth found in level $\mathrm{F}$ is characterized by the dark, organic rich sediments and lack of large clasts except for the ring of rock found lining the area.

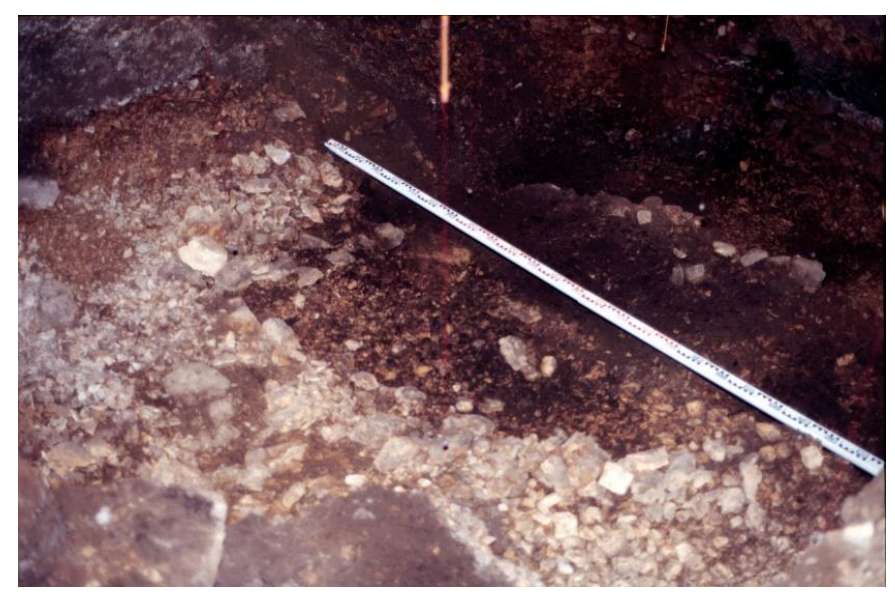

Fig. 17. The Hearth (Haws 2003)

Layer $\mathrm{G}$ was first identified as a natural, dark, seemingly organic rich sediment layer. Later excavation revealed this layer to be an area specific hearth within the geologic level F. Because of this, layer G was added to level F. Levels I and J are firmly in the Magdalenian and are distinctly different form the previous layers in terms of sediment color and content.

\section{DATES}

The dates obtained from Picareiro for the time between the LGM and the Younger Dryas were almost entirely charcoal samples submitted for AMS C14 dating. Table 3 shows dates relevant to level F. The four arrows show dates for the Level F and the surface of the Sala. The dates obtained from samples taken from the Sala surface show the continuity of level F into, and sealing off, the Sala. 


\begin{tabular}{|c|c|c|c|c|c|c|c|c|c|c|c|c|c|c|c|c|}
\hline $\bar{w}$ & ? & 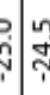 & & & & & & & & & & & & & $\begin{array}{l}\text { พิ่ } \\
\text { พิ }\end{array}$ & \\
\hline 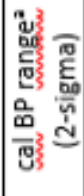 & 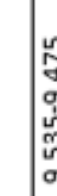 & 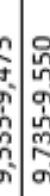 & & & 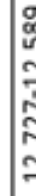 & 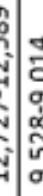 & 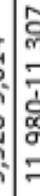 & 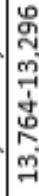 & 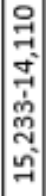 & 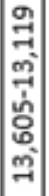 & 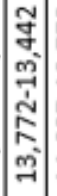 & 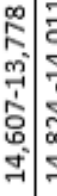 & 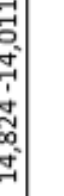 & $\mid$ & 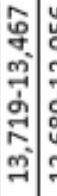 & \\
\hline 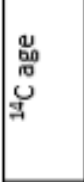 & 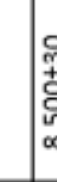 & \begin{tabular}{l|l}
0 \\
0 \\
0
\end{tabular} & 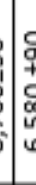 & & 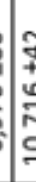 & 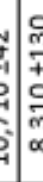 & $\begin{array}{l}0 \\
+ \\
+\end{array}$ & 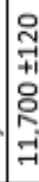 & 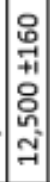 & 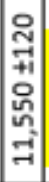 & 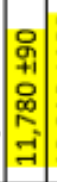 & 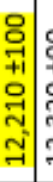 & & 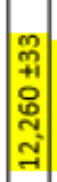 & 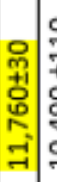 & \\
\hline 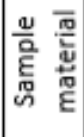 & 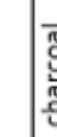 & 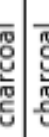 & & & 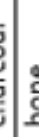 & 5 & 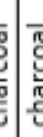 & 要 & 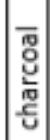 & 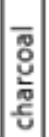 & 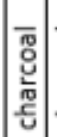 & 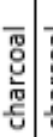 & 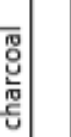 & 气̆ & 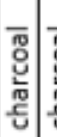 & 苟 \\
\hline 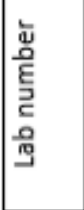 & 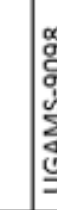 & 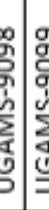 & 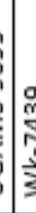 & & $\underset{\alpha}{\alpha}$ & $\begin{array}{l}0 \\
\vdots \\
\vdots \\
\vdots\end{array}$ & & 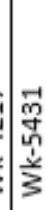 & 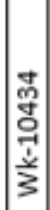 & 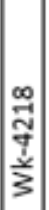 & 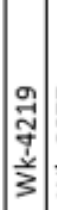 & 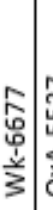 & & $\begin{array}{l}\hat{2} \\
7 \\
7 \\
\bar{z}\end{array}$ & 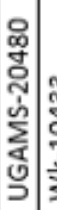 & \\
\hline 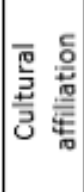 & 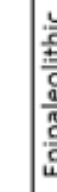 & 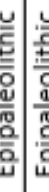 & 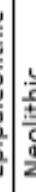 & 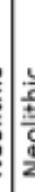 & & 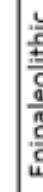 & 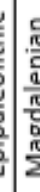 & 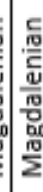 & & 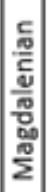 & 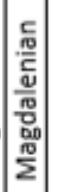 & & 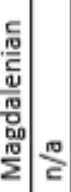 & 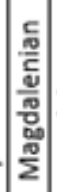 & 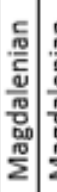 & \\
\hline 讋 & & $\begin{array}{l}E \\
0 \\
0\end{array}$ & & & 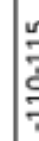 & & & 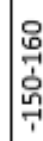 & & & & & & 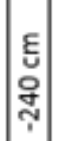 & 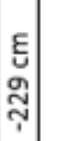 & \\
\hline 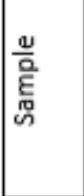 & & 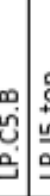 & 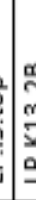 & & & 5 & & 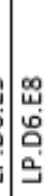 & & 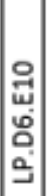 & $\mid \begin{array}{l}0 \\
0 \\
0 \\
0 \\
0 \\
9\end{array}$ & & & 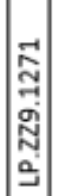 & 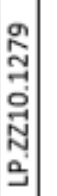 & \\
\hline 离 & $\varangle \infty$ & & 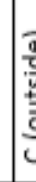 & & & $\bar{y}$ & u & 宸 & & 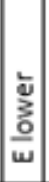 & u. & & $\checkmark I$ & 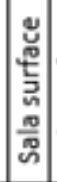 & 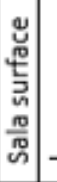 & \\
\hline
\end{tabular}




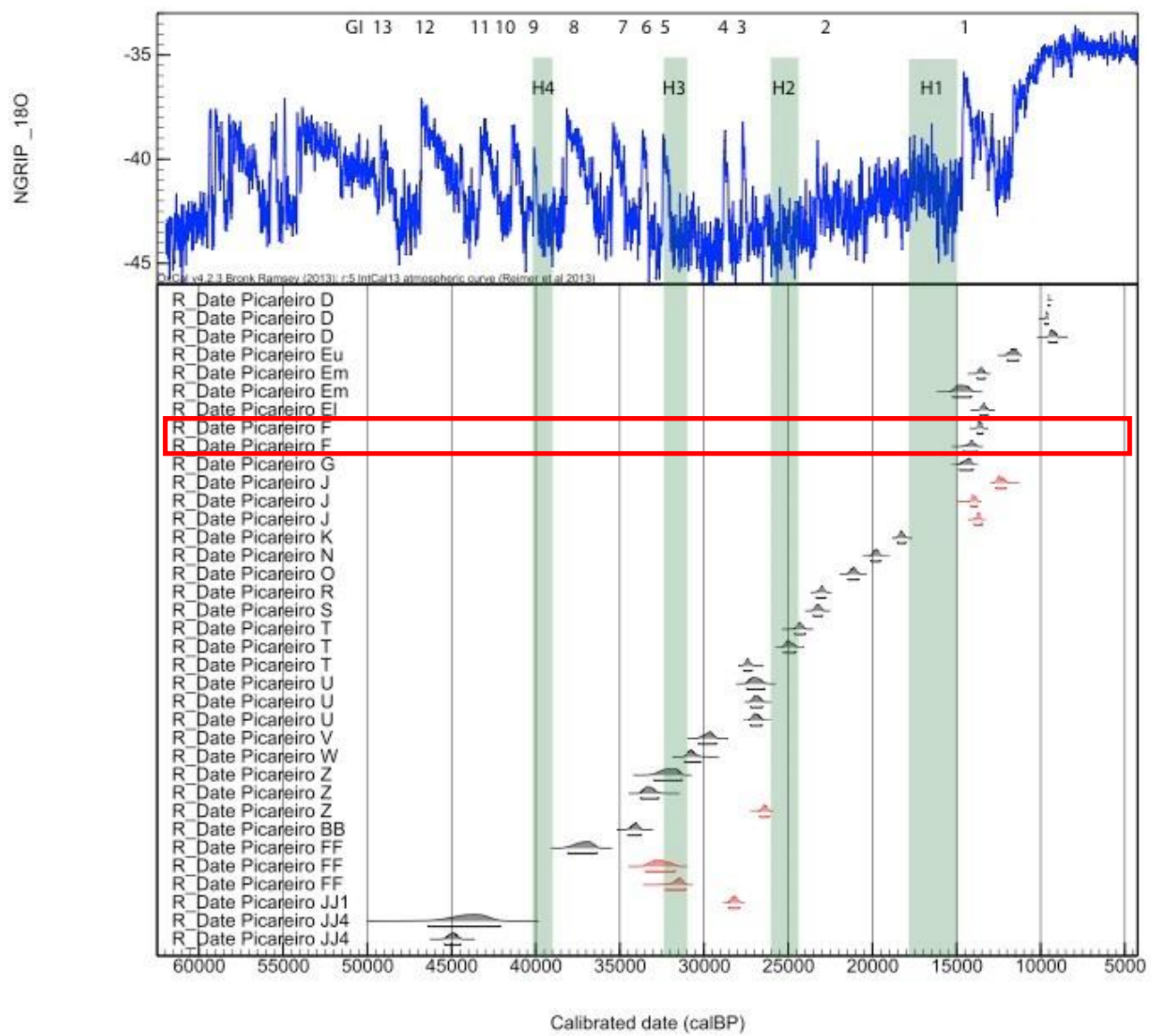

Fig. 18. Level F dates and NGRIP data (Lapa Do Picareiro NSF Proposal 2014 1998)

Figure 18 shows the dates obtained form level $\mathrm{F}$ in relation to the NGRIP Oxygen

Isotope record. Level $\mathrm{F}$ dates appear in the warmer Allerød, between the cold periods of Heinrich 1 (LGM) and the Younger Dryas. 


\section{MATERIALS}

The material used in this project are divided into two main categories. The first is the physical material being recovered by the site and studied. This includes the lithic and faunal remains, as well as charcoal, clasts, and sediments. The second is the digital material, including the piece plot information gathered by hand levels, metric rulers, stadia rods, prisms, total stations and range finders. The digitized information on artifact type and location will make up the majority of analysis done here.

Multiple different total stations, data collectors, software packages, and versions of ArcGIS were used to recover material form level F and to analyze their distributions. A full list of the tools and software versions are given in Appendix A. 


\section{METHODS}

During the excavation, all lithic artifacts, faunal remains, and clusters of charcoal larger than $1 \mathrm{~cm}$ were piece plotted using varying methods. Over the course of the excavation, plotting methods changed from hand level to total stations utilizing multiple different collection softwares over multiple seasons. The first step to initiate spatial analysis was to combine the multiple seasons of data and to translate them all into a single format which can then be compared, a process discussed later in this section. Once all of the $\mathrm{x}, \mathrm{y}, \mathrm{z}$ coordinates of the artifacts were in a single format and system, ArcGIS (A suite of tools using a Geographic Information System Software) was used to visually inspect the distribution of artifacts for patterns. Next, ArcGIS was used to calculate cell based population density statistics and to create multiple maps and graphs demonstrating the distribution of artifacts within Layer "F".

\section{SPATIAL ANALYSIS}

For the spatial analysis of Level $\mathrm{F}$ at Picareiro, a range of visualization and statistical methods were used. To go beyond initial visual interpretation of the site, statistical methods must be applied to undertake a serious discussion of possible spatial patterning. Often, researchers make the mistake of trusting off-the-cuff analysis completed by visual inspection of point cloud data. Although this may serve a purpose, the mind often creates patterns when presented with a random set of points in space, a 
phenomenon well documented (Lock 2003). This analysis used a GIS (Geographic Information System) to organize, store, manipulate, and render the spatial data on the material recovered in Level F. Kriging Analysis was not used, as cell based, non-nearest neighbor approaches served the purpose of demonstrating recovered material density within the site. $\mathrm{K}$ value, nearest neighbor, and Kriging statistics may be useful as the site grows in size. Pictures of the site and Agisoft Photoscan were used to create the photogrammetric three dimensional models of the Sala for data context and to visualize the sealing off of the Sala by level F.

\section{POPULATION DENSITY ANALYSIS}

To render displays that demonstrate areas of Level $\mathrm{F}$ that show relatively dense accumulations of artifacts, population density statistics are calculated using the point cloud and a floor plan of the cave. Each cell, or pixel, in the image of the cave is defined as a neighborhood. The number of points that fall into that cell, or neighborhood, is the population of that cell. The total population of each neighborhood added together equals the total population of the entire image.

The density maps used in this analysis are rendered like heat maps. For the images, each cell in the image has a number of piece plots displayed within them. The more points that fall in the cell, the redder it becomes. These images show areas in the cave with the most points per cell. This gives density of piece plots in the cave by way of population density. The purpose of this type of visualization of data is to separate perceived patterns in distribution from statistical ones. These statistics, like all statistics, 
have their own problems associated with the set parameters, such as cell size, resulting in increased or decreased resolution, which may cause shifts in the distribution of hot spots (Wheatley and Gillings 2002). This was overcome by running multiple statistical events and comparing the results. Changing cell size only highlighted or hid density hotspots without changing their positions, in this example. The resolution provided by the arbitrarily chosen cell sizes are within the tolerances of the analysis performed for this paper.

\section{TRANSLATION OF DATA FROM VARIOUS FORMATS}

Only material with $\mathrm{x}, \mathrm{y}$, and $\mathrm{z}$ coordinates assigned to the location it was recovered within the site were discussed in this paper. In order to translate data from previous year's data collection formats, $\mathrm{x}, \mathrm{y}$, and $\mathrm{z}$ values were needed for each unit. Any material lacking unit designations or z values were left out. Material that was recovered by screening methods are without such designations and as such are left out of further discussions. The decision to limit the discussion on piece provenienced material comes from the desire to discuss the density and location of material within Layer F with a certain degree or resolution of certainty in regards to cell based statistics. With all three axis and unit designations from the old relative grid system, values from older excavations could be held to the same sub-centimeter accuracy as the current excavations. This keeps analysis using data collected across 15 years consistent. The translated data, when compared to the current grid using multiple different methods, shows less than a $3 \mathrm{~cm}$ radius of error, a resolution high enough to offer no real change in 
discussions on use of space within the cave. For a detailed description of this process refer to Appendix B.

As mentioned before, there were changes in recording methodology, the formats of data organization, and material labeling. Faunal analysis was also undertaken by multiple undergraduate and graduate students over 15 years, each using different analysis and organizational methods. All of these sources of error effect automated queries by GIS, visualization, accuracy, and ultimately the rendering of spatial analysis on the site. Through the recognition of these sources of error and the vigilance of the PI and the excavators, most were mitigated to nuisances that did not affect the overall interpretation of level F at Picareiro. 


\section{RESULTS AND DISCUSSION}

\section{POTENTIAL SOURCES OF ERROR AND BIAS IN THE SPATIAL ANALYSIS OF LEVEL F}

To have a conversation on the behavior of past hominins, in this case during the Magdalenian, sources of bias and error must be accounted for. Any archaeological excavation, indeed any scientific endeavor, encounters bias. The recognition of error, both its existence and its origin, is one of the researcher's most important challenges and responsibilities. Excavators, spatial data recorders, and artifact analysts all introduce forms of bias (Dibble et al. 2005). This paper will focus on errors associated with the excavation and mapping of level $\mathrm{F}$.

\section{THE IMPACTS OF EXPOSED OR COLLAPSED PROFILES ON SPATIAL} ANALYSIS

Level $\mathrm{F}$ was excavated over many years. Exposed profiles left over the course of a single year or multiple seasons are identifiable in the point cloud. Exposed profiles are prone to collapse, both slowly over time and, in extreme cases, many centimeters deep at once. Artifacts lost in such a way lose their piece provenience and so cannot be included in the spatial analysis at the $\mathrm{cm}$ level. However, their total count, if recovered right away, 
can be added to the overall inventory, which can then be used in the faunal and lithic analysis.
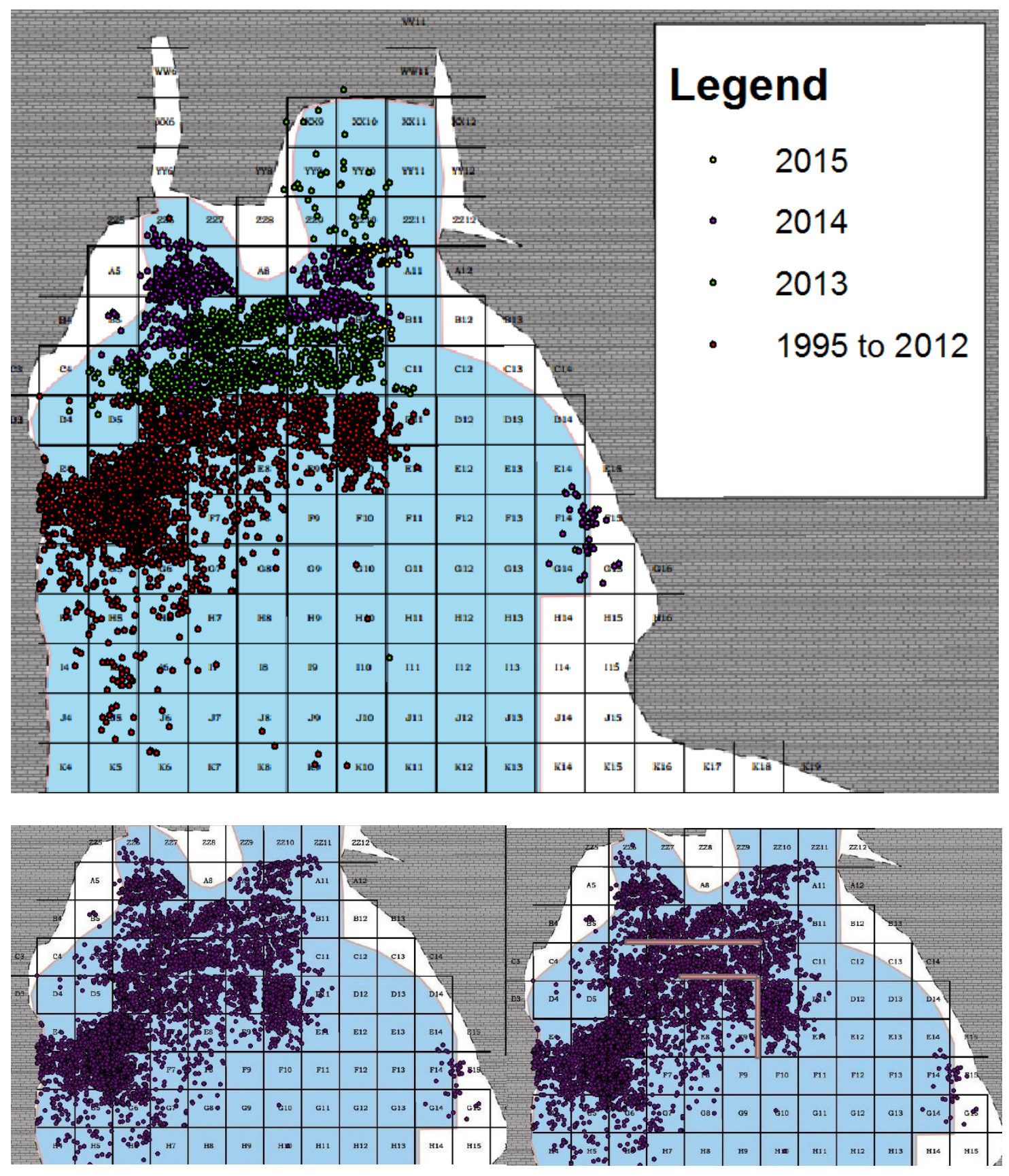

Fig. 19. Exposed profiles in the point cloud. 
Figure 19 shows the different years of excavation for level F, beginning with the introduction of the total station in 2013. All data prior to this is included but is lumped together as non-total station data. The greatest examples of the effect of collapsed profiles are seen between the years 2012 and 2013, when a profile left to preserve an intact section of the stratigraphy was removed, including the excavation of part of level F. The profile, left over multiple years had slowly collapsed, taking with the éboulis faunal and lithic material. This is seen again between the 2013 and 2014 data, although not to the same extent. On the right most section of the point cloud there is a vertical void separating the 9 and 10 columns. Column 10 was left as a path and the exposed profile to the left of it shows signs of collapse. All three of these areas are represented by red bars in the lower right section of Fig. 19, which shows the extent of collapse for each of these profiles.

\section{THE IMPACT OF PHYSICAL GRIDS AND INEXPERIENCED EXCAVATORS ON}

\section{SPATIAL ANALYSIS}

Physical grids and inexperienced excavators have been a part archaeological endeavors for many years. Unfortunately, both introduce visible signs of their presence in the point cloud. Excavators sometimes shy away from material on the edges of their units when using physical grids, especially grids demarcated by rulers, strings, or other tools. Picareiro uses channing pins and rulers to grid off the cave, and hosts undergraduates and other inexperienced excavators, many for which Picareiro is their first site. The combination of these two variables are especially evident in the point cloud in level $\mathrm{F}$. 


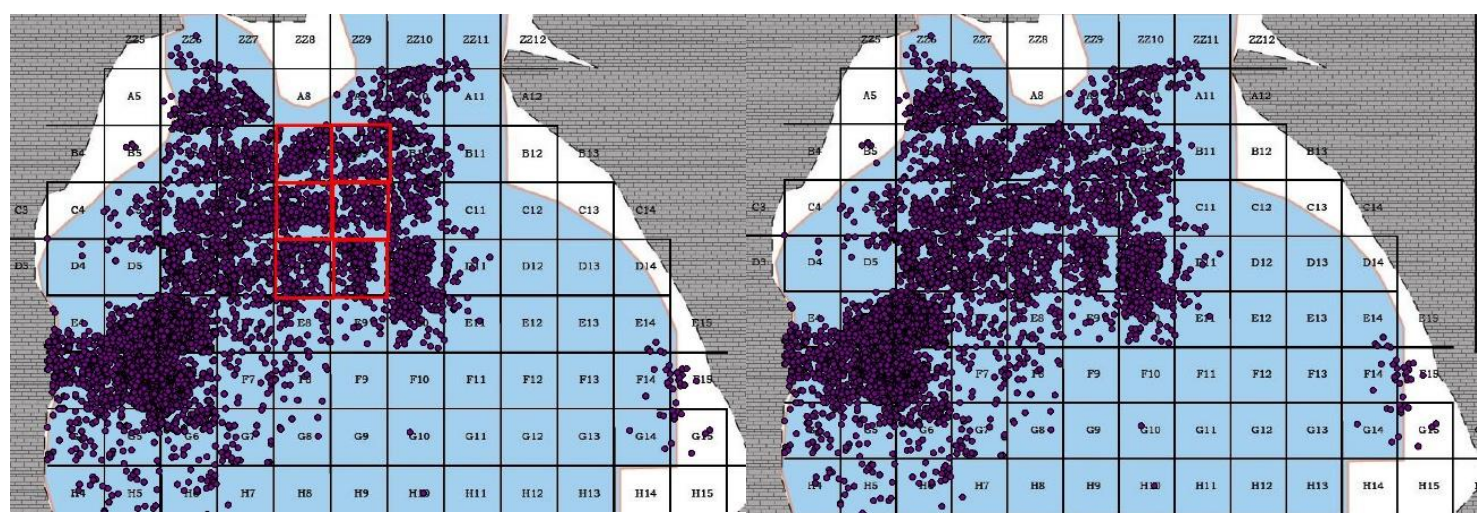

Fig. 20. The effects of physical grids seen in the point cloud.

Through the middle rows of $\mathrm{B}, \mathrm{C}$, and $\mathrm{D}$, the point cloud is segregated into unit specific clusters. The red boxes in Fig. 20 outline the most obvious of these. Interestingly, the hearth, and material excavated prior to 2013 appears to lack this division, except in column 10. This could be because of the sheer density of the hearth, but may also be attributed to the level of experience of the excavators present during these years.

Both exposed profiles and the use of physical grids and inexperienced excavators present a problem in analyzing density in point clouds. For level F, possible distinct occupation groupings may be overshadowed by these excavation phenomena. These excavator-made groupings look no different in population density maps than actual hot spots of material deposition. Although this is the case with level F, larger cell parameters in the density calculations allow only larger groupings to be seen. The effect of unit boundaries are usually seen no more than $15 \mathrm{~cm}$ on either side of the unit lines. The major groupings discussed in this analysis are separated by multiple units. This allows for distinction between actual high density areas and excavator made groupings. 


\section{SITE FORMATION: THE FORMATION OF LEVEL F AT LAPA DO PICAREIRO AND ITS CAVE CONTEXT}

The formation of Picareiro is still being explored, but two broad categories of deposition can be recognized; non-anthropogenic and anthropogenic. To perform even the most basic spatial analysis on the site, the behavioral component and the other natural agencies which formed the site must be discerned (Dibble et al. 2007). A full discussion on the mechanics of cave formation lay beyond the scope of this paper. It is, however, important to describe the cave in terms of site formation so, for this purpose, cave formation and depositional processes will be briefly reviewed for Picareiro.

\section{FORMATION OF GEOLOGIC DEPOSITS}

Geological deposits can originate from sources both inside and outside the cave (Goldberg and Macphail 2006). The most common fill material in cave settings is

éboulis, from the French word for rubble. Éboulis are clasts or individual grains separated from the parent bedrock, usually from the roof or walls of the cave. This can happen by dissolution, but in Europe this process usually occurs from the freezing and thawing of water that has seeped into cracks from the surface (Goldberg and Macphail 2006);(Goldberg and Arpin 1999).

The formation of éboulis is more complex than once thought, and for a period of time, there was an effort to connect geological levels from different sites to paleoclimate events using various amounts and sizes of éboulis (Goldberg and Macphail 2006). Although colder conditions may be linked to éboulis, there are problems with making any 
less general claims. Goldberg and Macphail give an example in their 2006 text, of thermoluminescent dating that placed burned lithics thousands of years off of climate conditions previously inferred from éboulis (Goldberg and Macphail 2006). With this being said, general trends in the changing of clast sizes and prevalence in layers of éboulis may be useful when visualizing climate conditions over large periods of time. However, these correlations must be made with caution.

The fill material at Picareiro is mostly éboulis. Differences in geological layers are often determined by changes in clast size and the amount of inter-clast sediments. The sediments come from material carried into the cave through percolating ground water, Aeolian deposits, as well as animal and human deposition, in the form of carcasses, fuel, and waste (Straus 1990). There are multiple levels composed mostly of very large clast $(15-90 \mathrm{~cm})$, evident of roof collapses. These large clast layers can be compared to Oxygen isotope, and magnetic susceptibility records to visualize correlations to climatic events (see fig 25). 

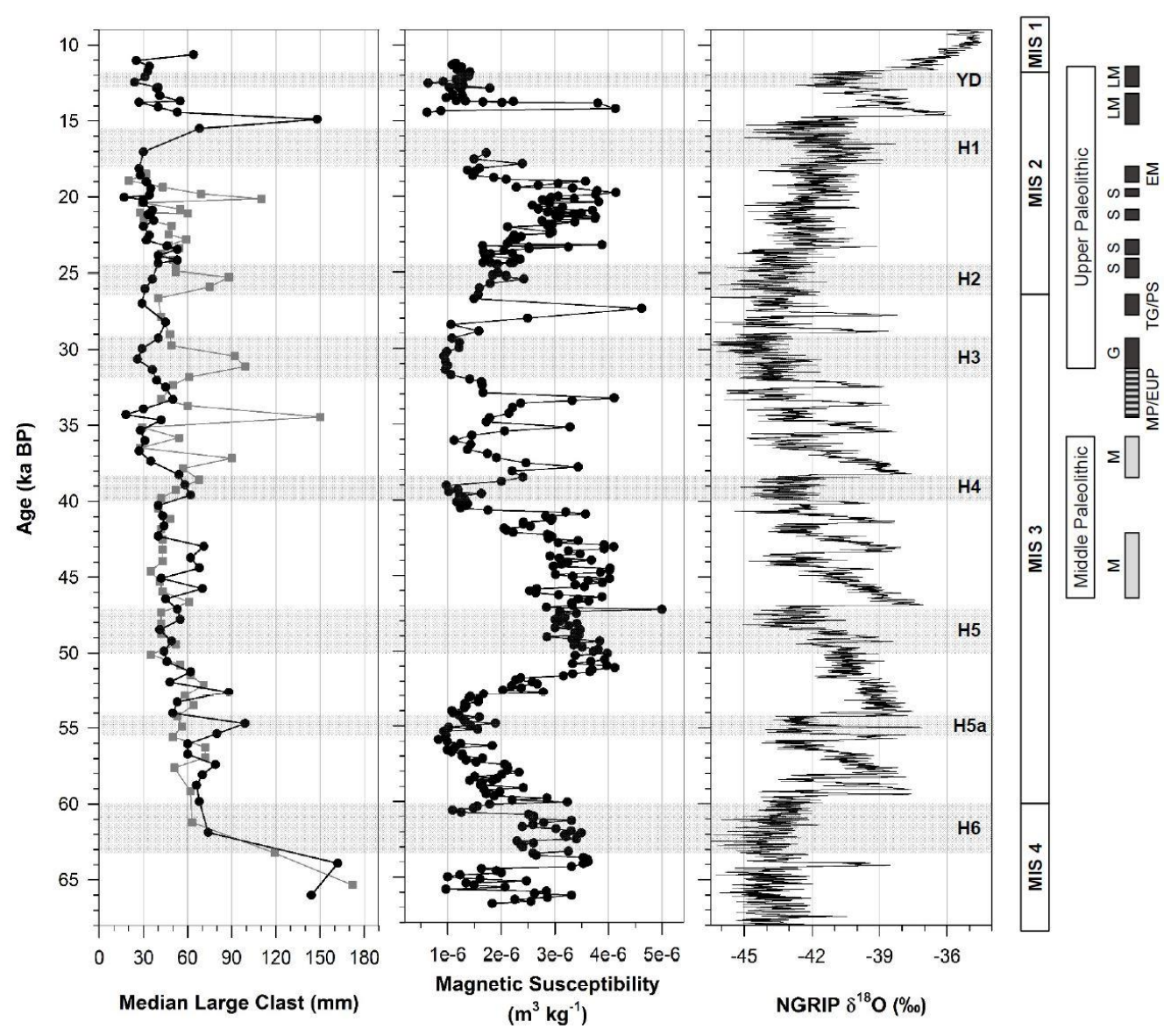

Fig. 21. Clast size, Magnetic Susceptibility, and NGRIP data (Benedetti et al n.d.)

As stated earlier, the NGRIP oxygen isotope record and magnetic susceptibility (MS) have been used to recreate past climatic conditions. Figure 21 shows the average clast sizes throughout the various strata at Picareiro. Starting towards the end of the LGM around $18 \mathrm{Kya}$, the changes in average clast size match the trends presented by the MS and NGRIP record, but not in the way most would assume. The largest recorded clasts appear in the warmer and more humid time periods. This goes against the popular vain of thought that associates an increase of clast size with colder periods (Goldberg and Macphail 2006). The increase in meteoric precipitation with a corresponding increase in ground water percolation and cold periods associated with the regular seasons could 
explain the increase in clast size. This demonstrates the dangers in building chronologies based on geological data from stratigraphy alone. Problems with inter regional inter site comparisons with climate conditions derived from geoarchaeological methods are discussed at length in many texts, but for a concise set of examples visit Lawrence Straus cave publications (Straus 1990). Still, if the limitations are understood and only general inferences are made, it is a useful exercise to compare general clast size and climatic events, although they may only be regional or site specific.

\section{NON-ANTHROPOGENIC SOURCES OF POST DEPOSITIONAL MOVEMENT}

The position of artifacts found within a site cannot always be trusted to give accurate information on activity areas (Robert Theunissen 1998). The first meter of deposits showed signs of significant post depositional movement in some areas due to burrowing by animals living within the cave. Burrowing can be seen sporadically through the deposits throughout the entire sequence to the extent of the current excavation, especially prevalent in the first meter of deposits, through level E. These are usually very evident with changes in sediment color and deposit composition. Rabbits (Lagomorphs) and badgers (mustelids) are known culprits of burrowing in cave settings and their remains are often found in strata corresponding to much earlier dates (Straus 1990).

Picareiro, as a cave, is a low energy environment. Water movement is present in the cave but in the form of percolating ground water from the earth above the roof of the cave. Percolation of water from the roof down through the stratigraphy formed multiple travertine layers. Flowstone is seen in levels E, F, and I, showing the cave is still 
hydrologically active. The existence of concreted sections of level $\mathrm{E}$ along the rear wall of the cave show water movement through the sediments, but again, in low energy. This is supported by the existence of large calcite, aragonite, and organic crystals in concreted sections. Concreted Breccia in level I, directly below Level F, show the slow movement of water from higher strata along the walls. There is almost no evidence of post depositional movement of material due to fluvial or Aeolian mechanisms.

One would expect sites with a high energy flow of water to demonstrate consistent trends in artifact inclination (McPherron et al. 2005). The pool of material with recorded orientations and inclinations at Picareiro is small, with half of the material not containing either of this data. Of the years with this data, $70 \%$ are missing cardinal direction orientation, and $61 \%$ are missing inclination. Inclination of recovered artifacts were recorded until 2013 and showed a random distribution along the cardinal directions. The majority of material had a horizontal or oblique inclination, with a negligible concentration of vertically inclined material around the hearth and into the center of the cave. Although the sample size is small and incomplete, from the data available no trends are present and suggest a random orientation, indicative of sound context (Cacho et al. 2016).

\section{ANTHROPOGENIC POST DEPOSITIONAL MOVEMENT}

Artifacts found during excavation have their own life history, from conception, to creation, use, and discardment (Hodder 2012). There are several variations on this life process, including those materials that experience reuse or post depositional movement. Anthropogenic sources of post depositional movement can include cleaning, caching, reuse, trampling, and kicking. Trampling and secondary removal of artifacts, or site 
maintenance may be the major source of post depositional movement of material in Picareiro, which lays within an enclosed space. The shape of the cave itself may determine which areas are used and where deposited material ends up, by both intentional and unintentional mechanisms. Cave ceiling height, which can determine traffic and use areas by humans, is the primary example of this at Picareiro.

\section{HEAD ROOM AND TRAMPLING}

Occupations in cave settings produce material that is not subjected to the same type or degree of environmental forces as their open air site counterparts (Straus 1990). Picareiro, located high above the water table, is more protected against fluvial redistribution of artifacts, and is protected against deflation and Aeolian redistribution. Because of this, depositional rates of éboulis and inter-clast sediments is slow, and material deposited by human occupations is subject to recurrent use of the space within the cave. Multiple occupations, evident in the density and vertical distribution of the material at Picareiro, presents a set of problems when discussing post depositional movement. When deposited anthropogenic material is left uncovered by sediments or clasts, they are subject to trampling, recognized within caves as a significant form of post depositional movement (Theunissen 1998).

Trampling involves the crushing, rolling, kicking, or otherwise relocation of artifacts by recurring human movement through a space. Larger artifacts would be displaced further from their original position due to the ease with which they are encountered by site occupants (Theunissen 1998). Over longer periods of time, the 
distribution of artifacts within a cave experiencing trampling form recognizable patterns. Artifacts accumulate in areas where the height of the cave ceiling is roughly the same as, or less than, the average height of the human occupants. For the purpose of this paper this is roughly 2 meters, with debates on past human skeletal morphology taken place elsewhere. This distinction separates the cave into two zones; areas with a ceiling height over 2 meters, and areas with a ceiling height under 2 meters. The areas of the cave with higher ceiling heights would be associated with areas of higher traffic, as higher ceilings facilitate movement within enclosed spaces. Theunissen et al's writings on experiments carried out at Petzke's Cave showcase this phenomenon.

As demonstrated by the experiments at Petzke's cave in Australia, artifacts that fall in areas of high traffic in cave settings tend to be kicked and trampled. Larger artifacts and material are moved further (Theunissen et al. 1998). Eventually, a distribution is seen to occur involving the height of the cave and the size of the artifacts. The distribution recorded at Petzke's cave demonstrates artifacts can accumulate under areas where the ceiling is around the average height of a human, with smaller material past that point as a push or toss zone (Theunissen et al. 1998). However, Theunissen et al. did note that if clusters of artifacts do not fall within recognizable patterns along areas with ceilings at head height, then it is reasonable to think the artifacts may be in their original position.

To examine this issue at Picareiro, Digital Elevation Models (DEMs) of the ceiling were placed over the piece plotted finds (Fig. 22). The average depth below datum for all finds in Level $\mathrm{F}$ was calculated and this value was used as the original floor for height calculations. Since the non-anthropogenic deposited material making up the cave 
fill is mostly éboulis spall from the cave roof, i.e. the cave floor rose at a corresponding although not quite equal rate. The absolute distance of the ceiling to the floor has changed minimally for deposits so close to the surface of the cave. Using ArcGIS, all finds located under areas of the ceiling that were 2 meters or lower were separated out. For a full description of this process refer to Appendix C.

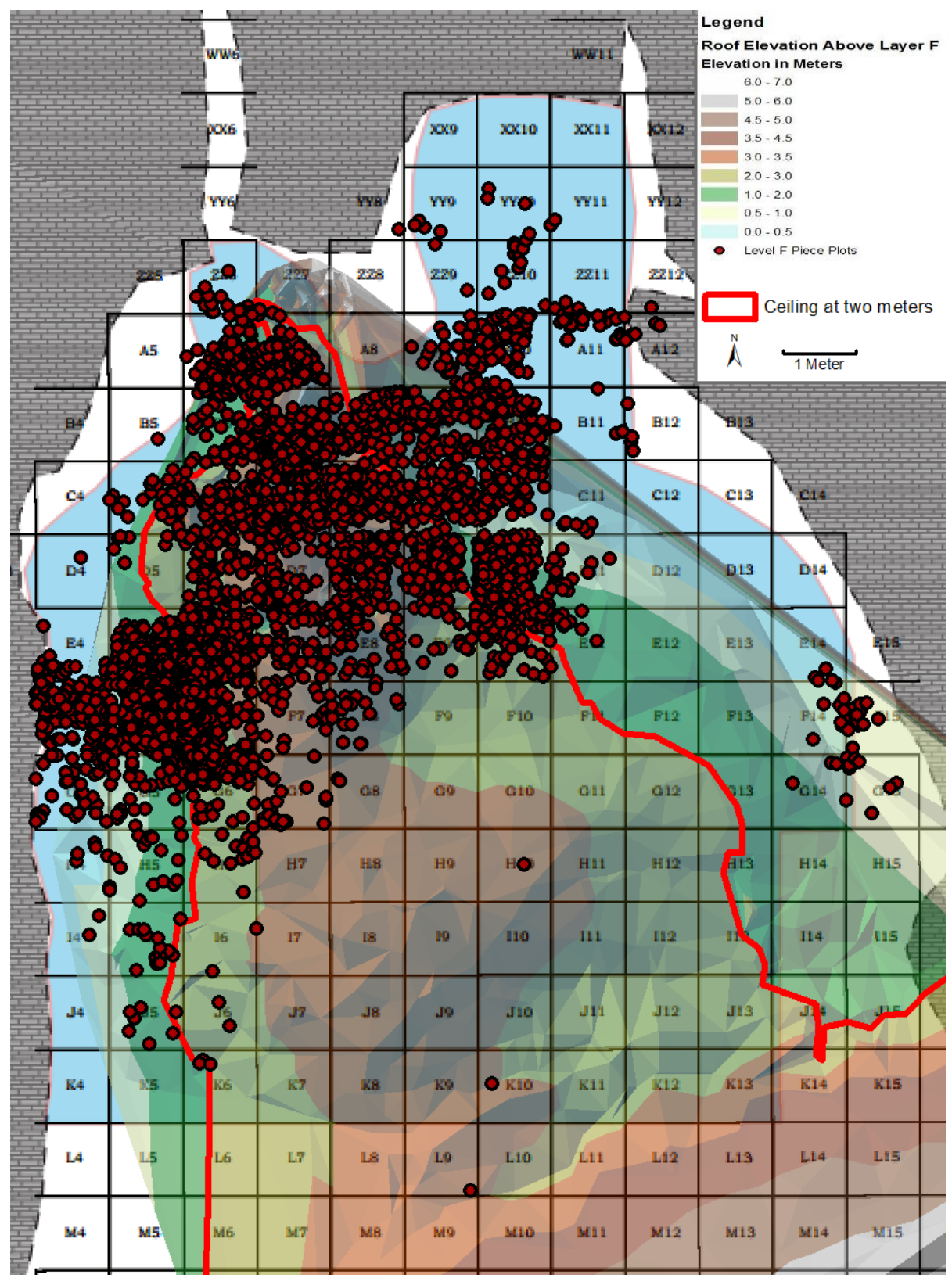

Fig. 22. Roof ceiling heights over faunal remains showing the two height zones 
Figure 23 shows the DEM (Digital Elevation Model) of the cave ceiling over the plan view of the site with faunal material for context. Areas the DEM does not cover represents areas where the sloping cave ceiling met the surface of Level F. The back right section of the cave, the Sala, was sealed off by Level F. Although the roof in the Sala is multiple meters high, the end of the DEM in that area represents the end of the main room, and rightly shows the surface of level F meeting the wall. At the time Level F was the cave floor, only a small crack would have been visible leading into the Sala. The following few figures show this DEM in three dimensions from different orientations.

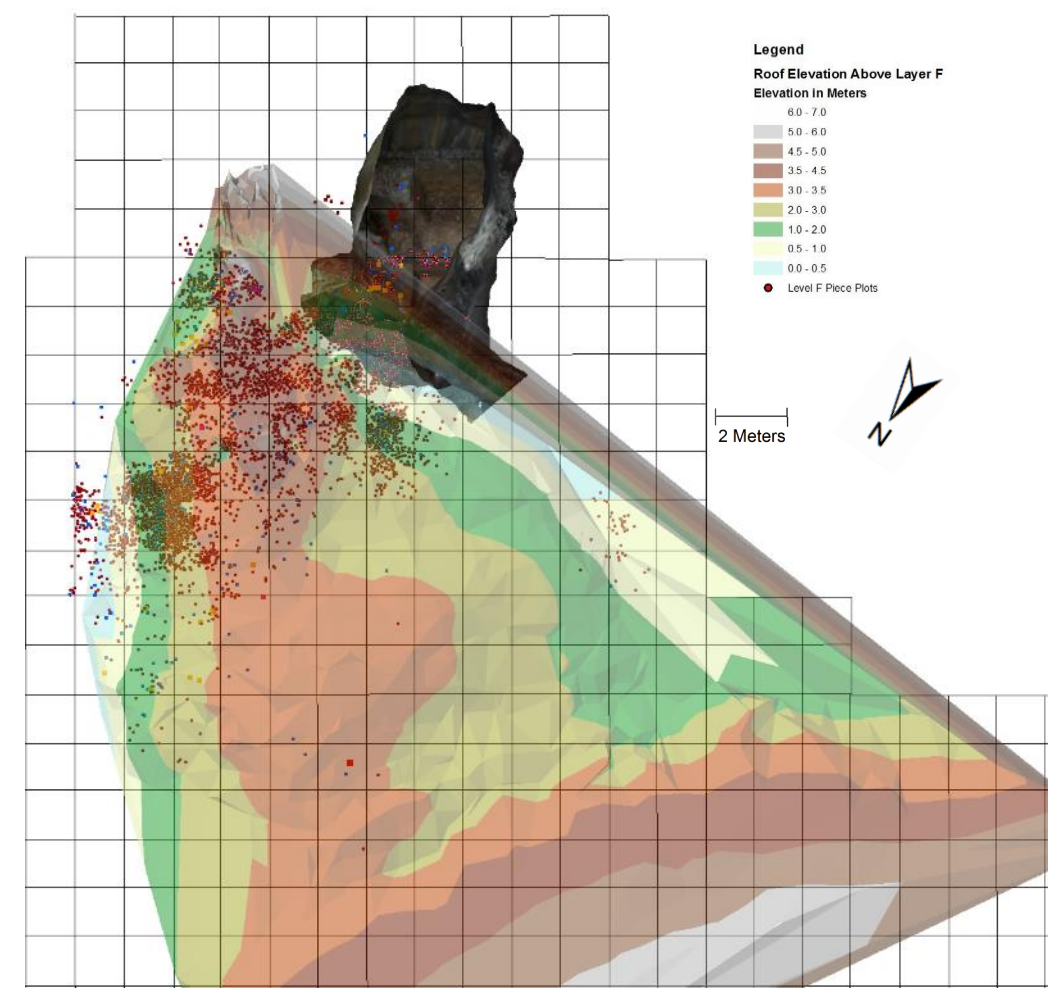

Fig. 23. The roof DEM with a photogrammetric model of the Sala. 


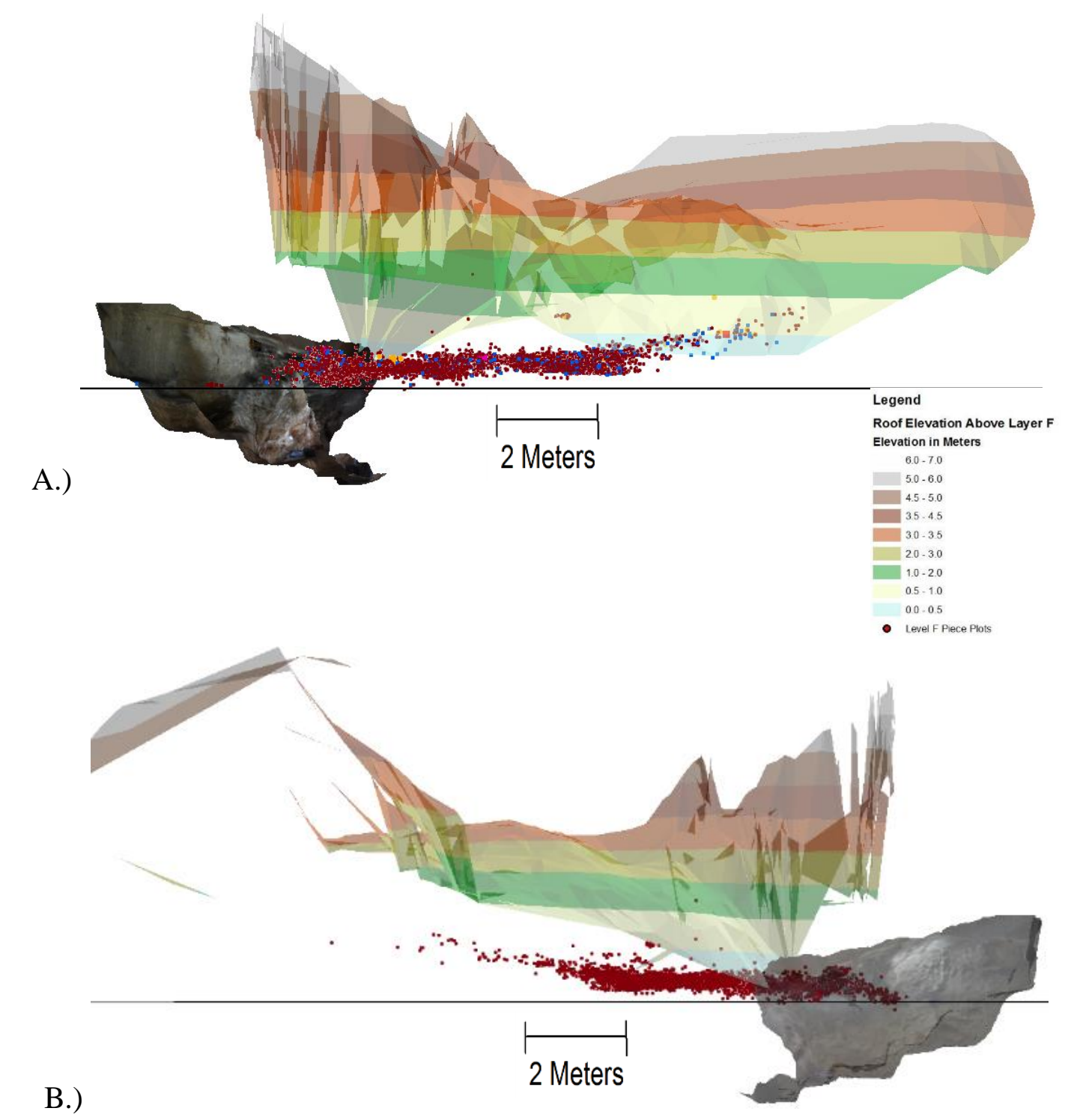

Fig. 24. The DEM representing the roof of the cave intersecting with the photogrammetric model of the Sala. The black line represents the "floor" at 569 meters above sea level. A.) facing the right side of the cave. B.) facing the left side of the cave. 


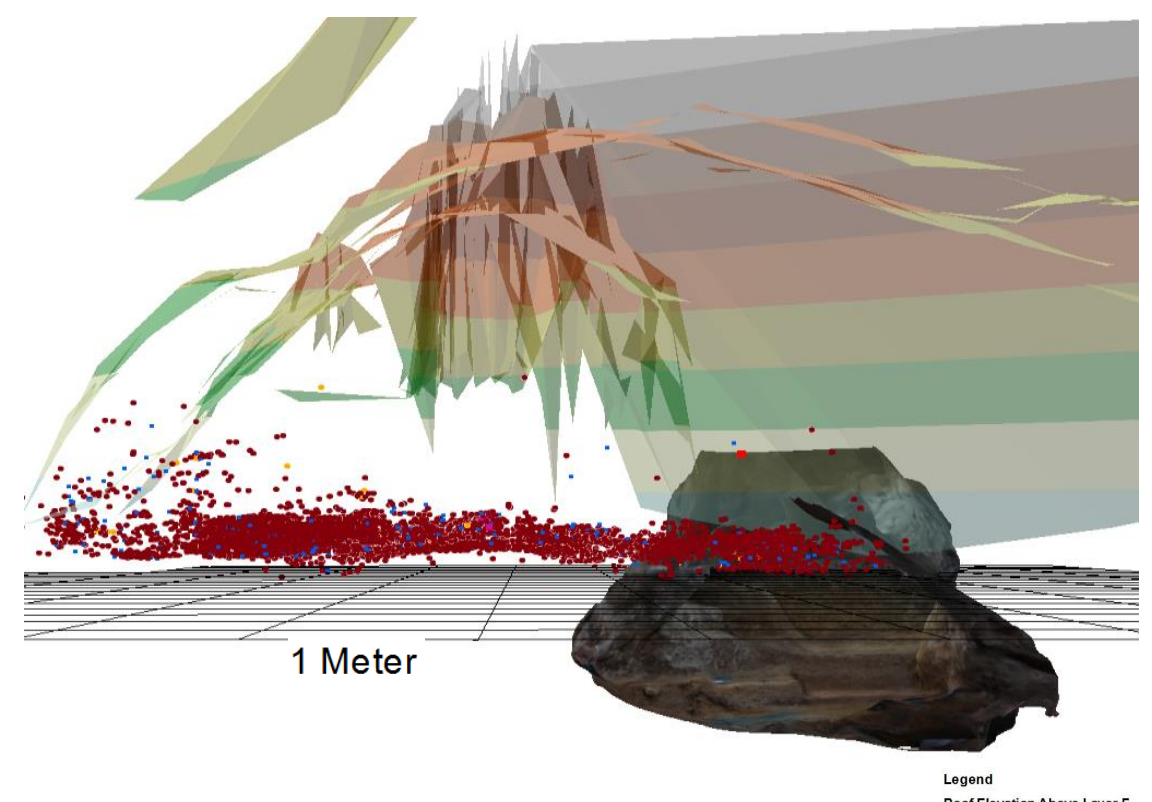

Roof Elevation Above Layer

Elevation in Meters
60.70

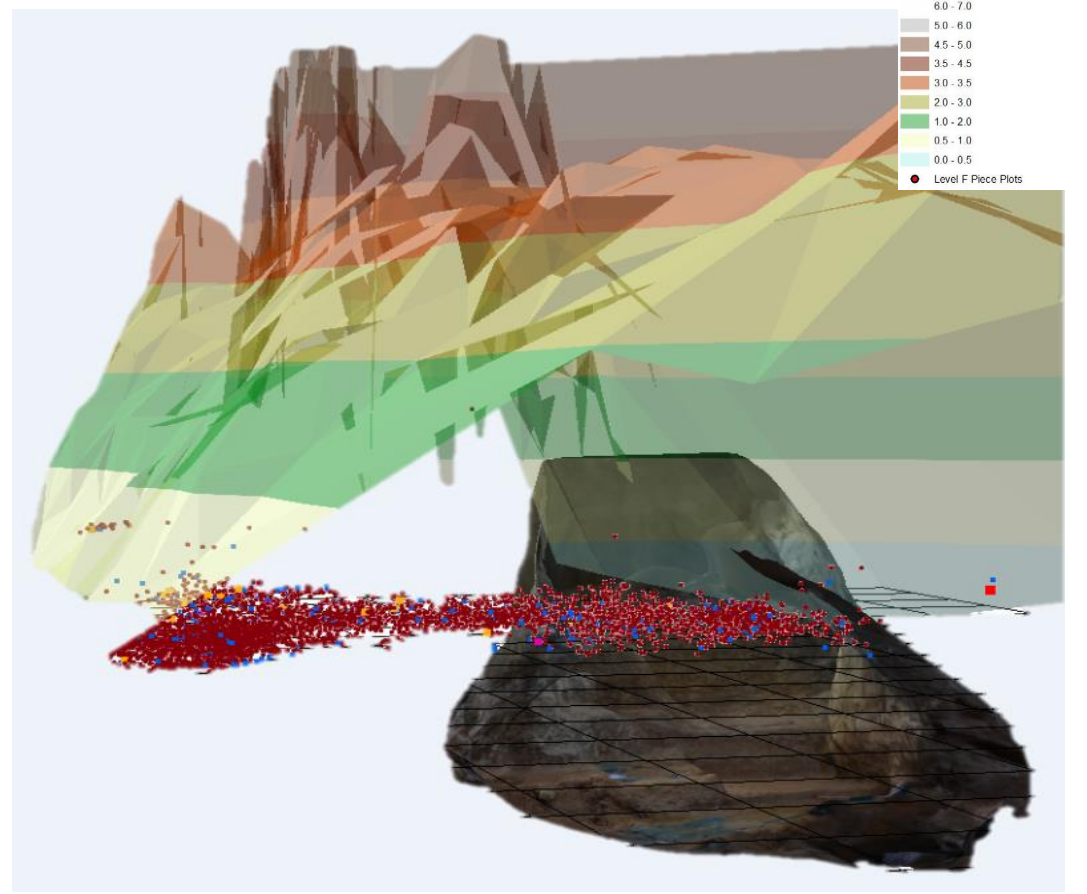

Fig. 25. Views from the mouth of the cave when level $\mathrm{F}$ was a floor. 


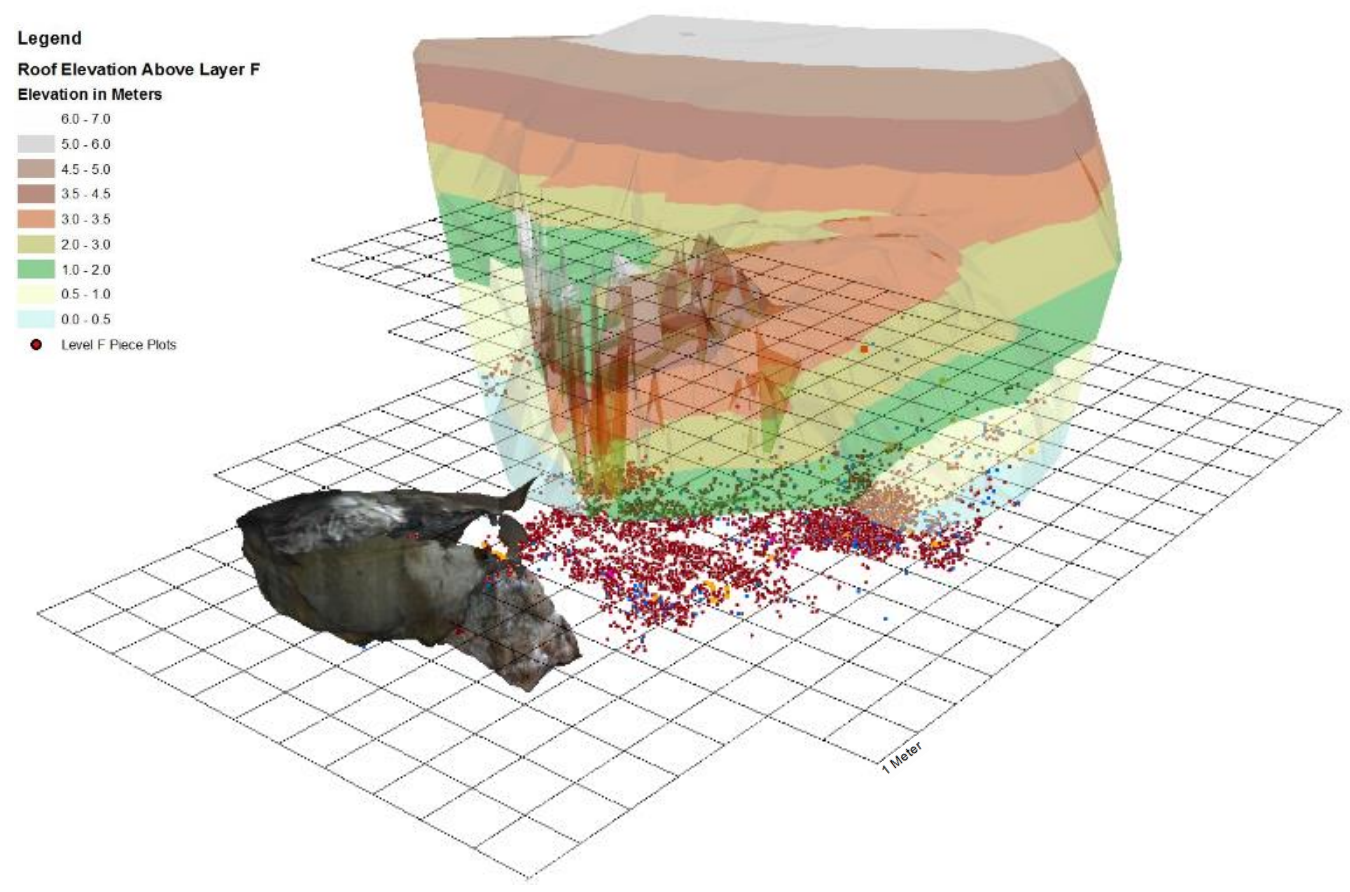

Fig. 26. An oblique view of the roof DEM and Sala

Of the 6,981 piece plotted artifacts, $50.3 \%$ were found in areas where the corresponding cave height is 2 meters or less. Over $75 \%$ were found in areas were the cave ceiling was 3 meters or less. The rest of the artifacts are found were the ceiling is between 3 and 7 meters high.

The spatial analysis of level $\mathrm{F}$ involves the identification of patterns in the distributions of any material recovered with piece proveniencing. Figure 27 shows a general map of the cave with areas of interest highlighted. For later discussions, the irregular red line separates the cave into two zones; areas under a ceiling height of 2 meters or less, and areas under a ceiling height of more than 2 meters. The sections closest to the walls are in the under 2 meters zone. 


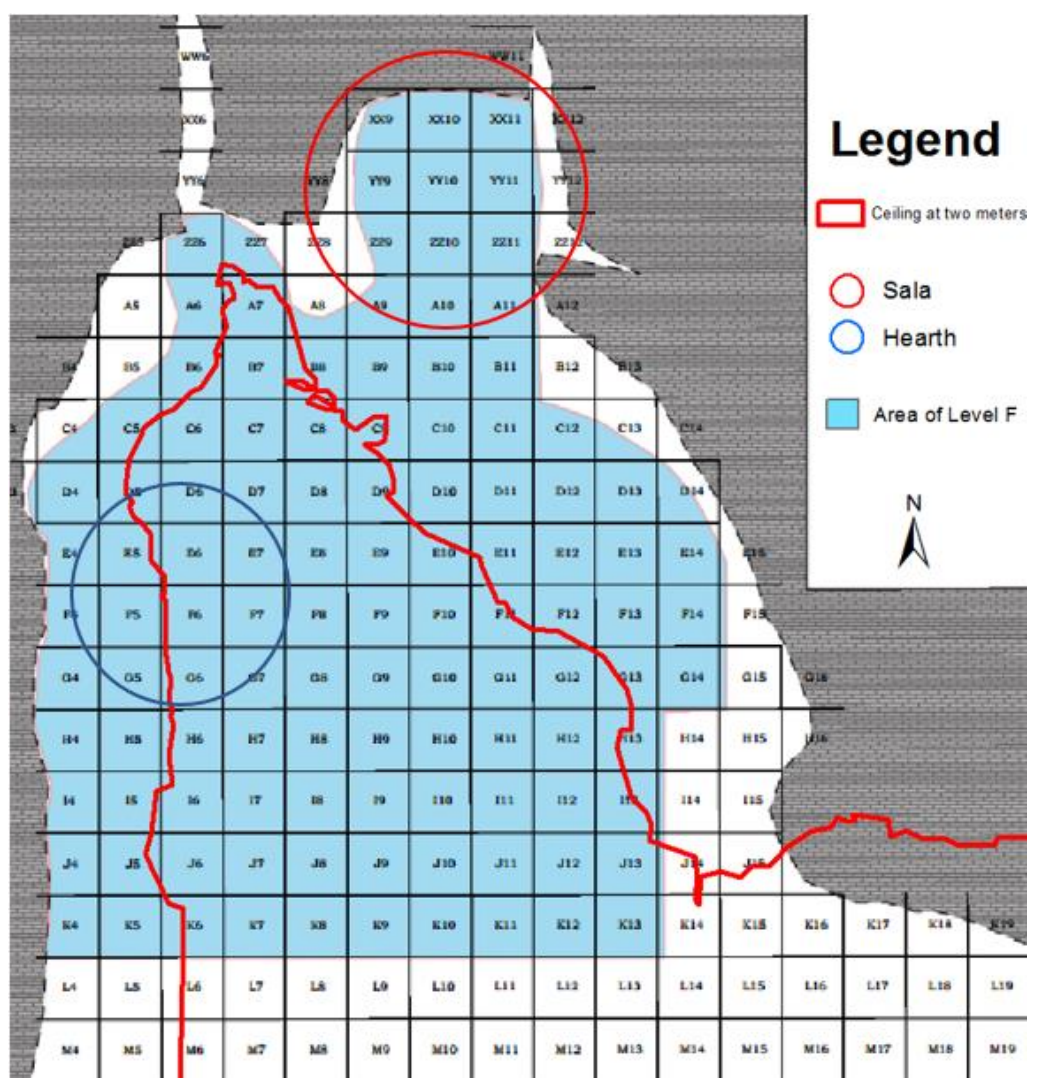

Fig. 27. Areas of interest in the cave circled

\section{MATERIAL FOUND IN LEVEL F}

Lithics, Faunal remains, Ochre, Shells, and Charcoal have been recovered from level F. Figure 28 shows all material with piece proveniencing data. Material found by screening are not included in the distribution maps, however, they are included in total count tables. 


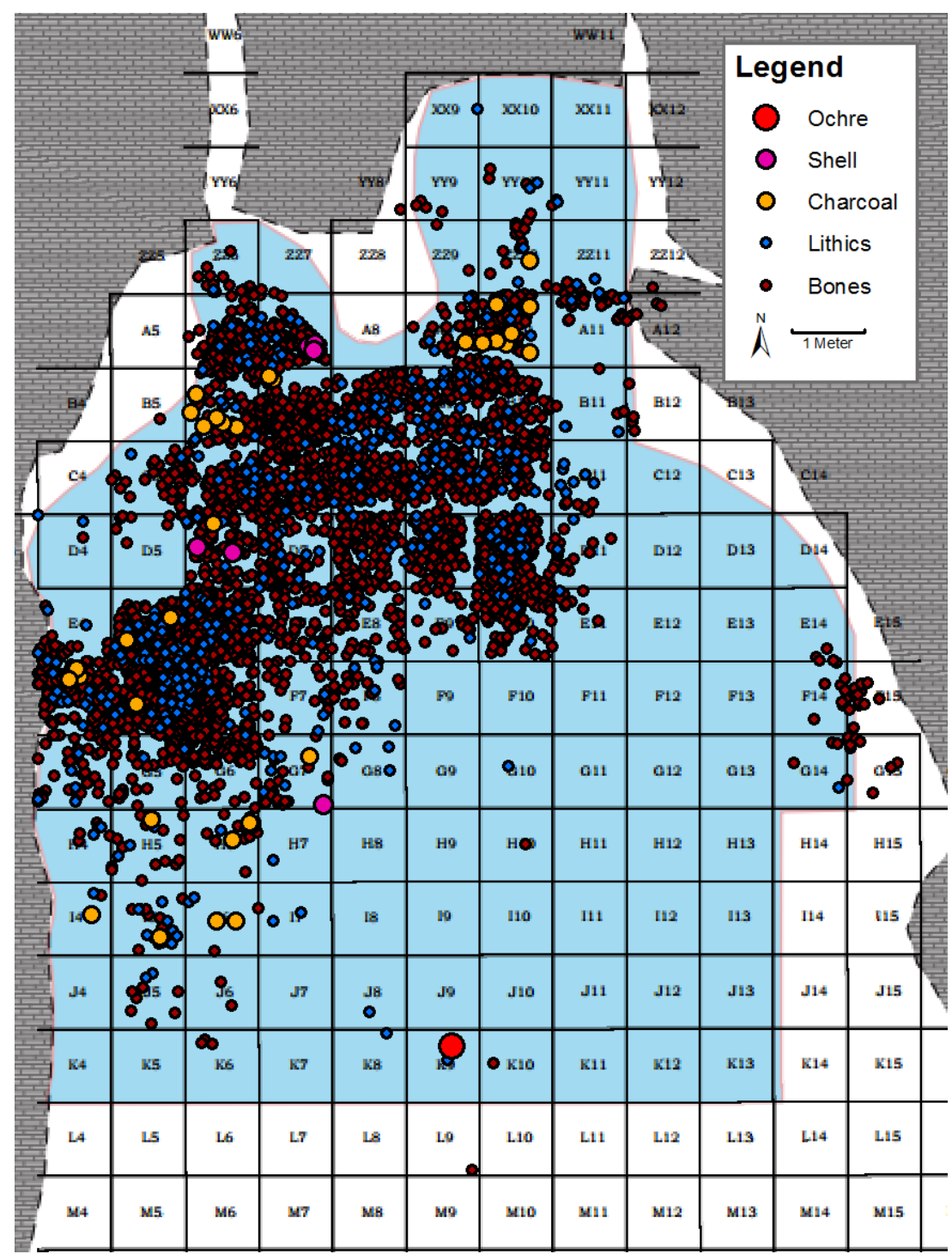

Fig. 28. Distribution of all materials

The materials recovered in level $\mathrm{F}$ are well distributed in the back of the cave. The point cloud does demonstrate groupings with strong statistical correlation to ceiling height and cave structural features which here are called the Sala and the Chimney. The densest area of recovered material is the hearth.

With the application of ArcGIS to the assemblage, the effects of headroom and trampling in level F becomes clear. As the experiments at Petzke's Cave show, larger 
materials are more likely to occur around head height, or 2 meters for Picareiro.

Overwhelmingly, the majority of material recovered in level $\mathrm{F}$ were found under a ceiling height of 2 meters or less. The Material classes with distributions which showed the strongest correlation to head room were larger objects (Fig. 29).

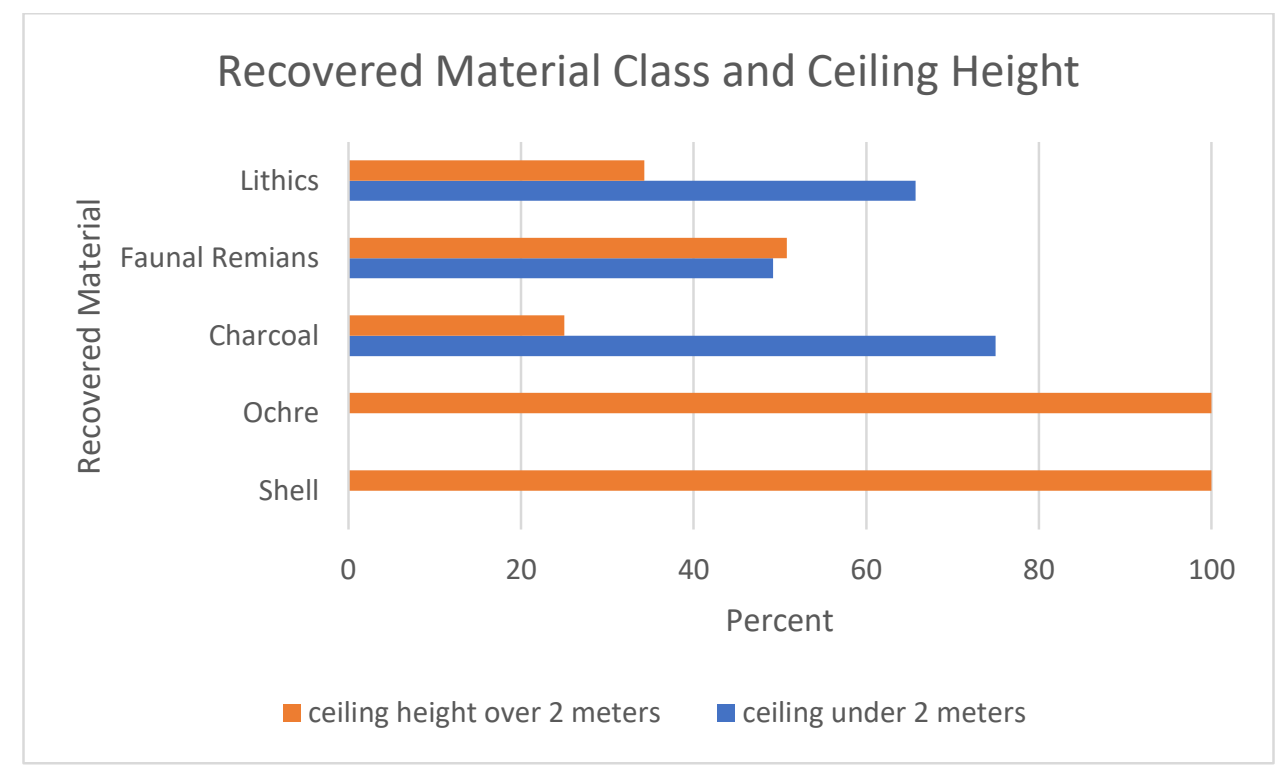

Fig. 29. Recovered material classes and ceiling height

\section{FAUNAL REMAINS}

Analysis of faunal material was completed as a continuous process since 1995, with a set of results published in 2006 (Bicho et al. 2006). In total, 18,959 mammalian faunal remains were recovered in Level F, not representing discrete individuals. This total includes both piece provenienced articles and those remains found through screening. A total of 6,432 faunal pieces were piece provenienced. The cut off for pieces selected for 
proveniencing was $1 \mathrm{~cm}$, and can account for the large majority of the difference between screened and plotted pieces. Amphibian and Bird material has not yet been fully analyzed and so was left out of this section, however, their piece plots are retained in the point cloud. Mammal faunal remain counts can be seen in Table 4 .

\begin{tabular}{|c|c|c|c|c|c|}
\hline Taxon & D & $\mathbf{E}$ & $F / G$ & I & J \\
\hline \multicolumn{6}{|l|}{ Mammals } \\
\hline Cervus elaphus & 9 & 107 & 440 & 12 & 51 \\
\hline \multicolumn{6}{|l|}{ Capreolus capreolus } \\
\hline Cervidae & & 71 & 3 & & 2 \\
\hline $\begin{array}{l}\text { Capra } \\
\text { ibex/pyrenaica }\end{array}$ & & & 4 & & 4 \\
\hline Rupicapra rupicapra & & 1 & 1 & & \\
\hline Capridae & & & & & 1 \\
\hline Bos primigenius & & 8 & 1 & 1 & 1 \\
\hline Sus scrofa & & 26 & 139 & 5 & 23 \\
\hline Medium ungulate & 16 & 314 & 1,155 & 35 & 158 \\
\hline \multicolumn{6}{|l|}{ Equus caballus } \\
\hline Lynx pardinus & & & & & 2 \\
\hline \multicolumn{6}{|l|}{ Felis sylvestris } \\
\hline Vulpes vulpes & & & 1 & 1 & 2 \\
\hline $\begin{array}{l}\text { Oryctolagus } \\
\text { cuniculus }\end{array}$ & 17 & 220 & 17,209 & 353 & 1,313 \\
\hline Lepus granatensis & & 1 & 1 & & 1 \\
\hline Erinaceus europeus & & & 5 & & 1 \\
\hline
\end{tabular}

Table 4. Total mammal counts for relevant levels at Picareiro (Haws N.D.)

The noted switch to red deer and ibex as preferred prey species during the Magdalenian, seen throughout western Iberia and Cantabria, is seen in Picareiro as well (Álvarez-Alonso et al. 2016). In Portugal, the switch to red deer was from Ibex dominated Solutrean assemblages. Medium ungulates are well represented in Level F, 
with 1,155 pieces recovered, and are only second in prevalence to Lagomorphs. Rabbit makes up the majority of faunal material found in Level $\mathrm{F}$, with 17,209 pieces $(90.8 \%)$.

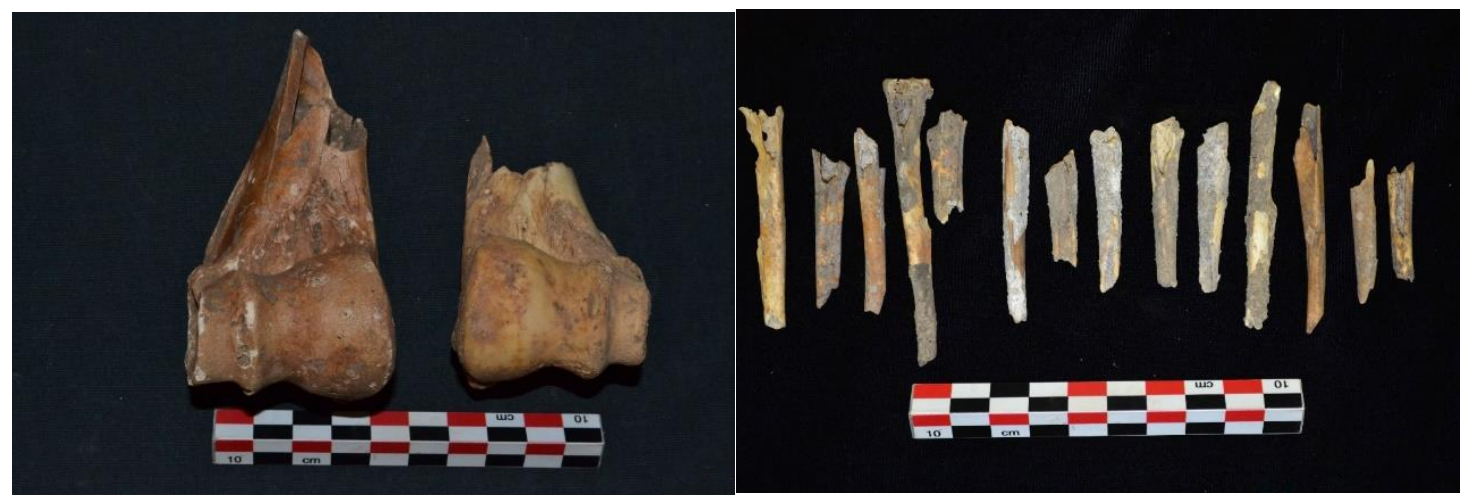

Fig. 30. Examples of faunal material recovered (Bicho et al. 2006)

Many examples of larger mammal material show signs of intentional fracturing for the removal of marrow (Fig. 30). Other faunal remains show signs of processing by humans or heat/burn related markings associated with the hearth (Bicho et al. 2006). The qualitative data regarding burning and processing is not available for the entire assemblage and so was not used as a discrete category for spatial analysis.

\section{TEETH}

Out of the faunal remains found, 547 mandibles, maxilla, and teeth were recovered. Of these, 109 were jaws and teeth were from large and medium mammals. The 438 remaining pieces belong to rabbit, hare, and other small fauna, making up roughly $80.1 \%$. This breakdown mirrors the overall makeup of the assemblage almost 
exactly, in regards to the prevalence of micro-fauna. Figure 31 shows an example of the teeth recovered.

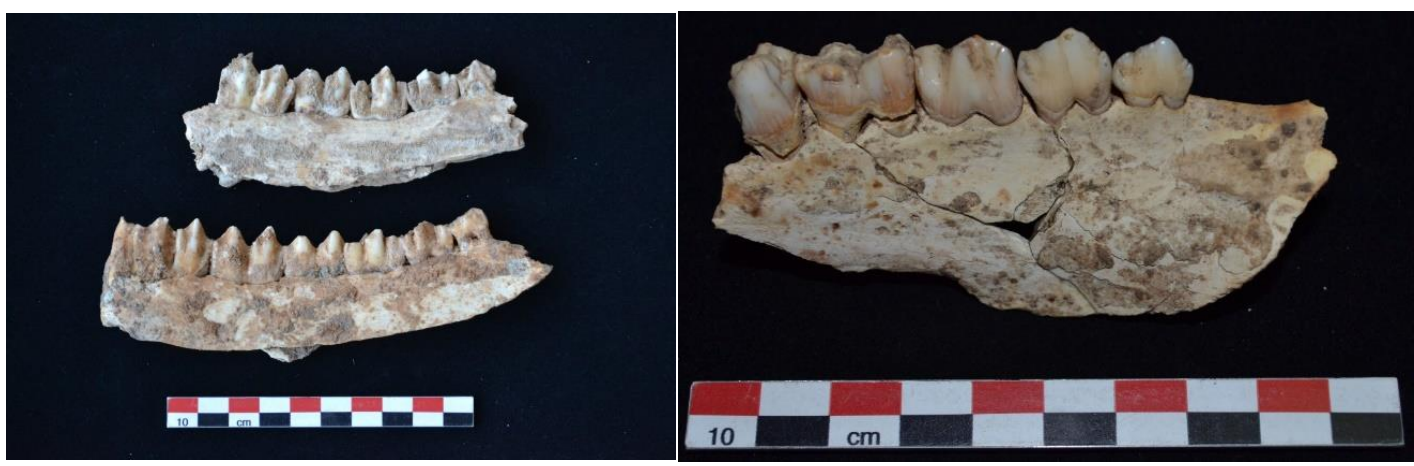

Fig. 31. Examples of Teeth and Jaws

\section{FAUNAL DISTRIBUTIONS}

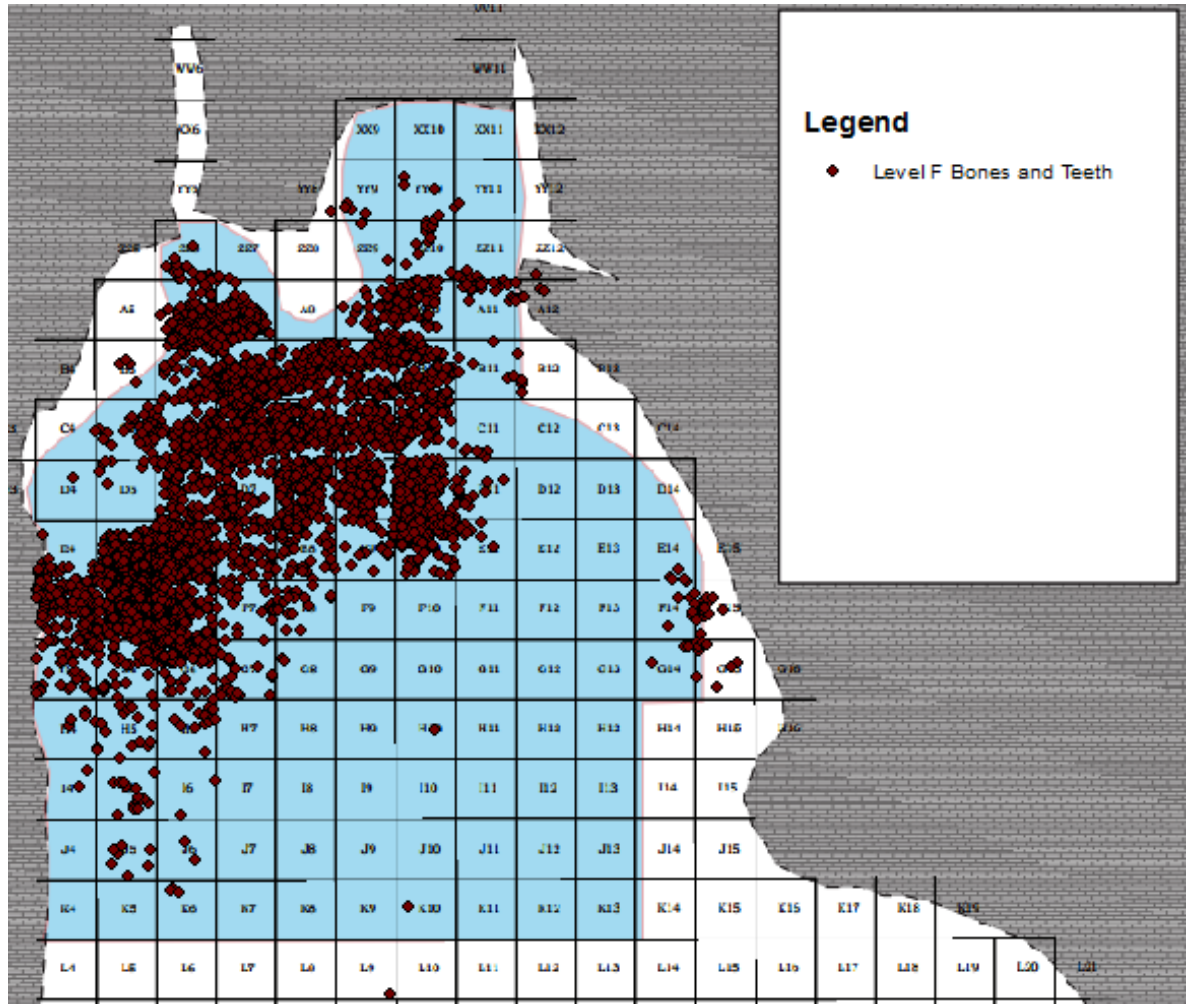

Fig. 32. Distribution of all faunal material 
Figure 32 shows the general distribution of all faunal material recovered. The faunal remains recovered and identified represent every anatomical region, suggesting most animals were brought to the site whole and butchered (Cacho et al. 2016). This is especially true with small mammals such as hare and rabbit. Only 7 examples of horn were recovered, almost all within the hearth, indicating this material was taken with the occupants when they left the site, and most likely used and discarded elsewhere. In the case of medium and large mammals, high numbers of axial elements such as vertebra, scapula, innominate, and ribs indicate these larger animals may have been butchered at the site, contradicting the quantitative data found from other examples (Binford 1978). These quantities are seen in Fig. 33.

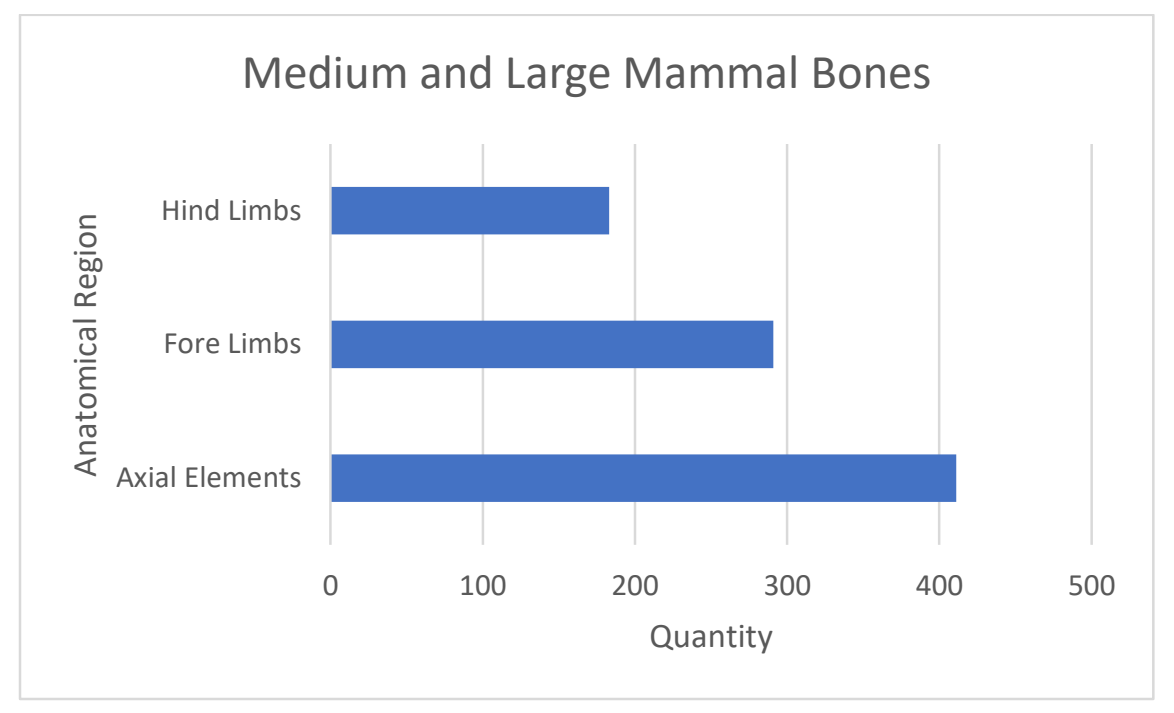

Fig. 33. Amount of bones from each anatomical region for medium and large mammals

If Picareiro acted as a hunting camp, entire animals killed on the mountain could have been butchered at the site. Hind limbs, with more meat, and some fore limbs may have been carried away from the site back to nearby, more permanent, encampments. 
Fore limbs may have been consumed on site, explaining their higher rate of recovery. The presence of ribs and teeth from micro-fauna indicate good bone preservation. The distribution of micro-fauna is so ubiquitous, discussion on spatial analysis is better served on medium and large mammal (MLM) remains, which show better patterning because of their smaller sample size.

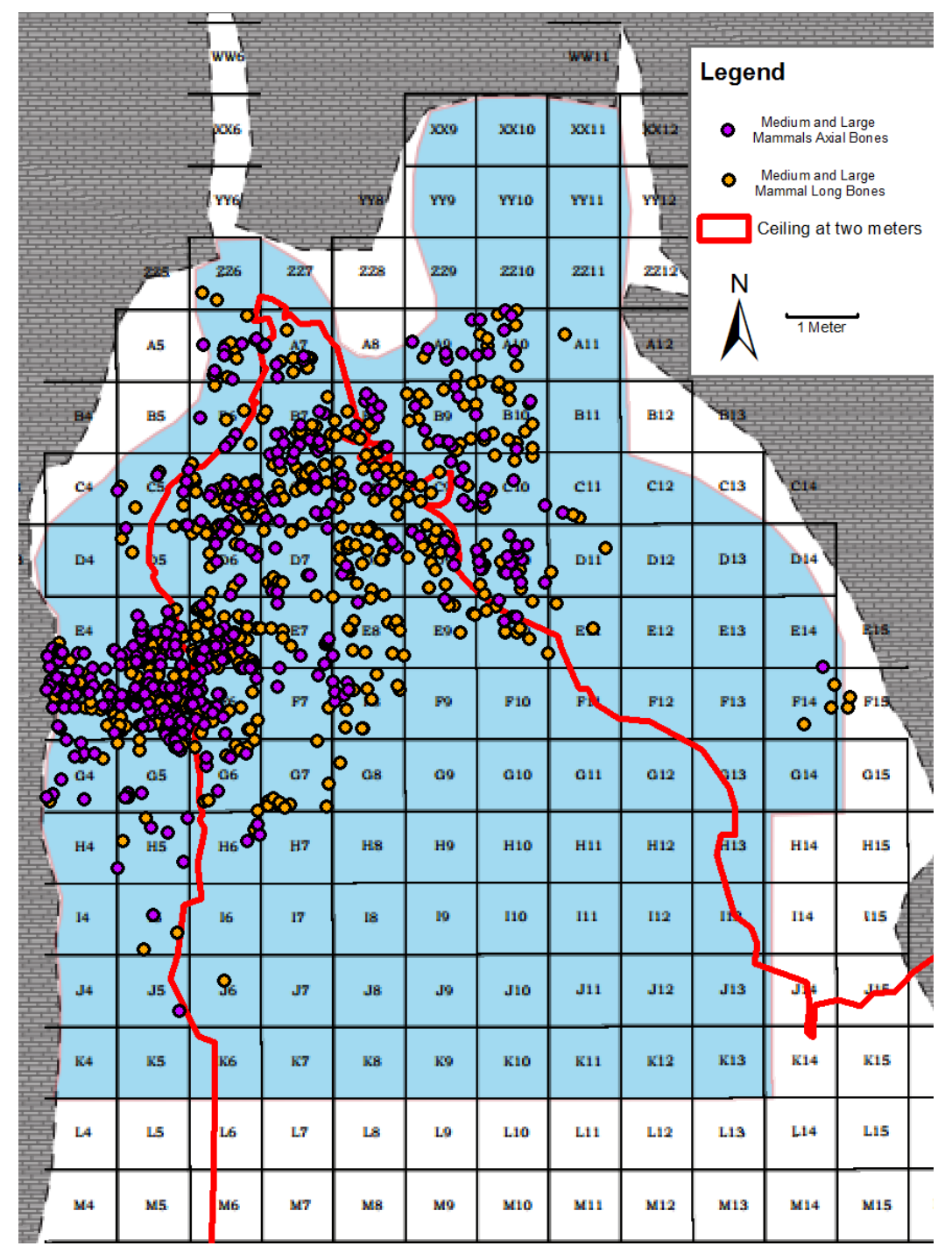

Fig. 34. Axial and long bone distributions of medium and large mammals 


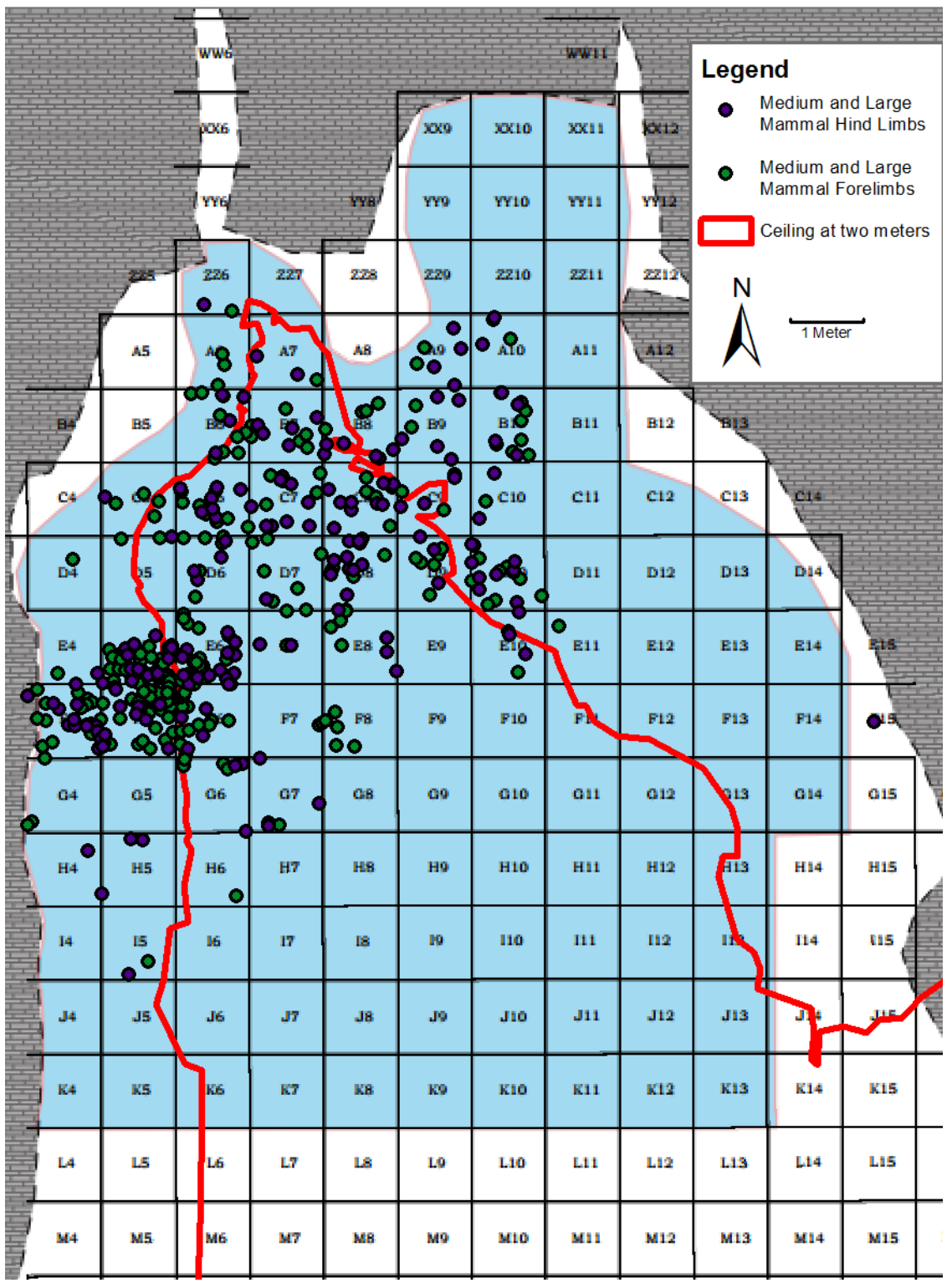

Fig. 35. Distributions of hind and fore limbs for medium and large mammals

The distributions for axial and long bones can be seen in Fig. 34. Forelimbs are more represented in the assemblage but share a similar distribution to hind limbs (Fig.35). The genus Cervus (Deer) and Sus (Boar) are the most prevalent in the faunal assemblage for MLMs. Their distributions do not differ from one another and can be seen 
in Fig. 36, closely matching long bone distributions. Also in this figure is the material designated juvenile or sub-adult. The distribution of juvenile remains center around the hearth and extend up into the Sala.

All horn, antler, and tine are found under ceiling heights of 1 meter. Their distributions can be seen in Fig. 37 plotted against other axial elements. MLM teeth and jaws show the most distinct horizontal distribution. Both the hearth and the entrance to the Sala show groupings here. These groupings straddle the line denoting a ceiling height of 2 meters. 

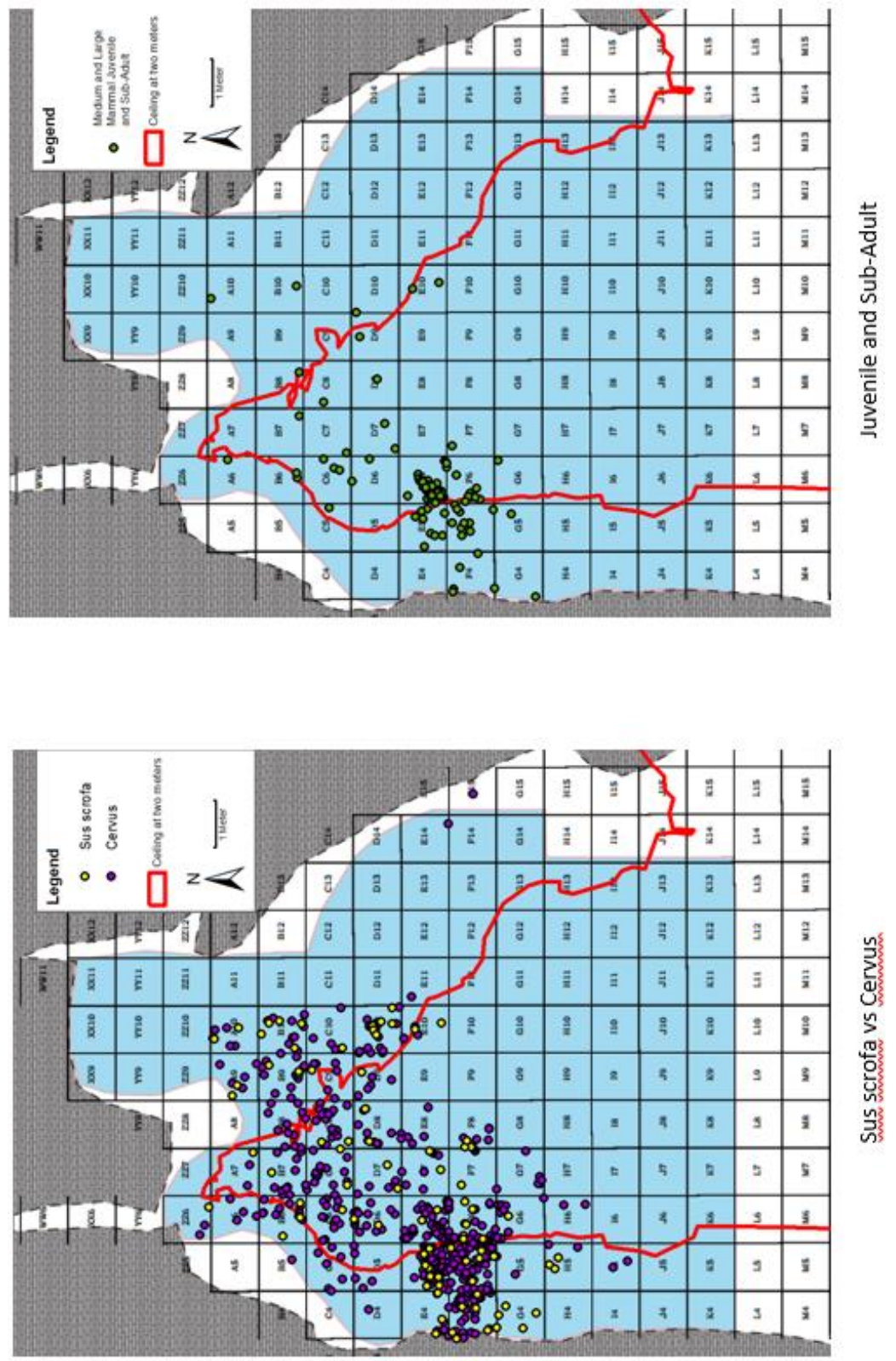

Fig. 36. Species and age distributions for medium and large mammals 

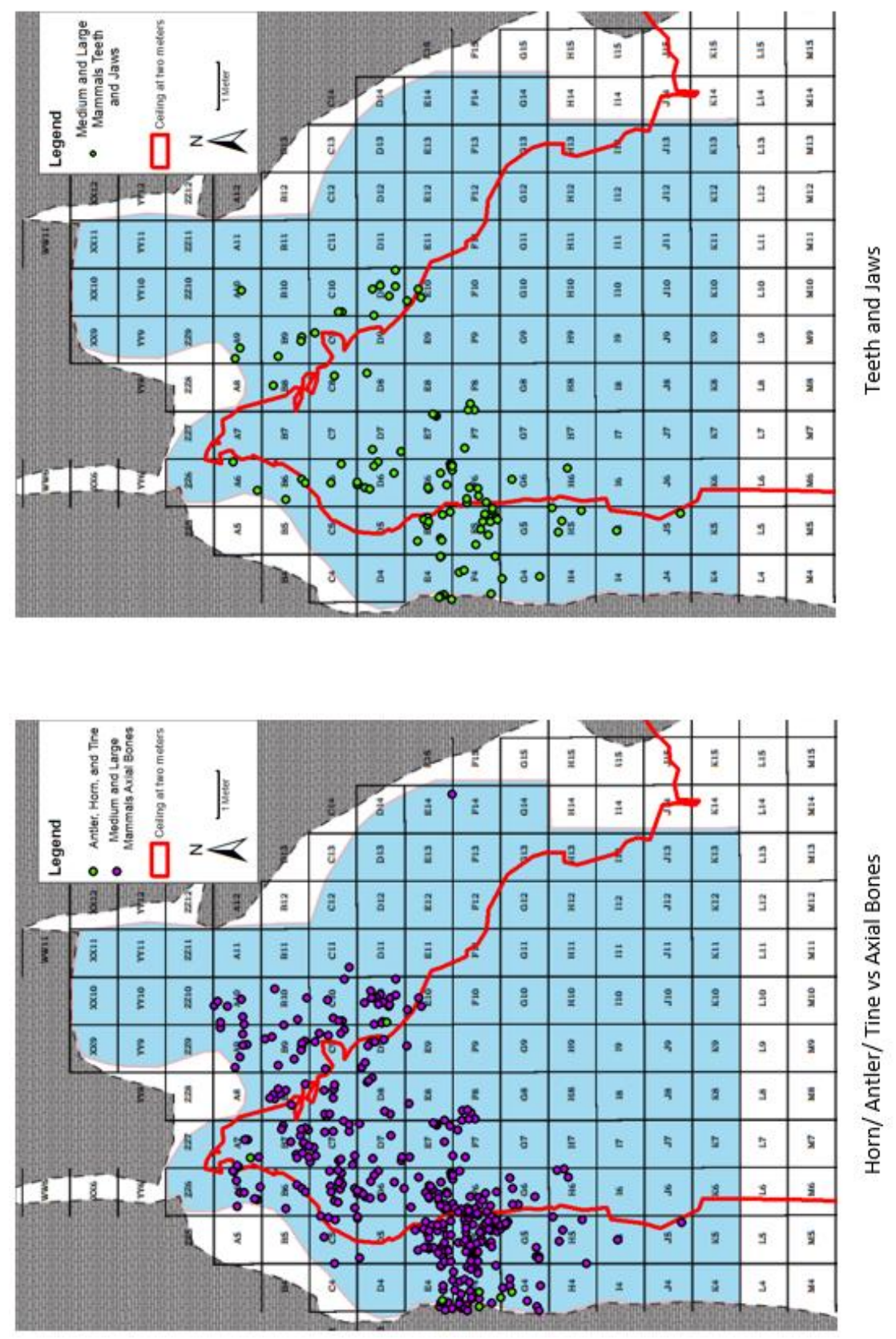

Fig. 37. Distributions of different axial elements for medium and large mammals 


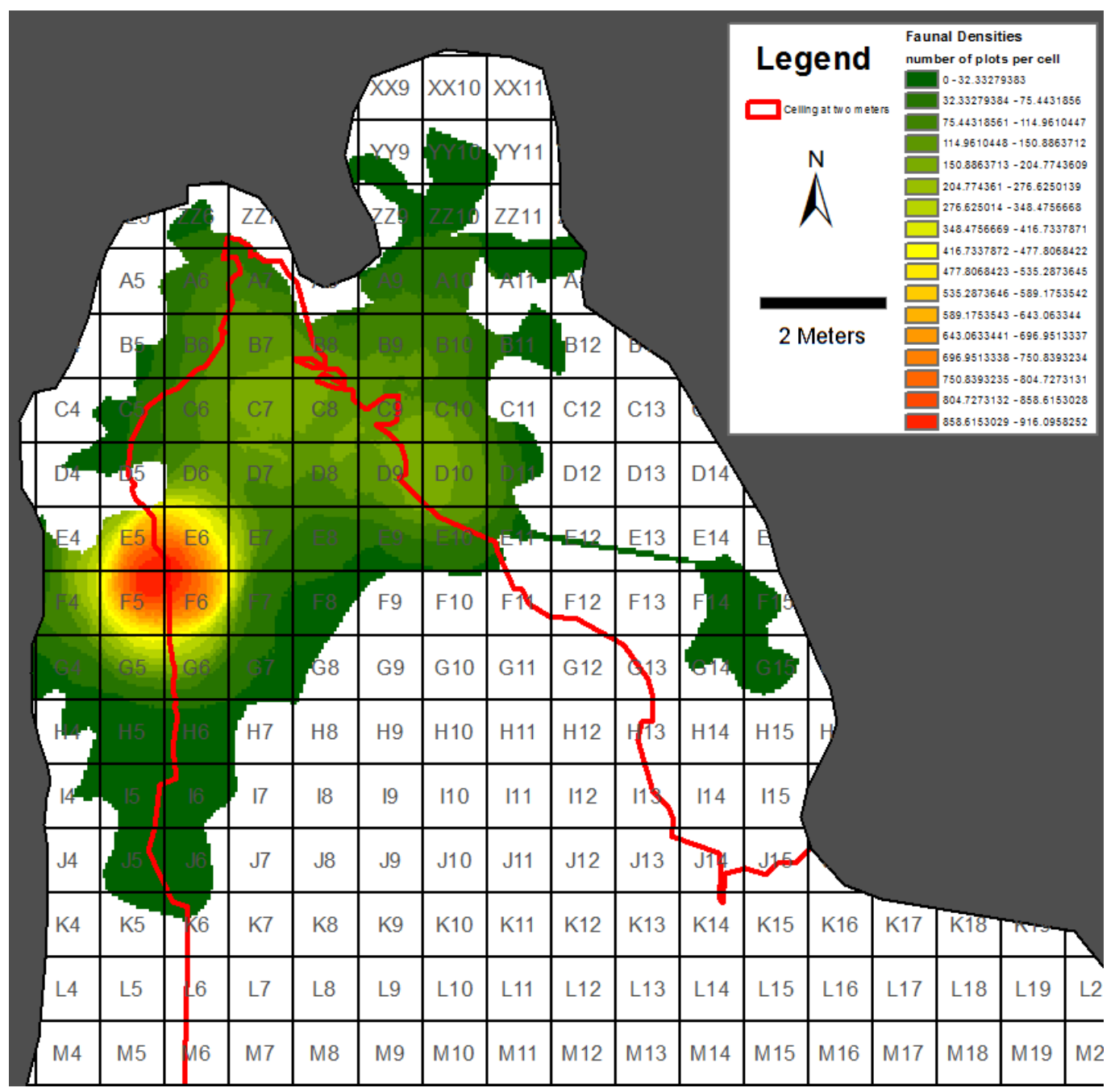

Fig. 38. Population density (heat) map of faunal material

When using the general data set, heat maps can be made through population density tools in ArcGIS (Fig. 38). This type of data rendering gives the most complete picture in terms of use areas and is supported by cell based statistical analysis. Only the areas which yielded piece plots are included and individual outliers were left out to keep them from obscuring the density map. Figure 38 shows the areas of denser faunal remains in level F. The lowest yielding areas appear as green and the reddest areas represent more bones piece plotted. The large red spot on the left side of the cave in the E and F rows 
represent the large amount of material associated with the hearth. The hearth, which glows red, would have been the most used area of the cave. This is only true if the presence of material is directly equitable to use of space for actives.

Although the hearth contains the highest density of faunal material, it is not the only area that shows signs of activity within level F. In rows B, C and D, columns 9 and 10 , the second highest density of faunal remains is seen. This area lays just outside of the mouth of the Sala, and represents where the opening to the Sala was first discovered. Because material in the Sala was thought to have been pushed or fell from the main room, the presence of a grouping of faunal remains at the point the Sala was sealed off is not surprising. The hearth and the Sala entrance are possible activity areas based on the results of faunal population density analysis. A yellow zone is also seen under the chimney in the back of the cave, showing a less dense distribution of material.

To discuss headroom and trampling in the faunal assemblage, it was divided into two groups; small and micro fauna; and medium and large mammals. The latter is used here because of its smaller sample size. Small and micro fauna distribution covered the entirety of level F, with the only pattern showing the hearth and the back of the cave as preferred areas. No other subdivisions showed special patterning. Medium and large mammals, being relatively larger, would also be more useful in terms of tracking trampling (Theunissen et al 1998). 


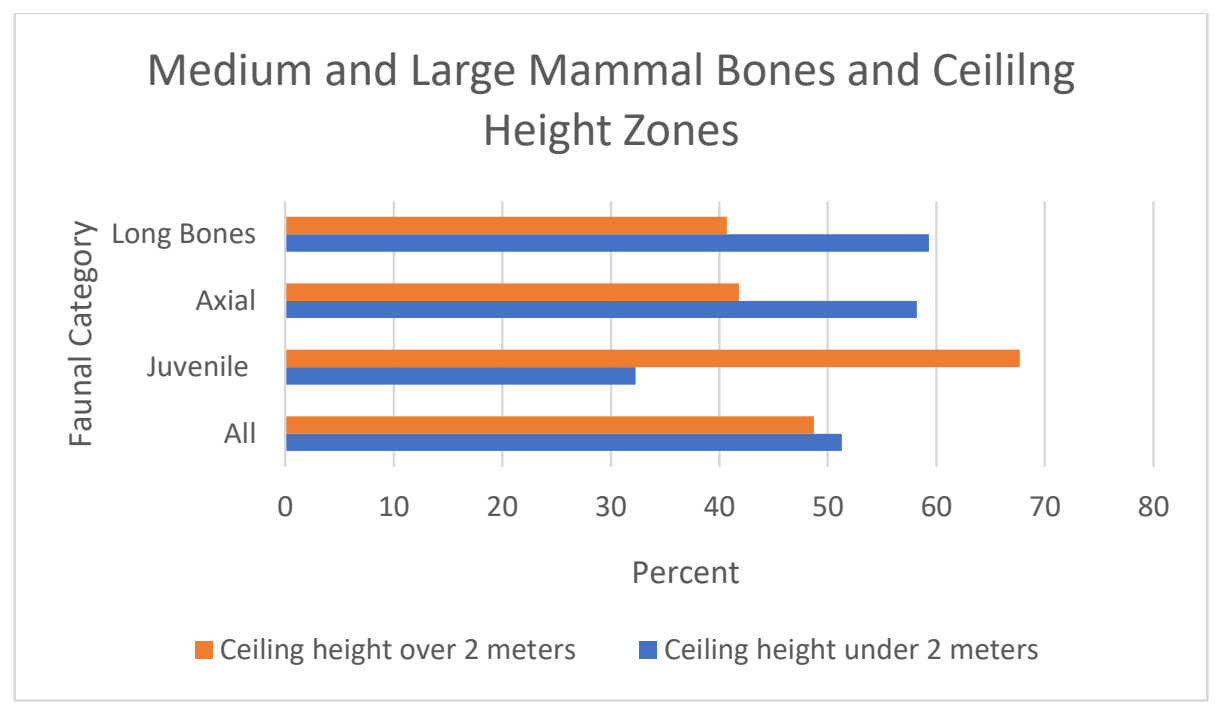

Fig. 39. Medium and large mammal bones and ceiling height zones

The larger bone elements from medium and large mammals (MLM) show a distribution relationship to ceiling height (Fig. 39). The long bones and axial elements show a greater propensity of being recovered under 2 meters of ceiling height. Juvenile bones, which are smaller, do not show this correlation.

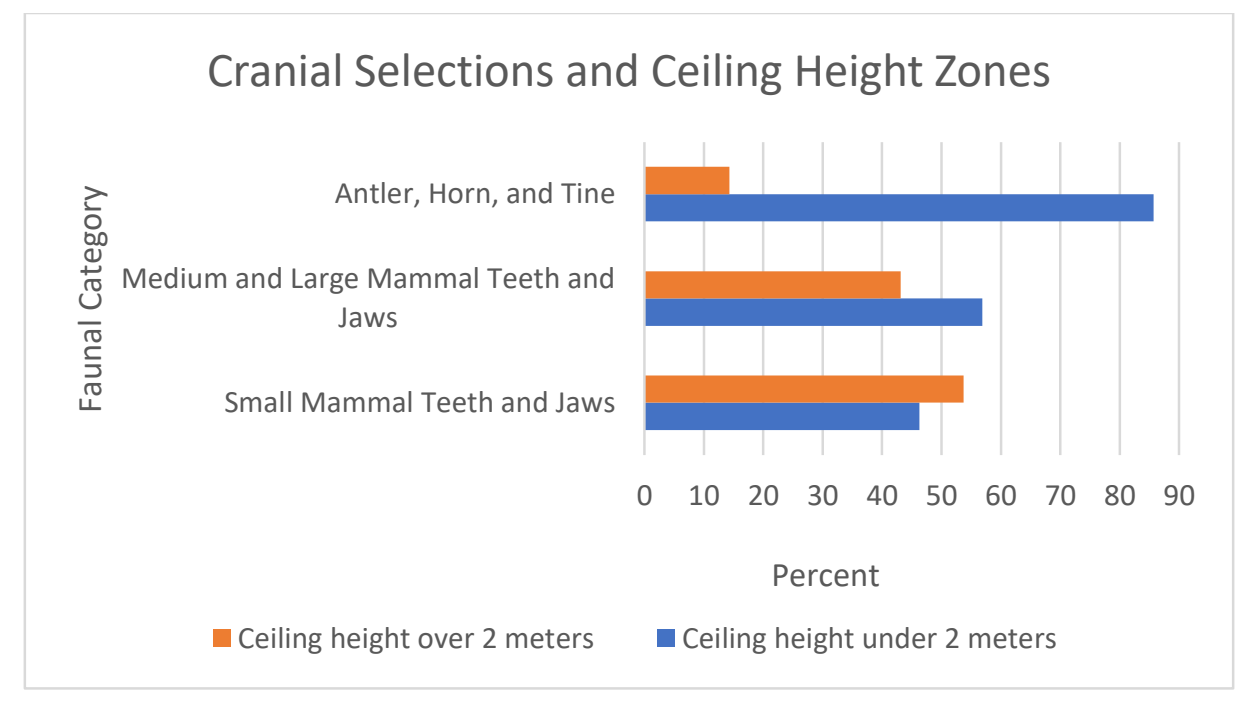

Fig. 40. Cranial selections and ceiling height zones 
Looking at cranial bones for MLMs shows an interesting trend (Fig. 40). The unique shapes of mandible and maxilla may contribute to the ease with which trampling may affect them. All examples of horn, antler, and tine are found under ceiling heights of 1 meter and by the hearth, suggesting purposeful deposition by tossing or maintenance. Small mammals were included in this figure to show the relatively even distribution in the two ceiling height zones. This is strongly representative of the total distribution for small mammals, and is a good example of the confounding impact of including small mammals in the analysis of headroom and trampling.

\section{LITHICS}

All lithic analysis and totals for level F come from Melissa Holst's unpublished Master's Thesis (Holst 2017). A total of 3,276 lithics were recovered in Level F. Without chips and fine debris, the assemblage totaled 1,257 lithics. This includes Fire Cracked

Rock (FCR) fragments and nodules of raw material. Without unworked raw material and FCR (8 pieces), 1,171 lithics were found. Totals lithic counts represent material recovered by excavators as well as lithics found while screening. The location of all lithics $1 \mathrm{~cm}$ or more in length were piece plotted in Level F. A total of 315 pieces have associated provenience data. A large portion of the lithics recovered are associated with the hearth and the area which sealed off the Sala.

Multiple raw materials were used, including chert, quartz, and quartzite. Chert was used for over half of the lithic material recovered, while quartz makes up $19.5 \%$ of the total lithic assemblage, and quartzite makes up $15.3 \%$. Chert also made up the vast 
majority of the retouched tools, comprising $89.6 \%$ of the collection. Quartz, being the second most abundant raw material, makes up $9 \%$ of the retouched pieces. The remaining $1.4 \%$ of the retouched lithics are quartzite. (Table 5)

\begin{tabular}{|c|c|}
\hline \multicolumn{2}{|c|}{ Number of Artifacts per Raw Material } \\
Count of Material \\
\hline Basalt & 1 \\
\hline Chalcedony & 1 \\
\hline Chert & 2124 \\
\hline Limestone & 7 \\
\hline Quartz & 639 \\
\hline Quartzite & 502 \\
\hline Sandstone & 1 \\
\hline Schist & 1 \\
\hline Grand Total & 3276 \\
\hline
\end{tabular}

Table 5. Lithic raw materials (Holst 2017)

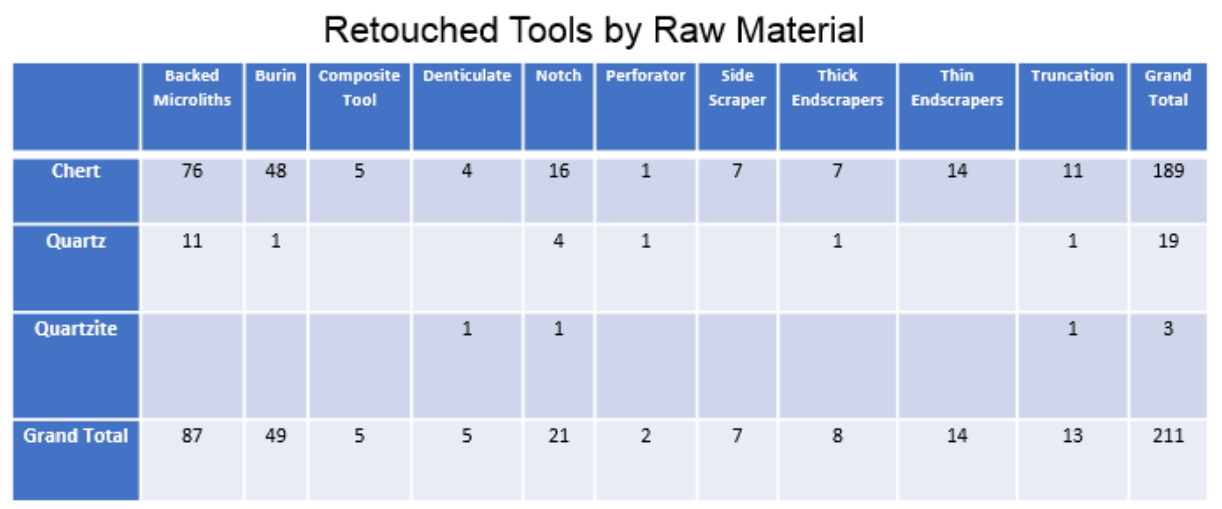

Table 6. Retouched tools by raw material (Holst 2017)

Of these 315 piece plotted lithics, 211 are retouched. The retouched tools are diverse and include denticulates, notched pieces, side and end scrapers, truncated pieces, and a large number of burins (Fig. 41). 


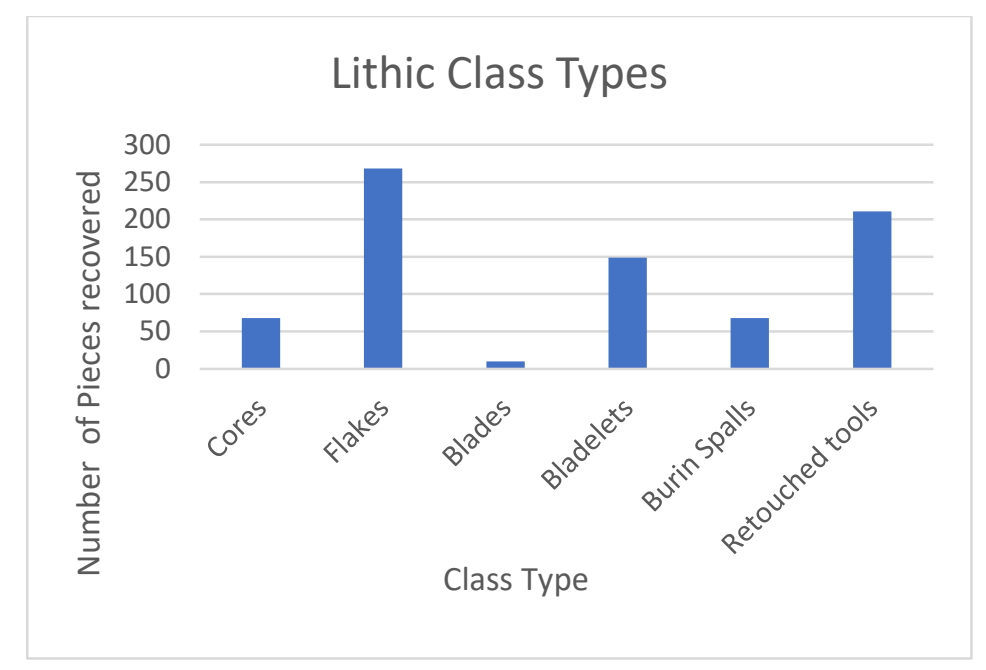

Fig. 41. Lithic Class Proportions (Holst 2017)

The presence of such a diverse assemblage is characteristic of the Late Magdalenian. The large amount of burins, however, is unusual for Portuguese Magdalenian assemblages and may warrant further discussion (Straus et al. 1996). The high number of bladelets and backed microliths demonstrate the noticeably smaller size of lithics when compared to the Solutrean and even some early Magdalenian assemblages. A selection of microliths can be seen in Fig. 42.

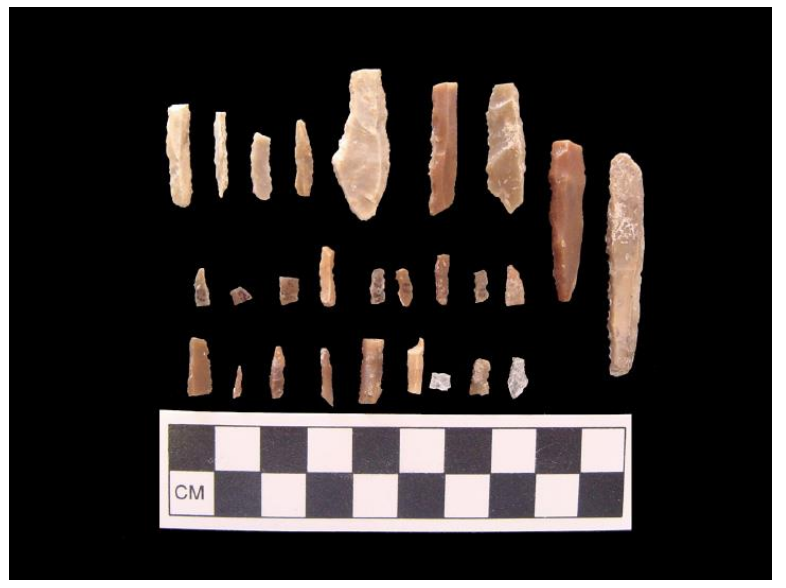

Fig. 42. A selection of Micro-lithic tools form level F (Bicho, Haws, and Hockett 2006) 
Backed microliths, with 87 pieces, make up $41 \%$ of the retouched lithics recovered. The presence of a large amount of backed microliths strongly suggests the use of composite projectiles or tools, a common occurrence in the later Magdalenian (Straus et al. 1996). Bladelets and backed microliths far outnumbered larger blades in the assemblage, seen in Figure 24. Blanks, defined here as any flake or blade not exhibiting retouch, number 217 pieces.

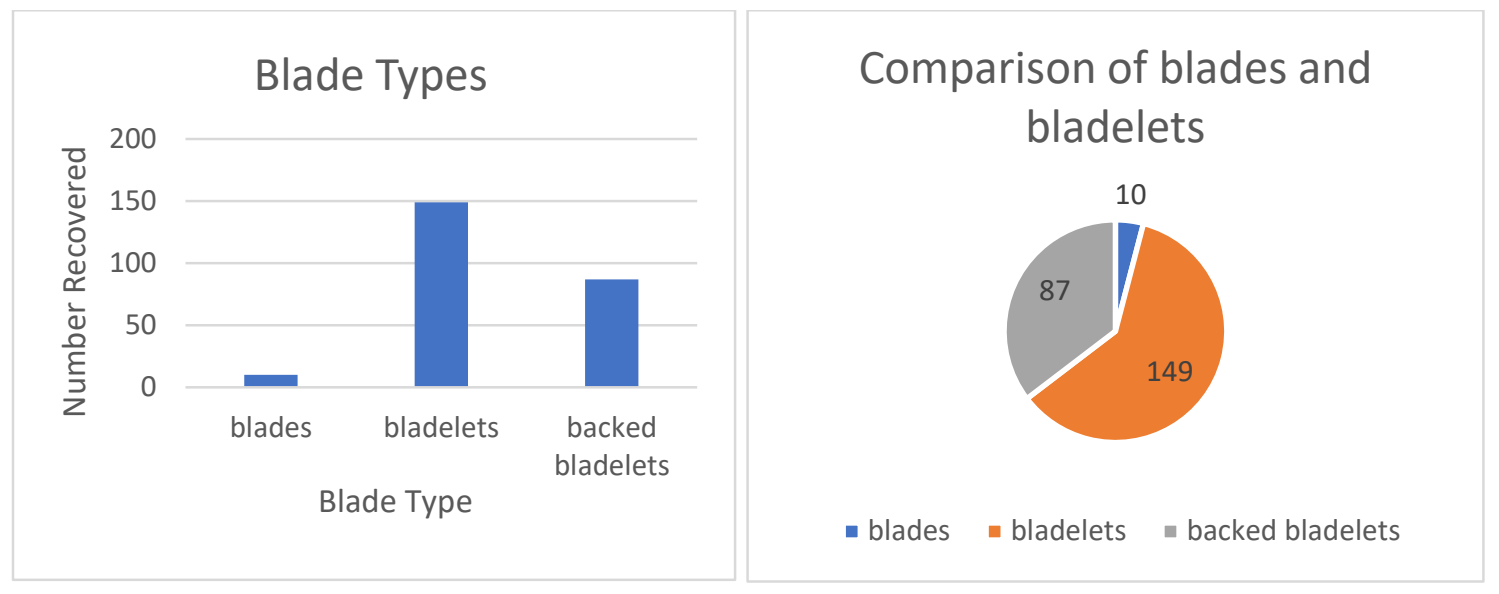

Fig. 43. Blades versus Bladelets (Holst 2017)

\section{LITHIC DISTRIBUTIONS}

The lithic material contains qualitative data for the entire assemblage thanks mostly to Melissa Holst's Master's thesis on the lithic material from Level F (Holst 2017). The general distribution of lithics, seen in Fig. 44, does mirror activity areas present in the faunal record. 


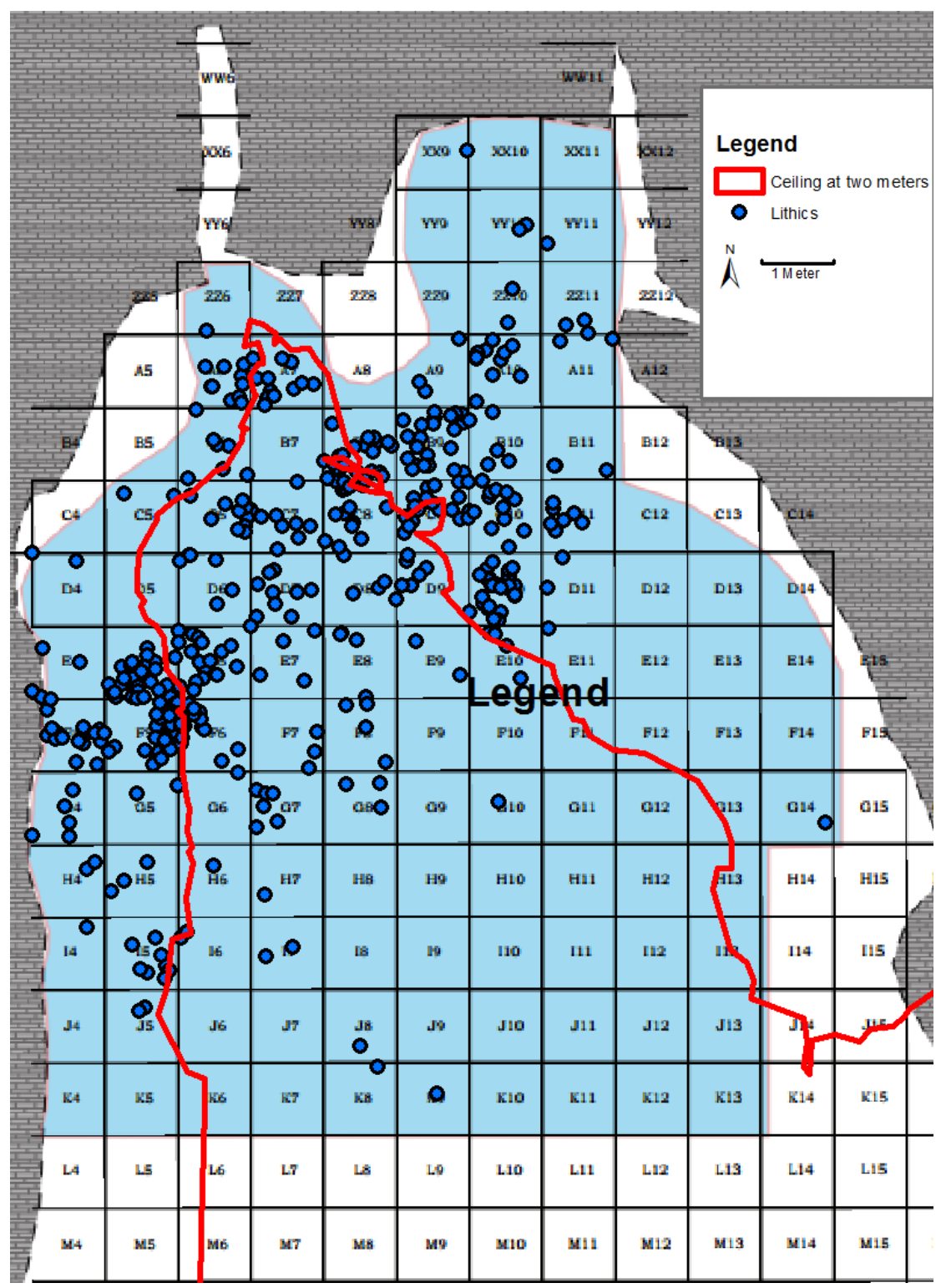

Fig. 44. General lithic distribution 


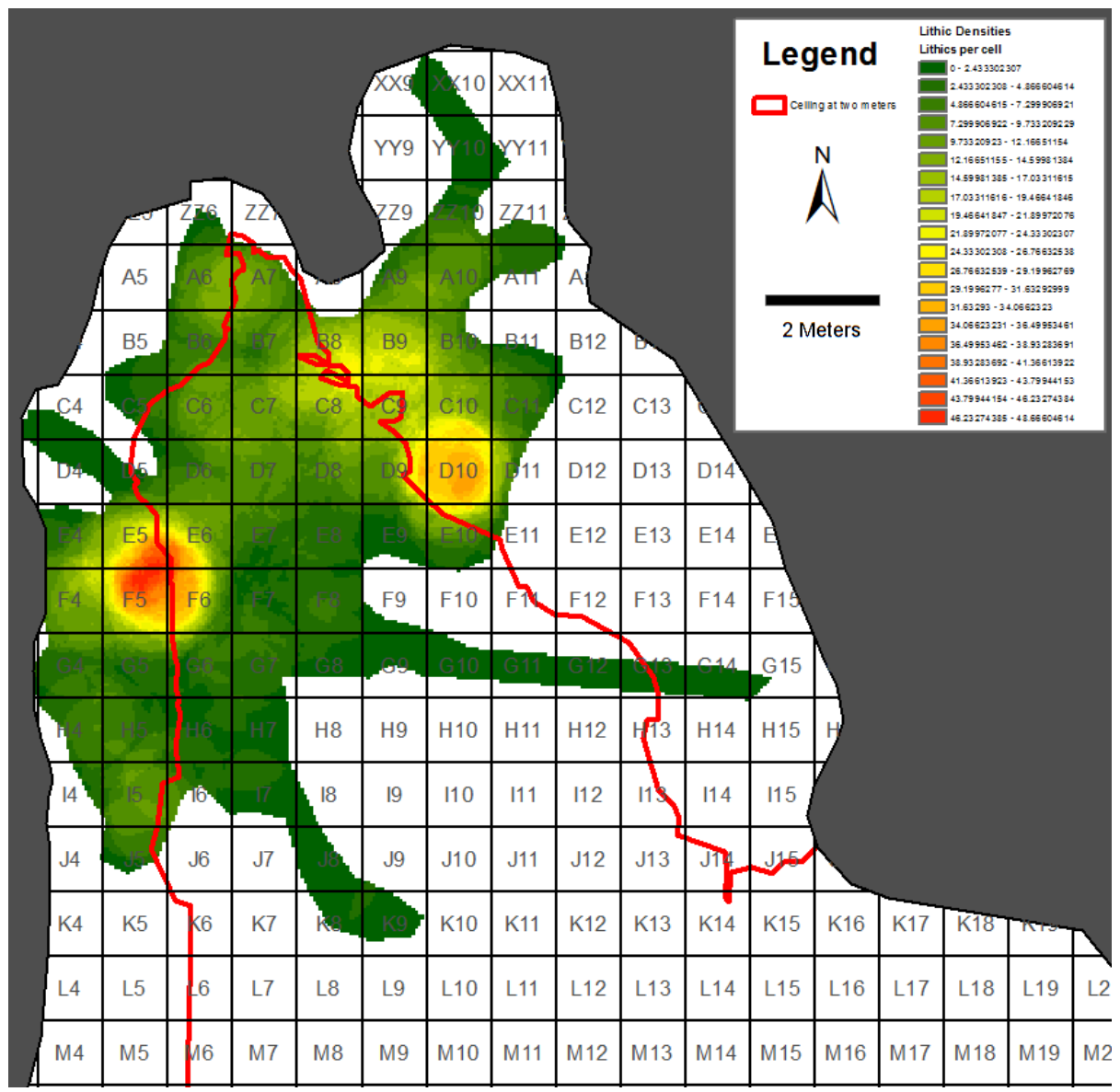

Fig. 45. Population density (heat) map of lithics

The lithic population density heat map (Fig. 45) shows the hearth still remains the area with the most material recovered when the analysis shifts to lithic distributions. The area in front of the Sala is more pronounced and the general trend of a higher density of material against the back walls of the cave remains present. The zone of material for the chimney seen in the faunal remains is reflected in the lithics distribution. However, the grouping of the lithics under the chimney appear a full meter further towards the back of the cave than the faunal remains in this area. The lithics in front of the Sala also appear closer to the wall. This could represent discard or site maintenance. 


\section{LITHIC DISTRIBUTION BY RAW MATERIAL}

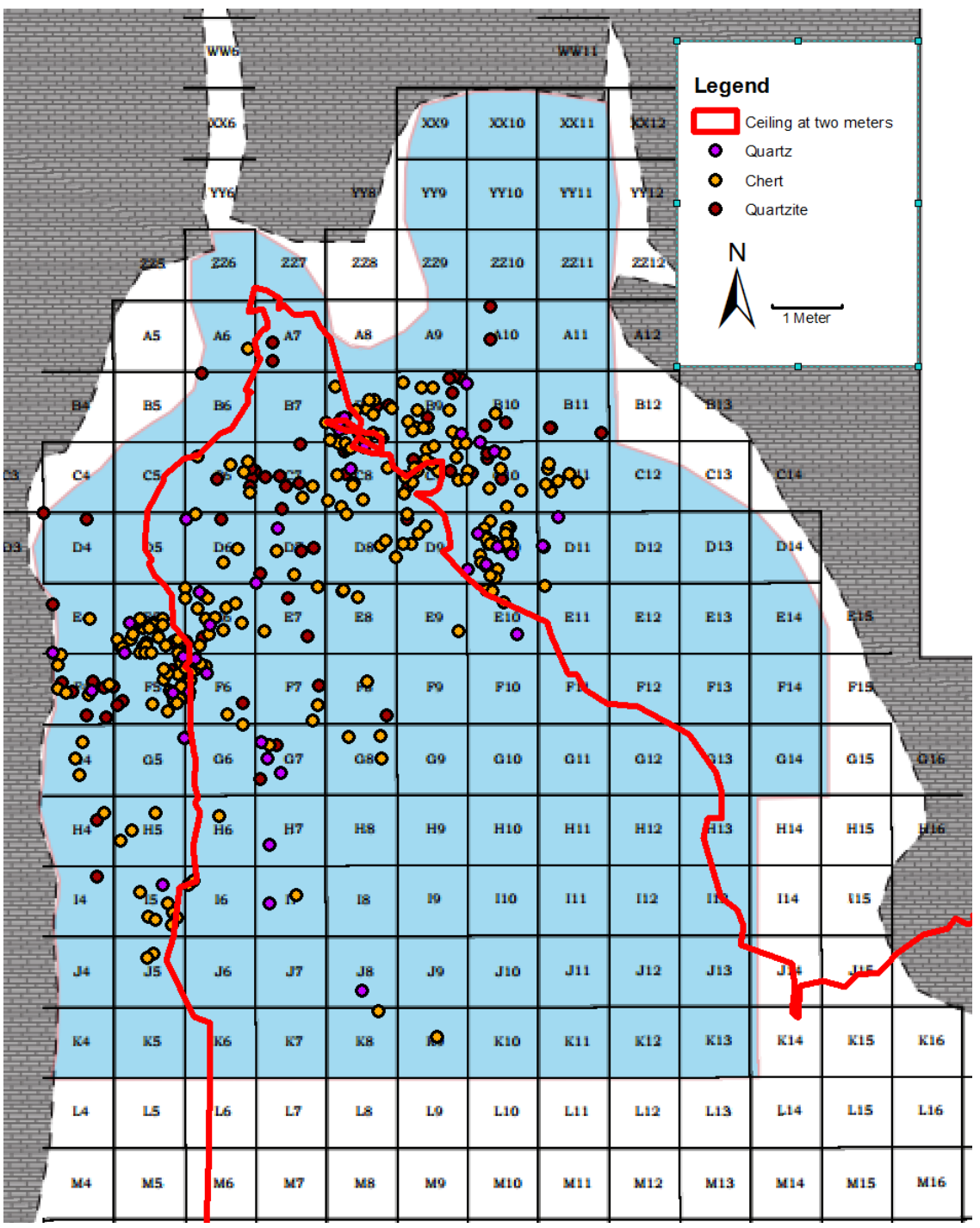

Fig. 46. Distribution of lithic raw material types

Separating the lithics by raw material showed no trend in the distribution of quartzite (Fig. 46). Chert was also widely distributed but showed a slight grouping of the material around the hearth and entrance to the Sala. Quartz showed the strongest 
groupings, with the most distance between the material found in front of the Sala and the Hearth.

\section{LITHIC DISTRIBUTION BY TOOL TYPE}

Dividing the assemblage into tool classes shows varying degrees of spatial patterning. General flakes are the most abundant and cover the most surface area of the floor (Fig. 47). A general grouping in the Hearth and in front of the Sala is noticed.

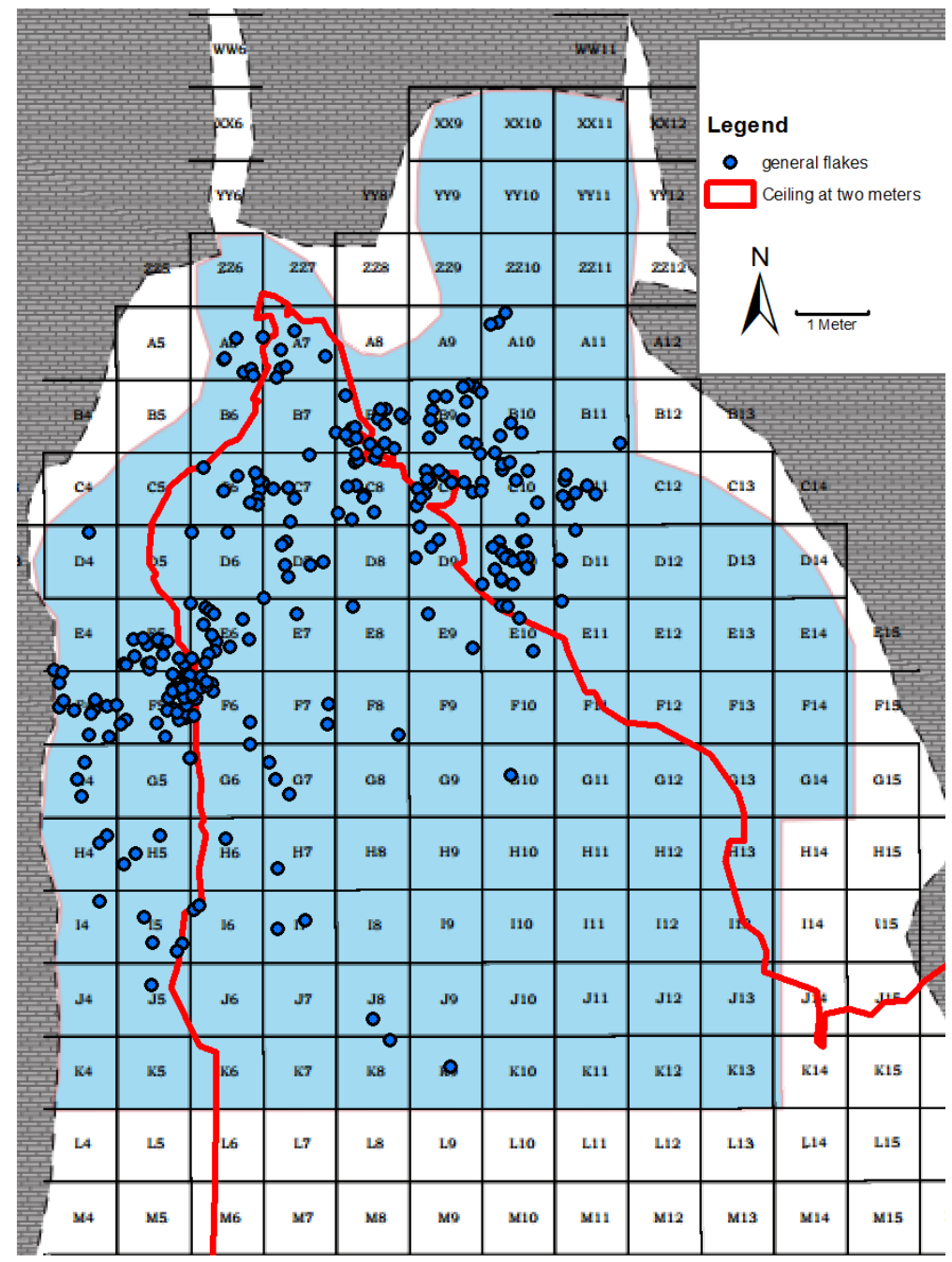

Fig. 47. General flake distribution 

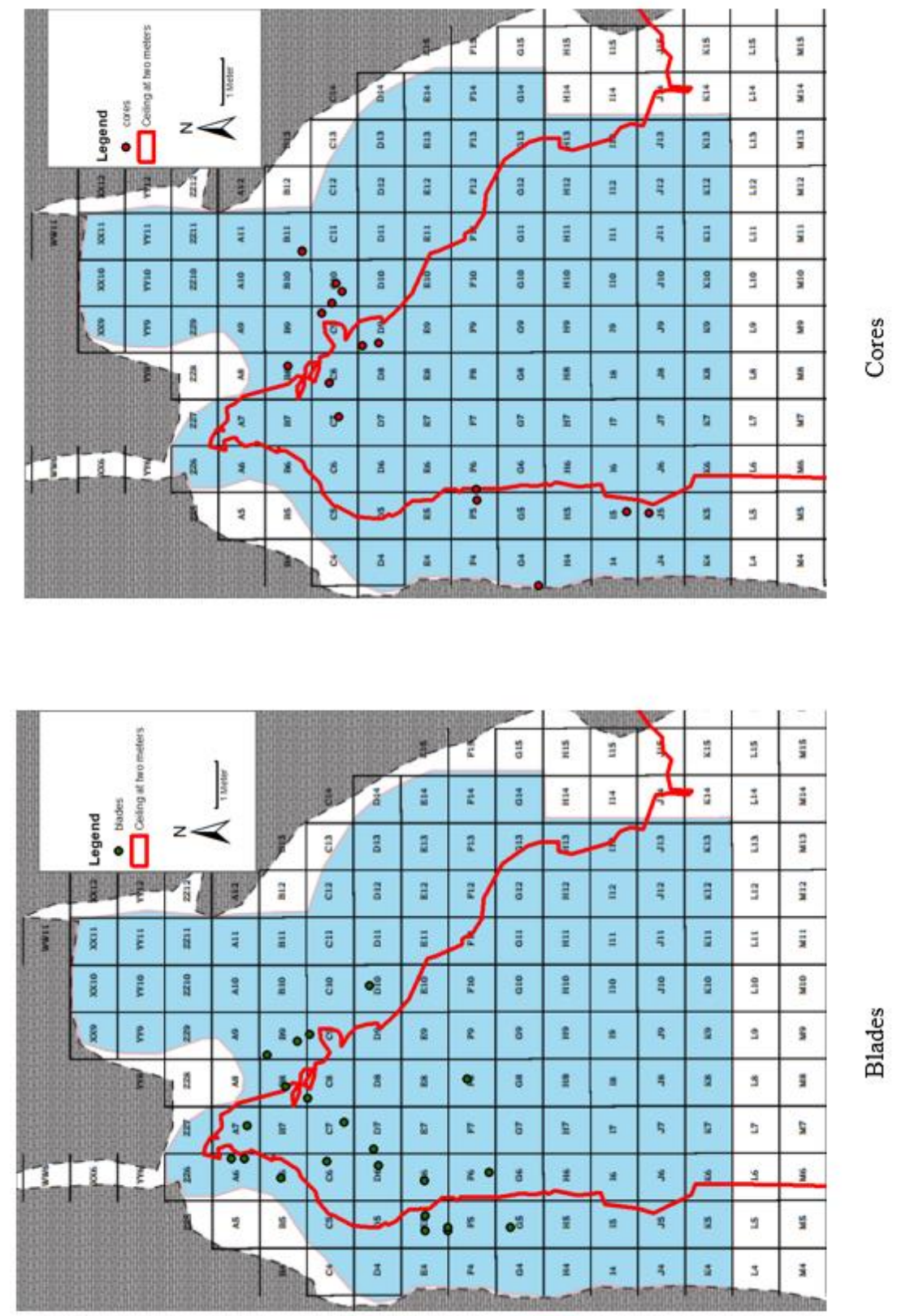

Fig. 48. Blade and core distributions 

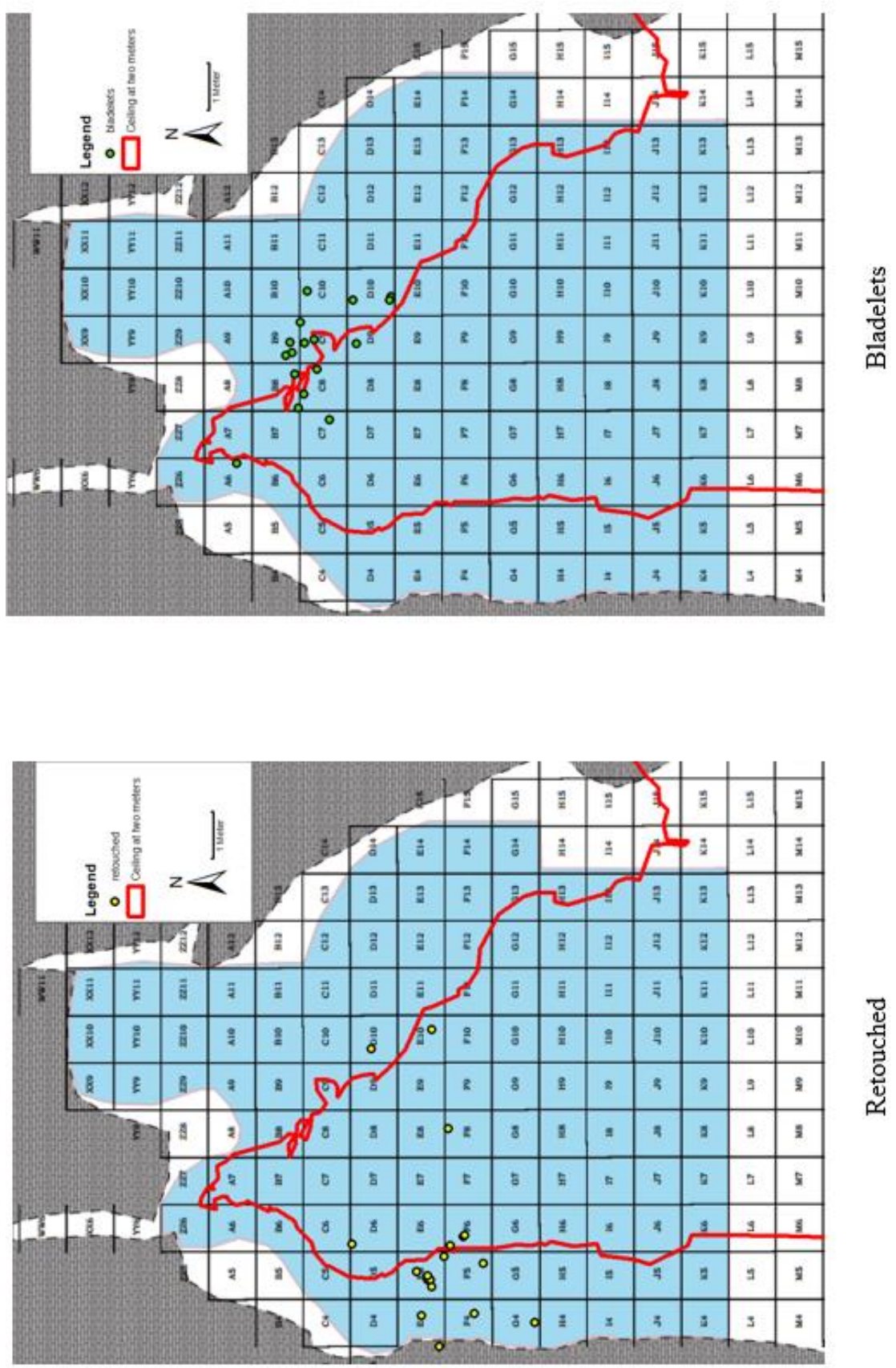

Fig. 49. Retouched tools and bladelet distributions

Blades show no patterning and are randomly distributed as a swath running diagonally through the cave. Cores show a strong grouping in front of the Sala with a 
smaller grouping on the outskirts of the hearth. The distribution of both of these classes are seen in Fig. 48. Bladelets show a distinct grouping in front of the Sala. Retouched material shows the opposite and occurs mostly in the hearth. These distributions are seen in Fig. 49. Combining the point clouds for different lithic classes forms the most telling story, and provides a narrative in separating the two activity areas in the cave. When comparing the position of general flakes and cores in the cave, seen in Fig. 50, a trend in lithic distribution begins to appear. The picture becomes clearer when comparing the distribution of retouched pieces, cores, and bladelets, seen in Fig.51.

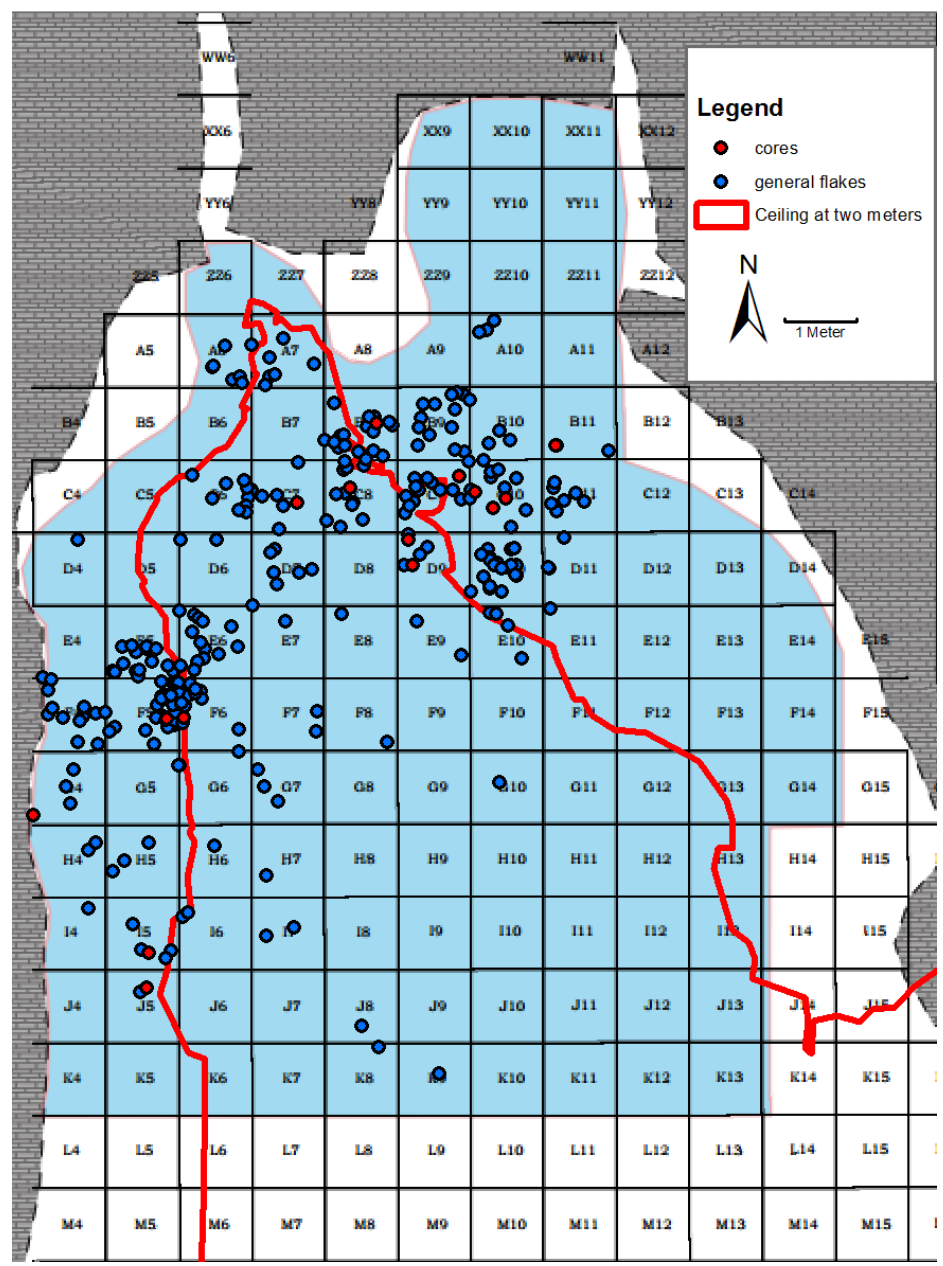

Fig. 50. Distribution of flakes and cores 
Flake production and lithic maintenance most likely took place in both activity areas. The flake and core distribution closely match in areas of highest density, as seen in Fig. 50. Flakes are well represented in both areas. The type of lithics being worked, however, changes between the two activity areas, seen in Fig. 51.

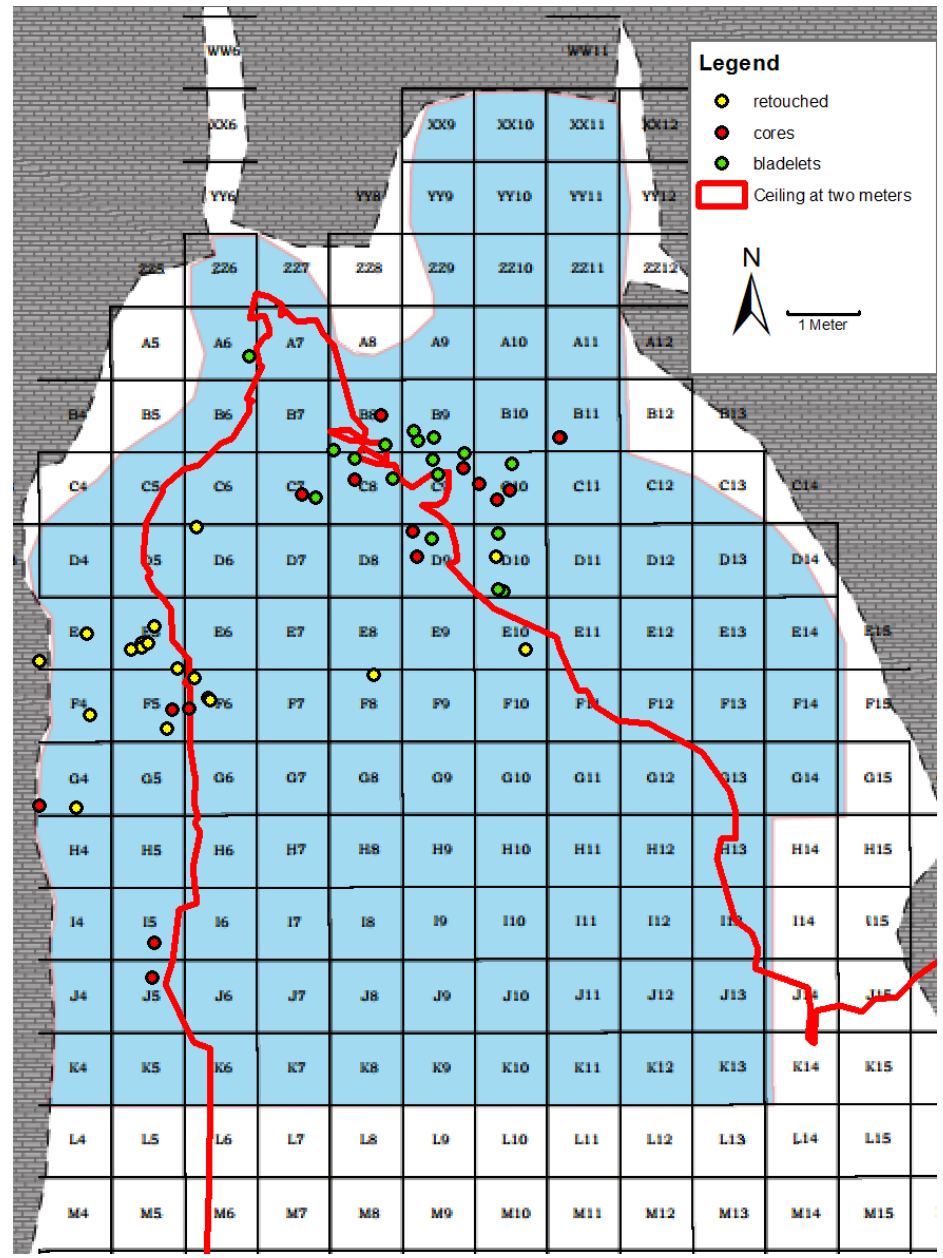

Fig. 51. Distribution of retouched pieces, cores, and bladelets

The majority of the retouched tools $(88 \%)$ were found near or within the hearth. This would suggest that lithic modification or use occurred here, with tools being 
discarded after use or exhaustion. The area in front of the Sala contains the majority of bladelets in the level $\mathrm{F}$ assemblage. The bladelet distribution is mirrored by the cores in that area. The separation of these two lithic classes in this way would be unusual if these lithics came from multiple different occupations. This patterning could suggest that the bladelets came from a single occupation. It is harder to make this claim about retouched tools as they cross many lithic classes, allowing blades, bladelets, burins, and scrapers to fall into this category. Human agents may also retouch discarded flakes from previous occupations, allowing retouched tools to have a greater "life history", with use occurring over several occupations, sometimes separated by stretches of time longer than a human life. It is the distinction of a single lithic class that suggests a single event. The grouping of bladelets could also suggest another use in this area. Bladelets used in composite weaponry are usually placed in wood, which preserves poorly. With the assumption that the wood has degraded, this could also be the location of a small cache of composite weapons, pre or post use.

The large amount of backed microliths, associated with composite tools and barbs used for hunting, suggest a specialized use of the cave, such as a hunting camp or game processing center (Straus et al. 1996). The high number of burins and the low number of cores suggests the site was not a major location for primary tool production, and instead, was a place for lithic modification and stone tool reuse. Primary production would have happened at the raw material source or at locations close to them, perhaps at more permanent residence areas.

Separating lithics by the two headroom zones shows, overwhelmingly, the majority of lithics with qualitative data were recovered in areas where the ceiling height 
was 2 meters or lower (Fig. 52). Blades show the weakest correlation, most likely owing to their thin profiles. The back of the cave, where the majority of the blades were found, would also be an area of low traffic. Bladelets, being the smallest class, may not mirror the distribution of blades because they represent an intact area of use.

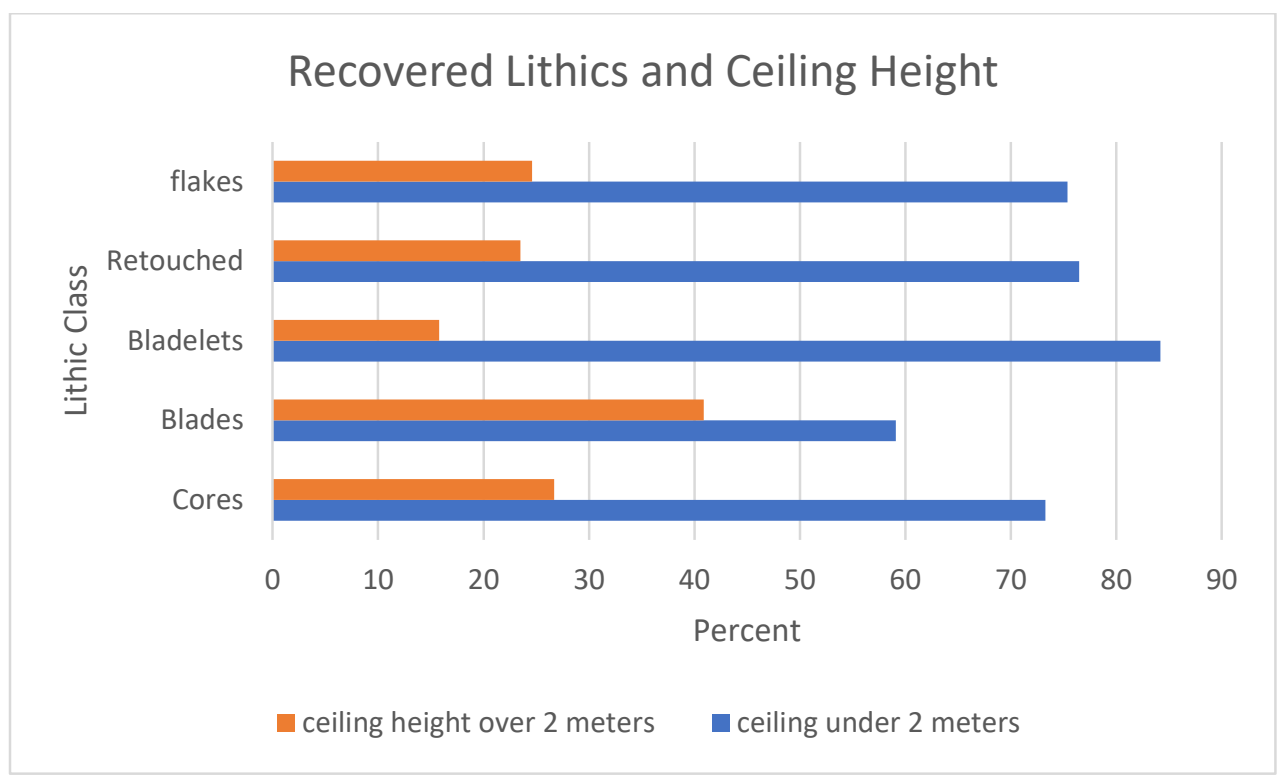

Fig. 52. Lithics and ceiling height

The vertical distribution of bladelets, seen in Fig. 53, also suggests a single occupation for their deposition. This could also occur from a series of occupations within a relatively short period of time, all utilizing the use area for the same activity. This latter suggestion is much less likely. Almost all of the bladelets are found in front of the Sala and show a tight grouping both along the $\mathrm{x}$ and $\mathrm{y}$ axis, as well as the $\mathrm{z}$ axis. A single bladelet is seen on the inside lip of the Sala. The distribution of bladelets demonstrate how small the opening of the Sala was at the time, and the continuity of level $\mathrm{F}$ in that area. 


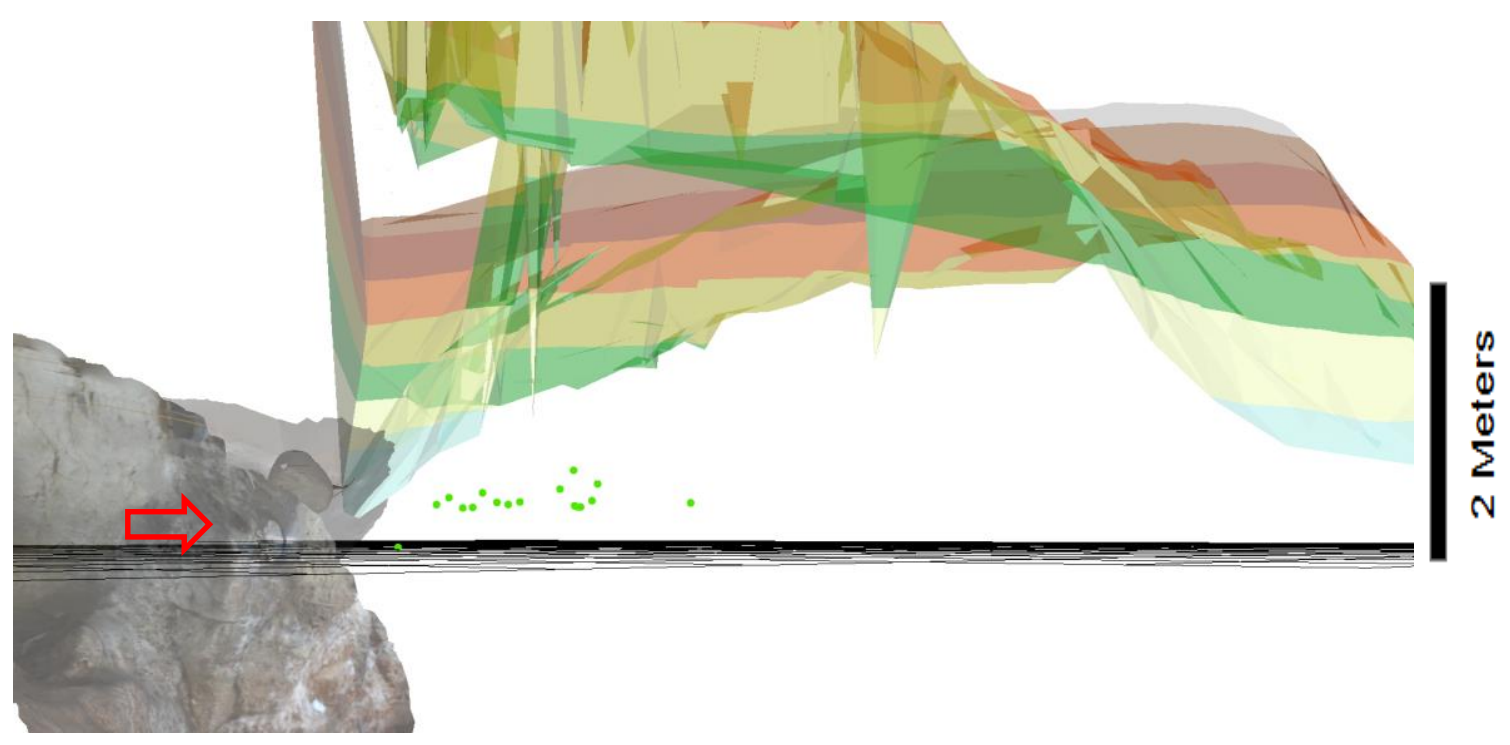

Fig. 53. A view from ZZ6 looking towards the mouth of the cave, showing the vertical distribution of bladelets (green dots), and the narrow entrance to the Sala denoted by the red arrow.

\section{SHELLS, OCHRE, AND ART}

A total of 7 shells were recovered in Level F. Along with shells belonging to terrestrial gastropods, there are a few that belong to marine species. Small conch shells, Scrobicularia plana, and a specimen from the Nassarius Genus, are found within a meter of the large hearth on the left side of the cave. The latter is perforated. The marine shells in Level F suggest movement from a coastal or estuary like environment. Picareiro is roughly $31 \mathrm{~km}$ from the current coastline. This distance was arguably similar in the Allerød, until the sea level decrease seen during the Younger Dryas. The estuaries and rivers extend inland however, and it is not unreasonable to think of human migration, seasonal movements, foraging, or trade taking place between these two areas. A small 
amount of ochre was recovered in level F near the mouth of the cave. In keeping with the current literature about the Magdalenian in the Portuguese Estremadura, no examples of cave art were found associated with level F, although a single instance of portable art in the form of a carved pebble is recorded.

Although charcoal belongs to the smaller material classes, its distribution is determined by headroom, strongly indicated by the amount recovered under ceiling heights of 2 meters or less. Interestingly, all the shells and ochre found in level F are in areas of the cave where the ceiling height was over 2 meters (Fig. 54). These are the only examples of artifact types whose distribution within the site was not split between the two ceiling height zones. In fact, the shells and especially the ochre are in the middle of what would have been the highest area of foot traffic within the cave during the Late Magdalenian.

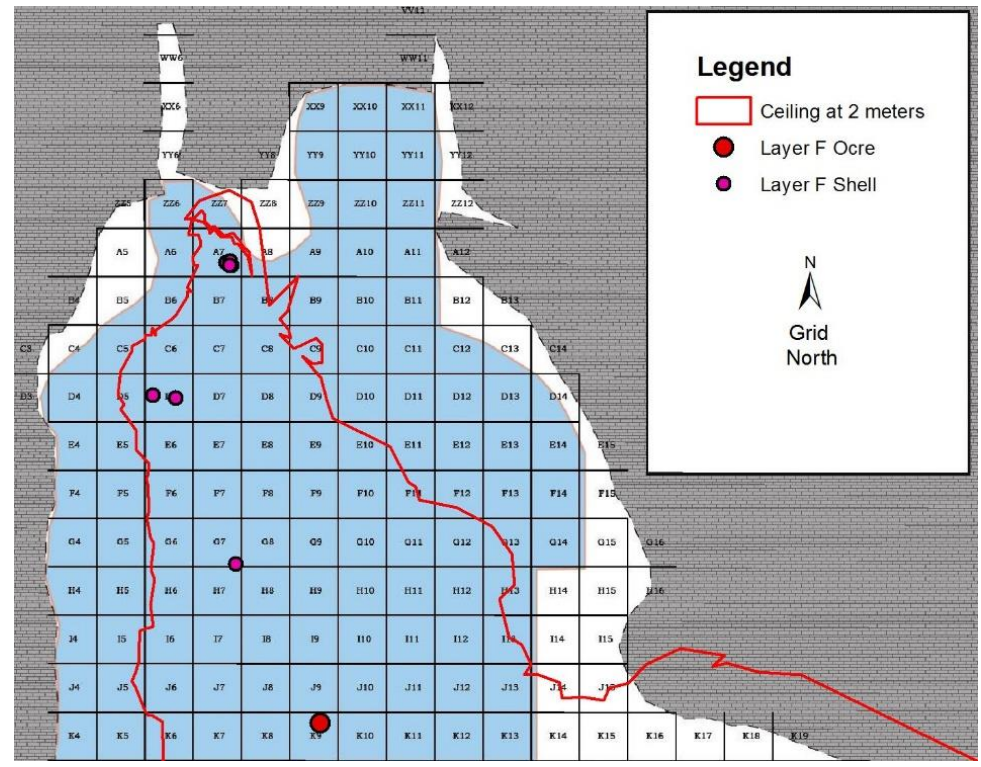

Fig. 54. Distribution of Shell and Ochre 
The findings of the experiments at Petzke's cave would suggest this could be a result of the relative small size of the artifacts, helping them to avoid being kicked around. This leads one to wonder if more shells were once present, but over time had been crushed by foot traffic and so were not preserved. The majority of the recovered shells were found in the back of the cave, an area that most likely did not receive much foot traffic. This area could have experienced other meaningful activities by human occupants, explaining the higher concentration of shells.

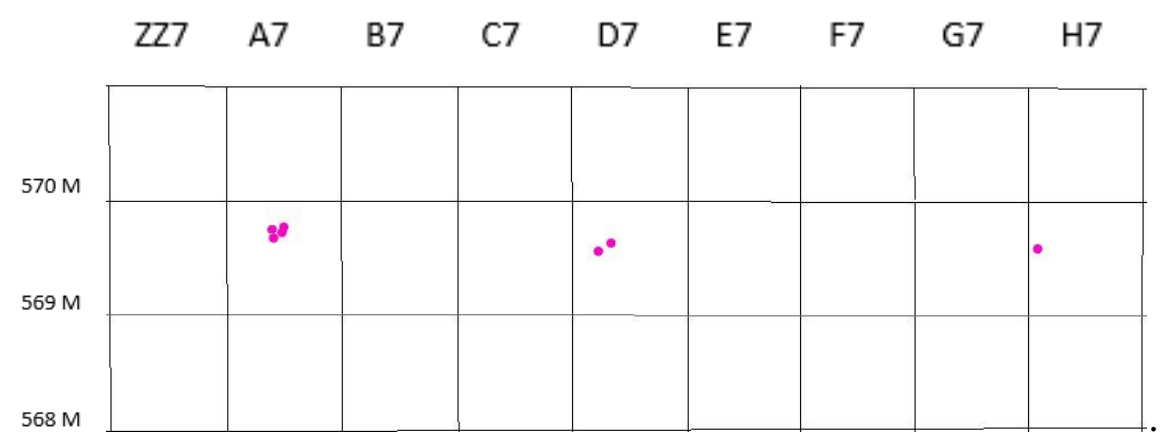

Fig. 55. Vertical distribution of shell facing the right side of the cave.

The location of shells recovered in level $\mathrm{F}$ are also interesting because of their vertical distribution, seen in Fig. 55. Among the artifact classes, the shells have the tightest vertical groupings and may represent the only definable distinct occupations thanks to their small sample size and the low probability of post depositional movement. Because they are mostly found in the rear of the cave, and may represent a distinct occupation due to their vertical distribution, this area of the cave may have served as a distinct area of use, carrying some significance because of the difficulty of obtaining and maintaining shells. 


\section{VERTICAL DISTRIBUTION: PALIMPSESTS AND LIVING FLOORS OF LEVEL F}

Palimpsest are undoubtedly present in Level F. Thick bands of natural and cultural material were recorded and dated to times of relatively low geologic deposition and accumulation. The slow rate of sedimentation in the cave supports the idea that cultural material was not buried fast enough to preserve "living floors" or to keep it from being effected by a myriad of post depositional processes. This is paired with few visible sterile lenses, which would serve to separate occupations. 

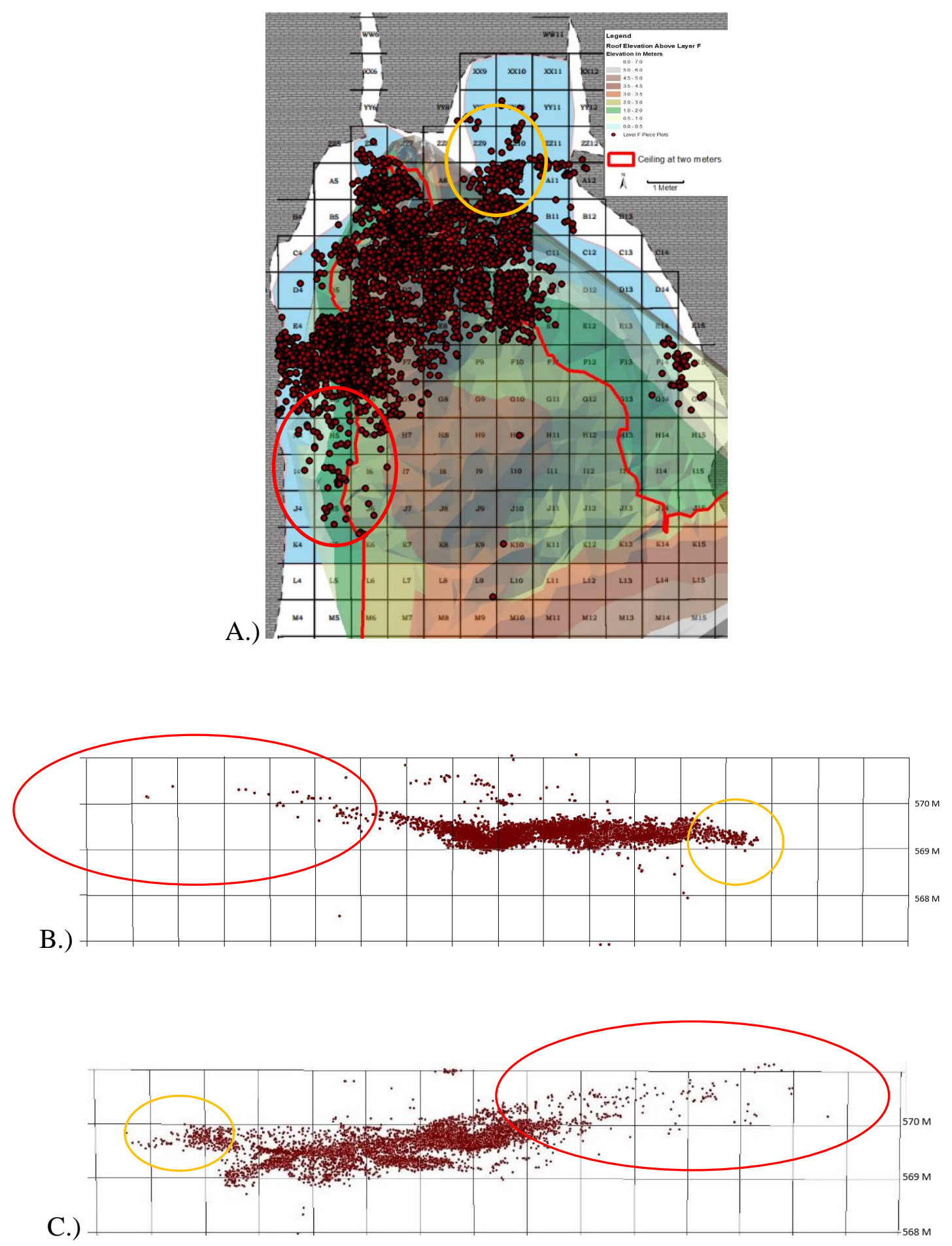

Fig. 56. A.) Areas of thinner vertical distribution under the roof DEM; B.) facing the left side of the cave, or cave west; C.) facing the right side of the cave, or cave east. 
As discussed earlier, finding living floors may not be likely, but some general inferences on occupational periods can be made by using the point cloud. Some areas of artifact density are thin and may represent discrete periods of occupation, although do not necessarily represent single activities. These thinner lenses occur on the outer most edge of the site within the cave. Looking at Fig. 56, you can see areas where the point cloud thins out, represented by circles on the map. The profile views of these areas are shown from two different directions. Unsurprisingly, these areas are against the cave walls, a phenomenon discussed in the next section.

The hearth that makes up the once designated level G may be a discernable occupation, or at the very least, a collection of occupations over a much shorter time frame than seen in the rest of level $\mathrm{F}$, as it must be conceded that the hearth could have been, and most likely was, revisited over several occupations. Level G, or the hearth, is also interesting in that it begins towards the top of Level $\mathrm{F}$, and is dug through the level almost intersecting with the top of Level I. This demonstrates the later occurrence of the hearth during the period represented by level $\mathrm{F}$. The alternative to this is that the hearth was started in the beginning of the time frame represented by level $\mathrm{G}$ and experienced regular use throughout the time frame represented by level $\mathrm{F}$, which is possible but not probable. The disturbance caused when making the hearth by the removal of previous deposits in layer $\mathrm{F}$ would add to the material found around the hearth, appearing in the point cloud like a scatter of artifacts. 


\section{THE HEARTH AND HEADROOM}

Head room was a major factor in determining use of space in the Upper Magdalenian at Picareiro. The center of the Hearth lay at head height, with the majority of the lithics associated with the hearth at or under areas where the ceiling is 2 meters high. Because the artifacts are evenly distributed around the hearth in a halo, or toss zone arrangement, the artifacts associated with the hearth may have experienced little post depositional movement due to trampling. Site maintenance in the form of pushing or tossing most likely occurred for the large number of artifacts and charcoal resting under 1 meter of space between the ceiling and floor (Fig. 57).

A.)
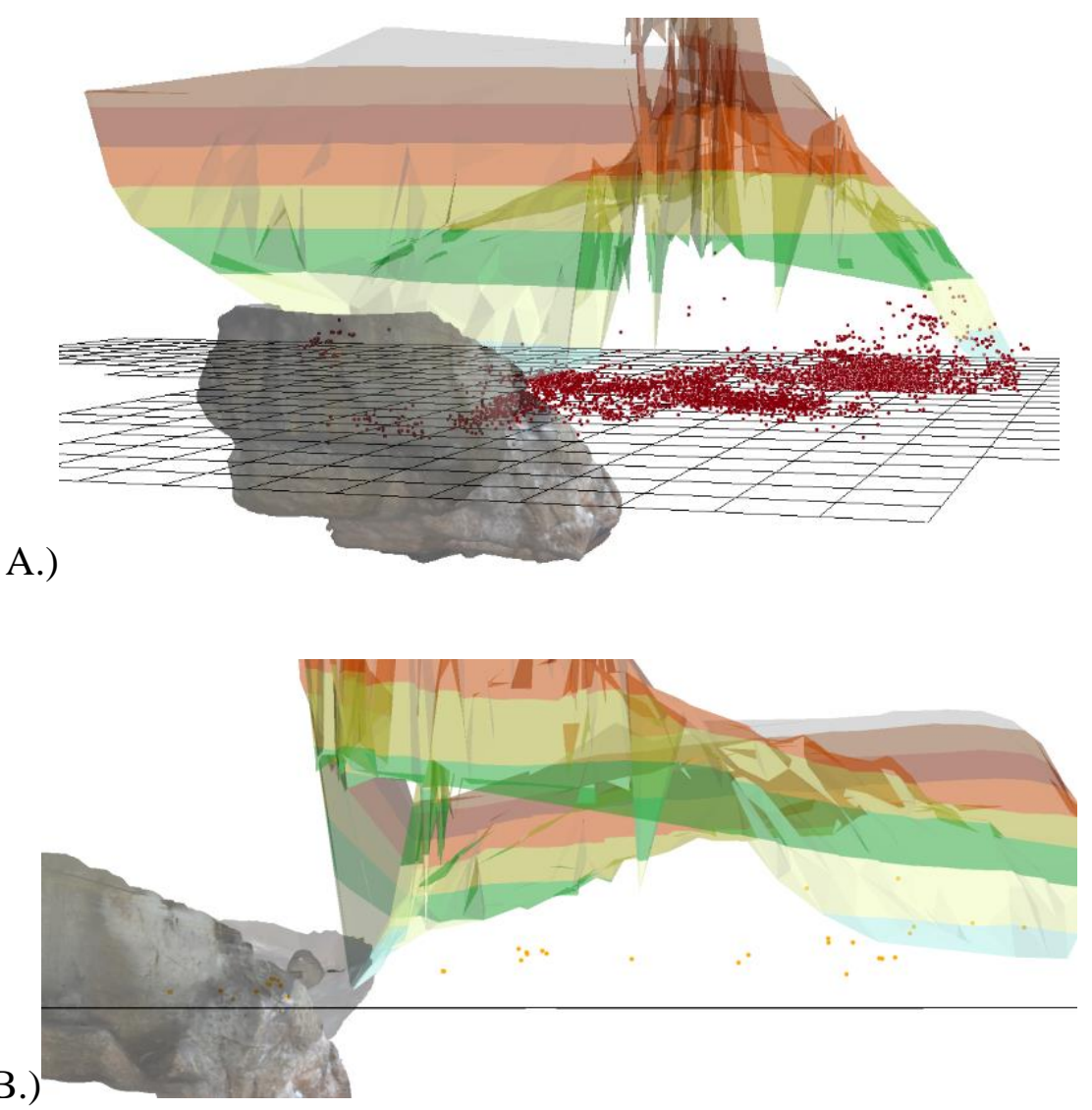

Fig. 57. A.) faunal material pushed against the wall, associated with the Hearth; B.) charcoal displays this same trend. 
This type of artifact movement most likely accounts for the artifacts within the Sala. Only a small amount of space between the floor and Sala, around $30 \mathrm{~cm}$, was left while level F was occupied. Material was either tossed, pushed, or slid into the Sala along the roofs natural dip as the room was ultimately sealed off.

Both the faunal and artifact distribution figures show that the areas of the cave in use for level $\mathrm{F}$ followed the natural shape of the cave, with the preferred area closer to the back and extending along the walls. This is not uncommon and many sites exhibit patterns of preferred occupation further away from the mouth of the cave and sunlight, albeit this distribution trait is usually associated with deeper caves (Straus 1990). It is interesting to note that the average slope of the roof and cave walls did not seem to directly impact the distribution of artifacts in level F, although future research involving ceiling slope and head room may yield interesting results in lower levels. The author has yet to come across an example of this in archaeological spatial analysis.

Although a large portion of artifacts are found in areas with lower cave ceilings and trampling most likely occurred, it does not fully explain the distribution of the artifacts within level F at Lapa do Picareiro. The effect of trampling at Picareiro may limited by the irregular shape of the éboulis that makes up the floor of the cave. Unlike the sand deposits from the sandstone setting of Petzke's Cave, the general size and shape of cultural material would not differ greatly from the natural limestone fill of the cave at Picareiro. Although the effects of trampling at Picareiro may be limited, Head room most likely played a large role in deciding areas of use and areas of traffic within the cave. 


\section{CONCLUSION}

Level $\mathrm{F}$ at Picareiro, dated to the Late Magdalenian, has provided an opportunity to explore how ancient humans used space in enclosed areas. Beyond the faunal and lithic record, the use of space at Picareiro has shone light on headroom and trampling, a subject in need of attention for the Upper Paleolithic of Europe. The experiments at Petzke's cave and the theories presented by Theunnisen et. al. (1998) are seen to be applicable when applied to this prehistoric assemblage in central Portugal.

The lithic and faunal material recovered overwhelmingly suggest headroom and trampling played a role in the formation of the site. The material recovered follows the walls and natural shape of the cave. Density maps show the hot spots of activity are the densest under ceiling heights of 2 meters, just over the average height of a human. Through the use of ArcGIS, the material recovered and used in this analysis show headroom played a large role in determining the use of space in level F. The effects of trampling are also evident, mostly in larger lithic and faunal categories. Interestingly, the shell found in level F may represent the only discernable distinct occupations and lay entirely in what was most likely the areas of highest traffic.

The hearth was one of three areas with the highest material density and was the main use of space in level F. Showing a slight trend in vertical inclination, and a scatter of material between the hearth and the wall, reuse of the hearth area and maintenance of the hearth occurred over almost the entire period level $\mathrm{F}$ was a floor of activity. The 
hearth may also have been dug out, with previous material being dumped against the wall. However, the point cloud lacks the dense grouping this type of construction may cause. Lithic exhaustion most likely occurred in this space, as the hearth contained the highest number of retouched pieces in the cave.

Two other areas in the cave showed signs of activity, including the area in front of the Sala entrance, with the highest amount of cores and micro lithics. This space also showed the second highest occurrence of axial elements and long bones. The area in front of the Sala, with a high amount of cores, bladelets, and the most diverse area for raw material, was most likely used for lithic tool maintenance. Periodic site maintenance probably occurred in this area, with bones and discarded lithics being pushed or thrown into the small opening of the Sala. The density maps show the slow phasing out of material into the Sala. The third area of activity is in the far back left side of the cave, directly under the chimney. This section showed no special distribution of material types and was most likely a toss or refuse zone for the other two areas.

Although site maintenance is strongly suggested in Level F, it was most likely the minimal amount needed to continue use of the site. Likely a hunting camp and processing site, minimal care was exercised in maintenance and organization. The presence of a high number of axial elements, along with low hind limb counts, suggest the larger animals were butchered whole here, with the cuts from game with the highest energy return being taken elsewhere.

Besides offering a glimpse into past human behaviors, the spatial analysis of Level $\mathrm{F}$ also provided a unique case study on how excavation biases may materialize in point clouds. Exposed profiles and physical grids are both shown to effect the appearance of 
material distribution. This data can inform future excavation methods at Picareiro.

Further analysis may yield distinct lenses from palimpsests. For future research, the spatial analysis of lower levels may be compared to level $\mathrm{F}$ to track changes in the use of a single space over relatively long periods of time. 


\section{REFERENCES}

Aldeias, Vera, Paul Goldberg, Dennis Sandgathe, et al.

2012 Evidence for Neandertal Use of Fire at Roc de Marsal (France). Journal of Archaeological Science 39(7): 2414-2423.

Álvarez-Alonso, David, José Yravedra, Jesús F. Jordá Pardo, and Alvaro Arrizabalaga

2016 The Magdalenian Sequence at Coímbre Cave (Asturias, Northern Iberian Peninsula): Adaptive Strategies of Hunter-gatherer Groups in Montane Environments. Quaternary International 402: 100-111.

Bahn, Paul, and Colin Renfrew

2011 Archaology: Theories, Methods and Practice. 5th edition. Thames \& Hudson.

Benedetti M., et al.

N.d. Late Pleistocene stratigraphy, sedimentology, and site formation at Lapa do Picareiro, Central Portugal. Unpublished.

Bicho, Nuno, and Jonathan Haws

2012 The Magdalenian in Central and Southern Portugal: Human Ecology at the End of the Pleistocene. Quaternary International 272-273. Elsevier Ltd and INQUA: 6-16.

Bicho, Nuno, Jonathan Haws, and Francisco Almeida

2011 Hunter-Gatherer Adaptations and the Younger Dryas in Central and Southern Portugal. Quaternary International 242(2). Elsevier Ltd and INQUA: 336-347.

Bicho, Nuno, Jonathan Haws, and Bryan Hockett

2006 Two Sides of the Same Coin-Rocks, Bones and Site Function of Picareiro Cave, Central Portugal. Journal of Anthropological Archaeology 25(4): 485-499. 
Binford, Lewis

1978 Nunamiut Ethnoarchaeology. New York: Academic Press.

Binford, Lewis R.

1981 Behavioral Archaeology and the "Pompeii Premise." Journal of Anthropological Research, 37(3): 195-208.

Cacho, Carmen, Juan A. Martos, J. Yravedra, et al.

2016 On the Use of Space at La Pena de Estebanvela (Ayllon, Segovia, Spain): An Approach to Economic and Social Behaviour in the Upper Magdalenian. Quaternary International 412: 44-53.

Clark, P. U., J. D. Shakun, P. A. Baker, et al.

2012 Global Climate Evolution during the Last Deglaciation. Proceedings of the National Academy of Sciences of the United States of America 109(19): 11341142.

Conyers, Lawrence B.

2016 Ground-Penetrating Radar for Geoarchaeology. Chichester: John Wiley \& Sons.

Dansgaard, W., and H Tauber

1969 Glacier Oxygen-18 Content and Pleistocene Ocean Temperatures. Science (New York, N.Y.) 166(3904): 499-502.

Davis, Simon J. M., Isabelle Robert, Joao Zilhao

2007 Caldeirão Cave ( Central Portugal ) - Whose Home ? Hyaena , Man , Bearded Vulture ... Who Accumulated the Bones ? Cour. Forsch. -Inst.

Senckenberg(259): 213-226. 
Dibble, Harold L, Philip G Chase, Shannon P Mcpherron, and Alain Tuffreau 1997 Testing the Reality of a "Living Floor" with Archaeological Data. American Antiquity 62(4): 629-651.

Dibble, Harold L, Teresa P Raczek, and Shannon P Mcpherron 2005 Excavator Bias at the Site of Pech de l'Azé IV, France. Journal of Field Archaeology 30(3): 317-328.

Goldberg, Paul, and Trina L. Arpin

1999 Micromorphological Analysis of Sediments from Meadowcroft Rockshelter, Pennsylvania: Implications for Radiocarbon Dating. Journal of Field Archaeology 26(3): 325-342. http://dx.doi.org/10.1371/journal.pone.0141923.

Goldberg, Paul, and Richard I Macphail

2006 Practical and Theoretical Geoarchaeology. Malden: Blackwell.

Guan, Ying, Xing Gao, Hui Min Wang, et al.

2011 Spatial Analysis of Intra-Site Use at a Late Paleolithic Site at Shuidonggou, Northwest China. Chinese Science Bulletin 56(32): 3457-3463.

Haws, Jonathan Adams

2003 An Investigation of Late Upper Paleolithic and Epipaleolithic HunterGatherer Subsistence and Settlement Patterns in Central Portugal. University of Wisconsin-Madison.

Hockett, Bryan, and Jonathan a. Haws

2002 Taphonomic and Methodological Perspectives of Leporid Hunting During the Upper Paleolithic of the Western Mediterranean Basin. Journal of Archaeological Method and Theory 9(3): 269-302.

Hodder, Ian

2012 Entangled: An Archaeology of the Relationship Between People and Things. Chichester: John Wiley \& Sons. 
Holst, Melissa

2017 Late Magdalenian Lithic Technological Organization at Lapa Do

Picareiro. Unpublished Masters Thesis. University of Louisville.

Jensen, John R.

2009 Remote Sensing of the Environment: An Earth Resource Perspective. 2nd edition. Pearson Educatioon India.

Lock, G

2003 Spatial Technology and Archaeology: The Archaeological Applications of GIS. International Journal of Geographical Information Science.

Lyman, R. Lee

1994 Vertebrate Taphonomy. Cambridge: Cambridge University Press.

Marín Arroyo, A. B.

2009 Assessing What Lies beneath the Spatial Distribution of a

Zooarchaeological Record: The Use of GIS and Spatial Correlations at El Mir??n

Cave (Spain). Archaeometry 51(3): 506-524.

McPherron, Shannon J P, Harold L. Dibble, and Paul Goldberg

2005 Z. Geoarchaeology 20(3): 243-262.

Mike Walker, et al.

2009 Formal Definition and Dating of the GSSP (Global Stratotype Section and Point) for the Base of the Holocene Using the Greenland NGRIP Ice Core, and Selected Auxiliary Records. JOURNAL OF QUATERNARY SCIENCE 24(1): 317.

Parcak, Sarah H.

2009 Satellite Remote Sensing for Archaeology. Routledge.

Robert Theunissen, Jane Balme and Wendy Beck

1998 Headroom and Human Trampling: Cave Ceiling-Height Determines the Spatial Patterning of Stone Artifacts at Petzkeys Cave, Northern New OSuth Wales. ANTIQUITY 72. 
Ruddiman, William F.

2008 Earth's Climate: Past and Future. Second. New York: W.H. Freeman and Company.

Schiffer, Michael B.

1985 Is There a "Pompeii Premise" in Archaeology? Journal of Anthropological Research 41(1): 18-41.

Schmidt, Isabell, Marcel Bradtmoller, Martin Kehl, et al.

2012 Rapid Climate Change and Variability of Settlement Patterns in Iberia during the Late Pleistocene. Quaternary International 274. Elsevier Ltd: 179-204.

Straus, Lawrence Guy

1990 Underground Archaeology : Perspectives on Caves and Rock Shelters. Archaeological Method and Theory 2(1990): 255-304.

Straus, Lawrence Guy, Berit Valentin Eriksen, Jon M Erlandson, and David R Yesner

1996 Humans at the End of the Ice Age.

Straus, Lawrence Guy, and Manuel R. González Morales

2012 The Magdalenian Settlement of the Cantabrian Region (Northern Spain): The View from El Miron Cave. Quaternary International 272-273: 111-124.

Wheatley, David, and Mark Gillings

2002 Spatial Technology and Archaeology: The Archaeological Applications of GIS. International Journal of Geographical Information Science. London: Taylor \& Francis.

Zilhão, Joao and Ana Cristina Araujoo

1991 Arqueologia Do Parque Natural Das Serras De Aire E Candeeiros. Lisboa: Servico Nacional de Parquees, Reservas e Conservacao da Natureza. 
Zilhão, Joao, and and Isabel Figueiral Anthony E. Marks, Reid Ferring, Nuno Bicho

1995 The Upper Paleolithic of the Rio Maior Basin (Portugal). Preliminary Results of a 1987-1993 POrtuguese-American Research Project. Trabalhoes de Antopologia e Etnologia.

Zilhão, Joao

1997 O Paleolitico Superior Da Estremadura Portuguesa, vol.2. Fernando Mao de Ferro, ed. Dissertation. Lisboa: Edicoes Colibri.

Zilhão, João

2006 Chronostratigraphy of the Middle-to-Upper Paleolithic Transition in the Iberian Peninsula. Pyrenae 37(1): 7-84.

http://www.raco.cat/index.php/Pyrenae/article/view/145166/196986. 
APPENDIX 


\section{APPENDIX A}

\section{SOFTWARE}

All of the data collectors after 2013 used software from

http://www.oldstoneage.com/index.html to organize and standardize the format of information and the method of data collection in the field. This software was used in conjunction with total stations, or electronic theodolites. EDMs, or Electronic Distance Meters, are built within the total stations to measure the distance and angle of an object from the location of a datum, or the transit itself. Because this software controlled the functioning of the EDM and stored the data it collected, this software is sometime just referred to as the EDM. Technology of this kind greatly impacted how an absolute grid system could be used in terms of time and reach. Most of these total stations have a guiding laser, making taking points much easier than with traditional transits. Stadia rods were usually unnecessary and direct reflection was the preferred method of taking points.

The EDMs obtained at http://www.oldstoneage.com/index.html are free software packages for archaeologists and created by Harold Dibble and Shannon McPherron. Their system was modified and adapted to the needs of Picareiro by the author of this thesis.

Below are the versions used at Picareiro. The first is the version used with a Surface Pro 3, utilized for almost two seasons as a data collector in the field $(2015,2016)$. The second is the version used with the other two hand held data collectors, and runs on Windows Mobile 6 and 7. Product summaries were taken directly from the source website. 
EDM Survey data collection. Well suited for general survey or piece proveniencing artifacts with a total station. Can be customized to record user defined fields with each recorded point.

$\underline{\text { EDM- }}$ Survey data collection (see above)

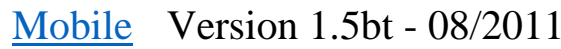

DOS. Windows 95/98 (in DOS

mode).
Windows Mobile 5, 6, and 6.5.

Does not work on Windows

Mobile 7 (known now as

Windows Phone 7).

\section{GIS}

ArcGIS. Release - 10.3, 10.4, 10.5 - ArcMap. ArcScene. ArcCatalogue. Environmental Systems Research Institute (ESRI)

\section{PHOTOGRAMMETRY}

Agisoft PhotoScan Version 1.3.1 Build 4030 (64 BIT). 


\title{
PHYSICAL DATA COLLECTION TOOLS
}

\author{
TOTAL STATION
}

Sokkia Surveying Instruments CX Series. CX-103. Compact X-ellence Station.

\section{DATA COLLECTORS}

Trimble Nomad (900 or 1050) series

Nautiz-X8 Handheld Terminal 


\section{APPENDIX B}

\section{TRANSLATION}

The first task in analyzing the distribution of artifacts was to accumulate all of the spatial data into a single database with a single format. All data from 1995 up to 2012 was taken using stadia rods, a single datum, and metric rulers. The points recorded were taken using the relative coordinate system. The relative, or analog, system of data collection was used in the cave prior to 2013. Each 1meter square unit acted as a single grid with the bottom left hand corner acting as the zero node for both the $\mathrm{Y}$ and $\mathrm{X}$ axis. Each axis ranged from zero to one hundred centimeters. Using basic histogram plotting methods, each artifact was assigned an $\mathrm{x}$ and $\mathrm{y}$ coordinate based on its position relative to each axis (see below). The coordinate of any given point could be repeated from unit to unit, hindering intra-site spatial analysis. For example, because each unit was its own grid, units A6 and A7 could both have an artifact with $x, y$ coordinates of $(73,28)$ in their respective units. To solve this and to place all 20 years of data into a single format, the points had to be translated to an absolute coordinate system. 


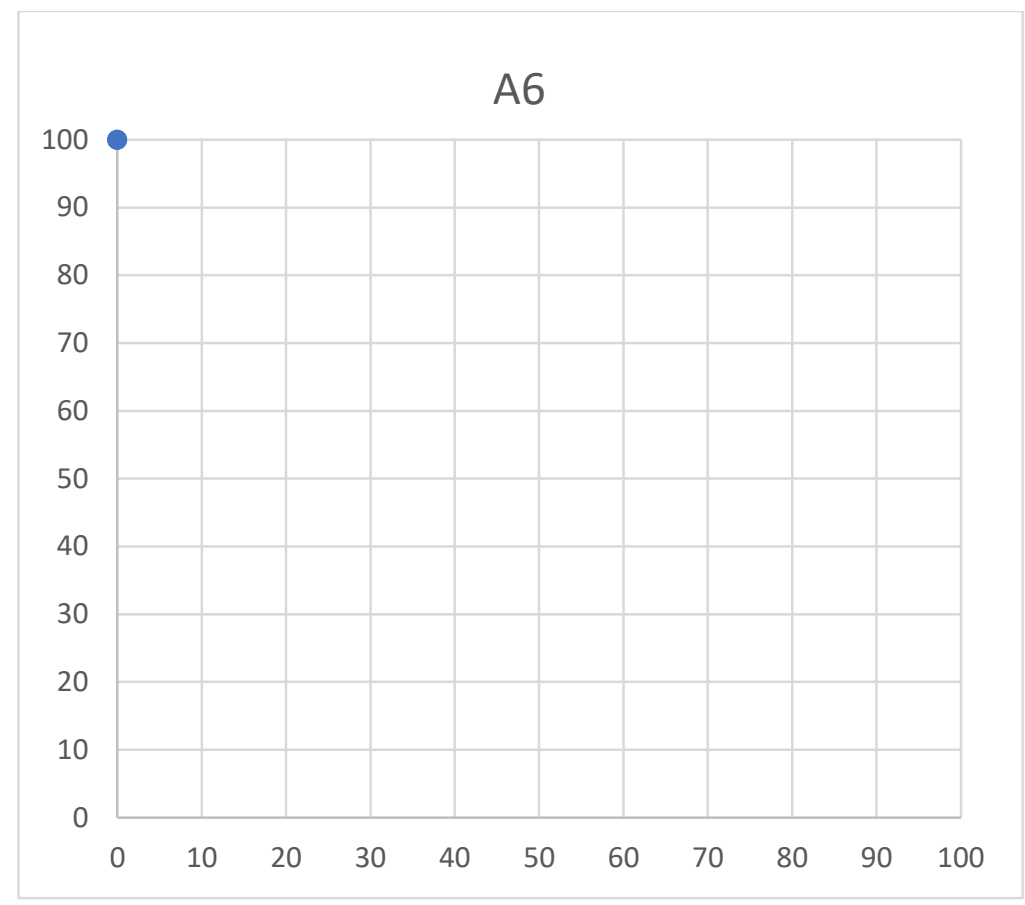

Fig. A single unit, showing the relative coordinate system

For this paper, an absolute coordinate system is defined as a system of assigning values to a location on three axes, independent of individual excavation units. This system relies on permanent datum that remain fixed and are assigned specific location coordinates. The location allows the excavation to be fixed in space. In this way, the physical grid can be altered, re-labeled or done away with, and the location of each piece plot relative to each other and the context of the site remains the same. This is useful for many reasons. It cuts down on label and communication error. It also diminishes the reliance on the accuracy of a physical grid, which is subject to shifting throughout the excavation due to excavator error. This is especially a problem in sites that employ untrained students. This allows the grid to act as an excavation guide and a way to organize and label space, while also limiting/ or even eliminating, its role in the 
coordinate system. A digital grid provides a greater degree of control over the excavation, the purpose of arbitrary units. An excavation could take place without a physical grid and still maintain millimeter accuracy when digitally recording, preserving, and rendering the excavation. This could, however, make a discussion of the site quite difficult with someone unfamiliar with it. Because of this, the physical grid system will be preserved while its functions have changed.

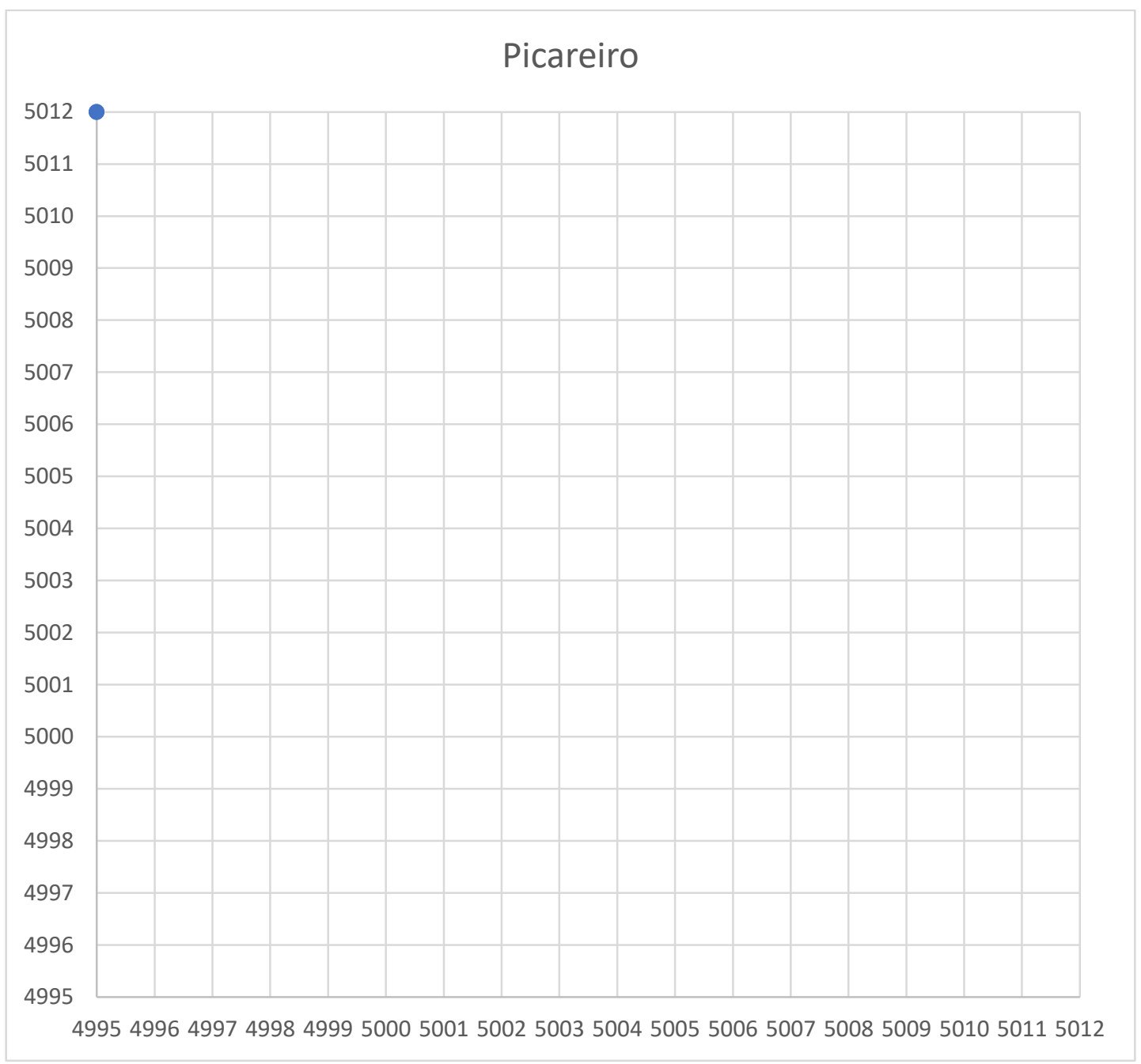

Fig. B The entire site grid used in the absolute coordinate system. 


\section{PROCEDURE}

The piece plots in the relative system were written down on paper so the actual database was "physical", as opposed to digital. Each plot had an x, y, and z value written into a blank table. These tables represented all of the spatial data for the excavation before the transition to total stations in 2013 , and had to be manually typed into an excel spreadsheet, done by Jonathan Haws. From here, the data had to be translated to the absolute coordinate system.

First the desired grid to be used in the absolute system had to be determined. For continuity, the original relative grid was chosen to be digitized and relabeled. The corners of each unit were to be assigned a value based on the new grid, which in turn was based off of the original datum (571.483 meters above sea level). Before this new grid could be trusted, the relative grid needed to be confirmed. In this case, the accuracy of the physical grid had to be confirmed, as it may have shifted over many years. The check was done using two separate methods.

The first method was a low resolution attempt. The point clouds for 2013 and 2014 were visually analyzed and compared to determine the tightest groupings of artifacts within each unit. This was done by observing a common short fall of excavation by physical grids, the seeming lack of artifacts around the borders of units. As excavators approach the edge of their unit thy are less inclined to record those artifacts as they may be in the neighboring unit. Using these lines, or voids in the point cloud, a grid was drawn and extrapolated to cover the entire site. 
The second method involved higher resolution methods. In the first years of the excavation in 1995, strings with lead balls attached to the ends were hung from the ceiling of the cave. The lead balls acted as plum bobs, and demarcated the corners of each unit. In 2015, eight of these strings with the attached lead balls were left still hanging from the ceiling. Because the new system is absolute and took advantage of the remote sensing capabilities of total stations, laser reflection was used to collect the $\mathrm{x}, \mathrm{y}, \mathrm{z}$ coordinates for each lead ball, which are now hanging roughly 8 meters above the excavation floor. These coordinates, which together provide a small grid consisting of the corners of four complete units, was used to extrapolate a grid that covered the entire current excavation. The resulting grids from these two methods matched closely.

Since the datum for the site hasn't changed over the course of the excavation, little had to be done in order to convert $\mathrm{Z}$ axis values, or elevation data. $\mathrm{Z}$ axis values were converted from a relative depth below the datum to an absolute above sea level depth, used for the new absolute system. 


\section{APPENDIX C}

\section{CREATING THE ROOF DEM AND CEILING HEIGHT ZONES}

In 2013, a total station was used to map the interior of the cave. Points were taken in general swaths and at specific, but indiscriminate, points of changes in geometry. Using ArcMap 10.2, these points were converted into a TIN, or Triangulated Irregular Network, a form of rendering a surface based on the location of points within a cloud. This TIN was used to create a Digital Elevation Model (DEM). Both of these process are found as tools in the ArcMap tool box. The DEM of the cave roof was then placed over the absolute grid of the site as two layers in ArcMap, and showed the different elevations of the cave roof over the grid. To determine the roof height above what would have been the floor while level $\mathrm{F}$ was occupied, the elevation data for all of the points in level $\mathrm{F}$ were averaged and this average elevation was used to create a floor. In this way, the roof Dem is now an approximate reconstruction of the cave during the Upper Magdalenian.

A line was drawn at the point where the cave roof rose to more than 2 meters in height, and continued to circle the site to form a polygon, effectively splitting the cave into two zones. One zone represented all areas in the cave under a ceiling height of 2 meters. The second zone represents the area of the cave with a ceiling height of over 2 meters. The decision to choose 2 meters as the dividing ceiling height came from the experiments done in Petzke's Cave, where it was associated with average human head height (Theunnisen et al. 1998). In this thesis, the choice of 2 meters is arbitrary, and 
provides a marker for areas of high or low foot traffic, a general trend highly dependent on an occupant's actual height. This division is represented in plan view figures as a thick red line. These two polygons were used in conjunction with the selection features in ArcMap 10.2, 3, and 4, to separate all of the piece plots into whatever zone they fell into. Statistics and figures for the results are all derived from this data. This process was repeated for 3 meters as well but was not included, as the majority of material fell under roof heights of 3 meters. It is important to remember that the shape of the roof has changed in non-uniform, ways over the life history of the cave. This would have minimal impacts on this analysis, however, because the focus material lay so close to the surface. Spatial analysis of this kind in deeper deposits may be impacted by this phenomenon to a larger degree, and it should be recognized as a potential source of error. 


\section{CURRICULUM VITAE}

\section{Brandon Zinsious}

University of Louisville

Department of Anthropology

(502)852-6864

Department website profile http://louisville.edu/anthropology/graduate/brandon-zinsious-1/

Research Gate Profile at https://www.researchgate.net/profile/Brandon Zinsious?ev=hdr xprf
BKZINSIOUS@gmail.com

Department Number

\section{EDUCATION}

Graduate studies, University of Louisville, Louisville, KY, USA

2013-2016 Master of Arts in Anthropology

$>$ MA Awarded in May of 2017

Undergraduate studies, University of Louisville, Louisville, KY, USA

2009-2013 Double Bachelors of Arts in Anthropology and Biology

$>$ BA awarded in May of 2013

\section{POSITIONS HELD (* On-Going)}

2015-2016* Graduate Research Assistant. University of Louisville Portuguese Studies Program. Research ` focused on the Middle and Upper Paleolithic in Iberia.

2014-2015 Grade Setter for Survey Engineers at Charah Inc. Learned Trimble survey equipment and landscape survey methods.

2013-2016* Field Archaeologist. Corn Island Archaeology (CRM). Surveyed and excavated multiple Archaic, pre, and post-colonial sites. Learned lab methods, report writing, and field planning. 


\section{RESEARCH ORGANIZATION MEMBERSHIP}

2016

ICArEHB

Interdisciplinary Center for Archaeology and Evolution of Human Behavior. Interdisciplinary research center. Universidade do Algarve, Portugal. Position: Graduate student/ Researcher.

\section{TEACHING EXPERIENCE}

2016

Graduate Teaching Assistant. Archaeology Field School (ANTH 377) at Lapa do Picareiro, Portugal, for the University of Louisville.

2015 Graduate Teaching Assistant. Archaeology Field School (ANTH 377) at Lapa do Picareiro, Portugal, for the University of Louisville

\section{RESEARCH AND FIELD EXPERIENCE (* On-Going)}

2012-2016* Neanderthal and Modern Human Response to Environmental Change at the Middle to Upper Paleolithic Transition, Lapa do Picareiro, Portugal

Middle and Upper Paleolithic Cave Site. NSF funded. Director: Jonathan Haws. Positions/ Duties: Graduate Research Assistant, Field School TA, Field Technician. Aided in excavations, general lab work, remote sensing data collection, adapted and implemented a new piece proveniencing and spatial data collection methods, translated previous 20 years of analog data to a new absolute coordinate system, post-collection LiDAR manipulation, Photogrammetric modeling, and spatial analysis of specific geological layers. Totaling over five months in the field and almost continuous post collection work processing GIS data since 2013.

2016* Inhambane, Mozambique

Survey of coastal areas for Middle and Late Stone Age Sites. Director: Jonathan Haws, Nuno Bicho. Position/ Duties: Collected aerial imagers using an Unmanned Aerial System, created maps of the survey area, and of diatom sampling areas. Aided in general survey and artifact/ sample collection. Totaling two weeks in the field. Post season data analysis still underway.

2015-2016* Massingier, Mozambique

Survey and Testing of Middle and Late Stone Age sites. Director: Jonathan Haws, Nuno Bicho. Position/ Duties: Collected aerial images for the creation of landscape models and orthophotos to aid in mapping sites using Unmanned Aerial Systems 
(Arch Aerial quad copter and DJI Phantom 3 Pro). Designed the layout and set up of a new archaeological site for future excavation. Aided in general survey, artifact collection, and OSL sample collection. Totaling six weeks in the field. Post season modeling and site mapping part of weekly work load since 2015 .

2014

Niassa, Mozambique

Survey and Testing of Middle and Late Stone Age sites. Director: Jonathan Haws. Position/ Duties: Collected aerial images using Unmanned Aerial Systems to supplement the pedestrian survey (DJI Phantom II quad copter). General pedestrian survey. Field technician. Totaling four weeks in the field.

2014

Body in a Box, University of Louisville

Independent study. Supervised by Phil DiBlasi. Identifying, articulating, photographing, cataloguing, and storing human remains.

2013-2016*

Big Bat Cave, LiDAR Collection, Kentucky, USA

Field collection of LiDAR installments for Kentucky Karst Conservancy with Qk4. Collecting, processing, and viewing LiDAR point clouds. Recently started applying photogrammetry to underground geological features.

2013-2016 Multiple Sites, CRM. Corn Island Archaeology. Louisville, KY, USA

Archaic and historical Sites. Position/ Duties: Field Technician and report writer. General survey, Phase I, II, and III excavations. Artifact cleaning, identification, storage, and curation. On-going.

2012-2013 Lagoa Seca, Portugal

Survey and Testing for Paleolithic Archaeological material near the known site of Lagoa Seca. Director: Jonathan Haws. Positions/ Duties: Field Technician. Aided in general duties, survey, and excavating test pits.

\section{2-2013 Large Scale Survey, Central Portugal}

Survey and testing for Paleolithic Archaeological material in multiple locations throughout central Portugal. Director Jonathan Haws. Positions/ Duties: Field Technician. Aided in general survey. 
Middle and Upper Paleolithic Coastal Site. NSF funded. Director: Jonathan Haws. Position/ Duties: Field Technician. Aided in general excavation duties and coastal survey. Totaling four weeks in the field.

\section{PRESENTATIONS ( * invited)}

$2017 *$

2016

2016

2016

2016*

2016

2016*

2015

2015
Brandon Zinsious, Jonathan Haws. Lapa do Picareiro and the Gravettian-Solutrean Transition: Refining the Chronology of the Solutrean Techno-complex in Western Iberia. Paper submitted and to be presented at the annual meeting for the Society for American Archaeology (SAA). Session Title: Upper Paleolithic Transitional 'Moments' on the Iberian Peninsula.

Jonathan Haws, Michael M. Benedetti, Nuno Bicho, Celia Goncalves, Joao Cascalheira, Mussa Raja, Brandon Zinsious, Milena Carvalho, Elena SkoseyLalonde, Ilona Benedetti, Joao Marreiros, Telmo Pereira, and Ana Gomes. Stone Age Archaeology and Quarternary Landscapes in Southern Mozambique. Poster presented at the conference for The Geological Society of America (GSA).

Brandon Zinsious, Jonathan Haws. Applications of Unmanned Aircraft Systems and Photogrammetry in Archaeological Survey for Middle and Late Stone Age Sites in Southern Mozambique. Poster presented at the annual meeting of the Society of African Archaeologists (SAFA).

Brandon Zinsious, Jonathan Haws. Photogrammetry at Lapa do Picareiro: $3 D$ Modeling of a Middle and Upper Paleolithic Cave Site. Poster presented at the annual meeting for the Society for American Archaeology (SAA).

Brandon Zinsious Recording and Displaying Spatial Information. Archaeological Methods. University of Louisville.

Brandon Zinsious Photogrammetry a Lapa do Picareiro: Innovative Techniques for Recording Spatial Information at a Paleolithic Site. Poster presented at the Graduate Student Counsel Interdisciplinary Research Conference. University of Louisville.

Brandon Zinsious Lapa do Picareiro: An Introduction to a Paleolithic Excavation. Falls of the Ohio Archaeological Society.

Brandon Zinsious, Jonathan Haws. Unmanned Aerial Vehicle in Archaeological Survey: Results from Portugal and Mozambique. Poster presented at the annual meeting for the Society for American Archaeology (SAA).

Celia Goncalves, Joao Cascalheira, Vera Aldeias, Mike Benedetti, Jonathan Haws, Omar Madime, Mussa Raja, Telmo Pereira, Brandon Zinsious, Nuno Bicho. GIS and archaeological survey data for the reconstruction of Stone Age settlement 
patterns in the Lunho valley (Niassa, Mozambique): preliminary results. Poster presented at the annual meeting for the Society for American Archaeology (SAA).

2015

Brandon Zinsious A Bird's Eye View: Unmanned Aerial Vehicles in Archaeological Survey. Poster presented at the Graduate Student Council Research Conference. University of Louisville.

\section{UNIVERSITY SERVICE AND PROFESSIONAL DEVELOPMENT}

2013-2016 Anthropology Graduate Student Association (AGSA), University of Louisville

$>$ President (Two Terms: 2014-2015, 2014-2015)

$>$ Treasurer (2013-2014)

2013 Kentucky Association of Mapping Professionals (KAMP).

$>$ Completed course on LiDAR manipulation in ArcGIS suite.

2011-2015 Sigma Phi Epsilon, University of Louisville

$>$ Alumni Counselor for Current Members (2013-2015)

$>$ Coordinator for the Phi Leadership Continuum Class (2012)

$>$ Social Chair (2011)

$>$

\section{SPECIALIZED SOFTWARE/ HARDWARE PROFENCIENCY}

$>$ ArcGIS suite of programs (Map, Scene, Catalogue)

$>$ Agisoft Photoscan

$>$ Meshlab

$>3 \mathrm{ds} \max$

$>$ Excel

$>$ ENVI

$>$ TRIMBLE GPS and Survey Instruments

$>$ Sokkia Total Stations

$>$ Oldstoneage.com EDM for total station data collection

$>$ Maker Bot Proprietary Software for 3D Printing 